JeRônimo BuzettI MILANo

\title{
Estudo das alterações em exame de ressonância magnética de pacientes em pós-operatório imediato de ressecção de tumores hipofisários por via transesfenoidal
}

Tese apresentada à Faculdade de Medicina da Universidade de São Paulo para obtenção do título de Doutor em Ciências

Área de Concentração: Neurologia

Orientador: Dr. Paulo Henrique Pires de Aguiar 
JeRônimo BuzettI MILANo

Estudo das alterações em exames de ressonância magnética de pacientes em pós-operatório imediato de ressecção de tumores hipofisários por via transesfenoidal

Tese apresentada à Faculdade de Medicina da Universidade de São Paulo para obtenção do título de Doutor em Ciências

Área de Concentração: Neurologia

Orientador: Dr. Paulo Henrique Pires de Aguiar 


\title{
Dados Internacionais de Catalogação na Publicação (CIP)
}

\author{
Preparada pela Biblioteca da
}

Faculdade de Medicina da Universidade de São Paulo

Creprodução autorizada pelo autor

\section{Milano, Jerônimo Buzetti}

Estudo das alterações em exame de ressonância magnética de pacientes em pósoperatório imediato de ressecção de tumores hipofisários por via transesfenoidal / Jerônimo Buzetti Milano. -- São Paulo, 2010.

Tese(doutorado)--Faculdade de Medicina da Universidade de São Paulo. Programa de Neurologia.

Orientador: Paulo Henrique Pires de Aguiar.

Descritores: 1.Adenoma hipofisário/cirurgia 2.Imagem por ressonância magnética 3.Período pós-operatório 4.Neoplasia residual 5.Recidiva 
DEDICATÓRIA 
Para meus pais, João Cícero e Marilete, exemplos e guias constantes na minha vida pessoal e profissional.

Para minha esposa Elaine, fiel companheira nas alegrias e nas tristezas.

Para a pequena Antonella, fonte de alegria e de inspiração. 
AgRADECIMENTOS 
Ao Dr. Paulo Henrique Pires de Aguiar, orientador desta tese, pela oportunidade de participar do seleto grupo de pós-graduandos por ele orientados.

Ao Dr. Ricardo Ramina, meu mestre e co-orientador desta tese, pelos constantes ensinamentos sobre o exercício de neurocirurgia.

Aos colegas neurocirurgiões do Instituto de Neurologia de Curitiba, Dr. Murilo Sousa de Meneses, Sonival Cândido Hunhevicz, Daniel Benzecry Almeida, Maurício Coelho Neto, Rogério Santos Clemente, Charles Kondagenski, Erasmo Barros da Silva Jr e André Giacomelli Leal, companheiros de jornada, pelo apoio constante e pela amizade consegue tornar agradável a inglória tarefa diária.

Aos radiologistas do CETAC, de modo especial a Ronaldo Pereira Vosgerau, Alessandra Bettega do Nascimento e Guilberto Minguetti, pelo auxílio no estudo das ressonâncias.

Ao amigo Dr. Erasmo Barros da Silva Jr, promissor neurocirurgião e hábil desenhista, pelas gravuras que ilustram esta tese.

Aos membros da banca de qualificação, Dr. Flávio Key Miura, Dr. Marcos Vinícius Calfat Maldaum e Dra. Eliane Correa Miotto, pelas críticas mais do que pertinentes e pelos conselhos que vieram a engrandecer o conteúdo desta tese. 
Aos funcionários do CETAC e do Instituto de Neurologia de Curitiba, pelo auxílio e paciência na seleção dos pacientes e seus exames.

Aos médicos residentes do Instituto de Neurologia de Curitiba, pelo auxílio na seleção e edição das imagens.

A meus irmãos Fabiano, Célio e Diego, que na salutar concorrência no seio familiar me serviram de estímulo para alçar grandes objetivos. Ao Diego, de modo especial, pelo auxílio nas viagens a São Paulo.

Ao casal de aviadores Eduardo e Edna, por possibilitar minhas viagens aéreas a São Paulo.

Aos pacientes envolvidos no estudo, pela disponibilidade de realizar os exames.

E a Deus, pelos dons que todos os dias recebo, em especial por dotar-me de saúde e perseverança ímpares. 
Esta tese está de acordo com as seguintes normas, em vigor no momento desta publicação:

Referências: adaptado de International Committee of Medical Journals Editors (Vancouver)

Universidade de São Paulo. Faculdade de Medicina. Serviço de Biblioteca e Documentação. Guia de apresentação de dissertações, teses e monografias. Elaborado por Anneliese Carneiro da Cunha, Maria Julia de A. L. Freddi, Maria F. Crestana, Marinalva de Souza Aragão, Suely Campos Cardoso, Valéria Vilhena. 2a ed. São Paulo: Serviço de Biblioteca e Documentação; 2005.

Abreviaturas dos títulos dos periódicos de acordo com List of Journals Indexed in Index Medicus. 
SUMÁRIO 


\section{SUMÁRIO}

\section{Lista de abreviaturas, símbolos e siglas}

\section{Lista de figuras}

Lista de tabelas

Lista de quadros

\section{Resumo}

Summary

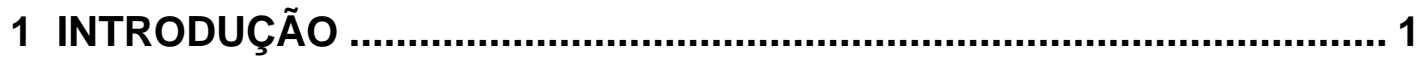

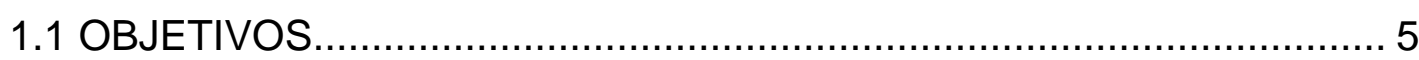

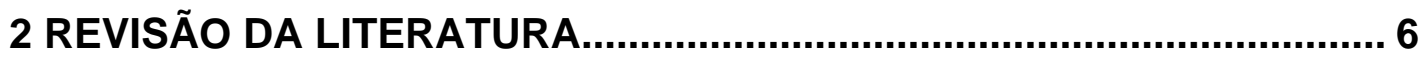

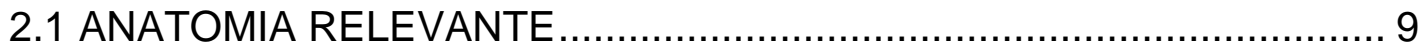

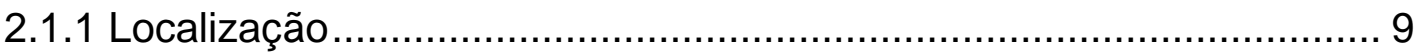

2.1.2 Relações anatômicas ................................................................. 10

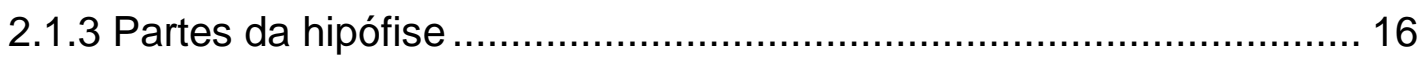

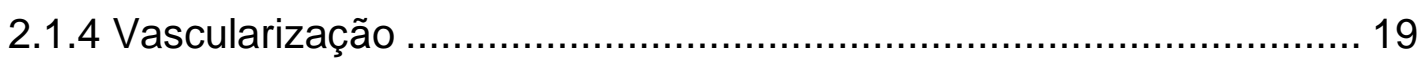

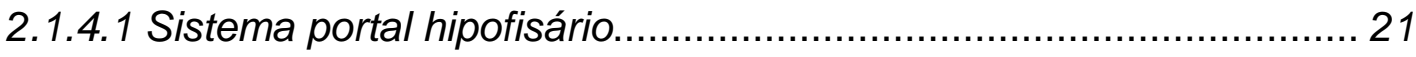

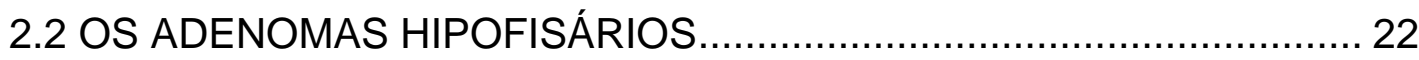

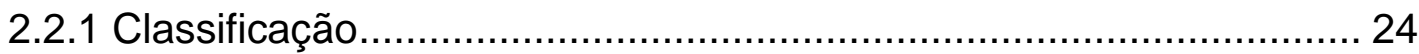

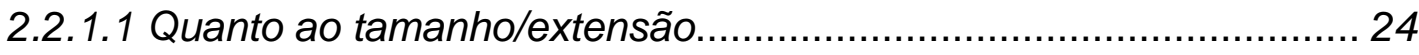

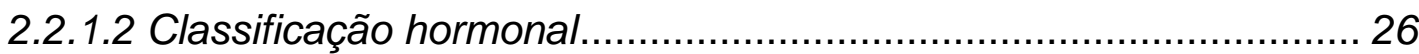

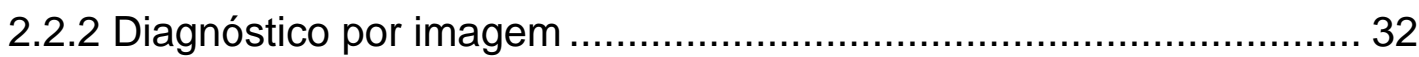

2.2.2.1 Ressonância Magnética dinâmica .................................................. 36

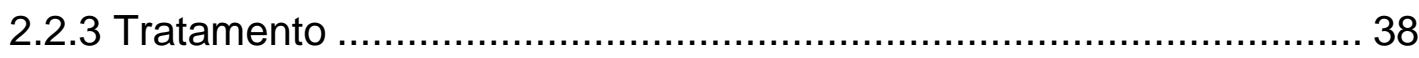

2.2.4 A cirurgia nos adenomas hipofisários .............................................. 42

2.2.4.1 O acesso cirúrgico transesfenoidal .............................................. 43

2.2.4 Ressonância Mangnética intraoperatória ...................................... 45

2.2.5 Prognóstico e acompanhamento pós-operatório .............................. 48

2.2.5.1 Ressonância Magnética pós-operatória ........................................ 49 


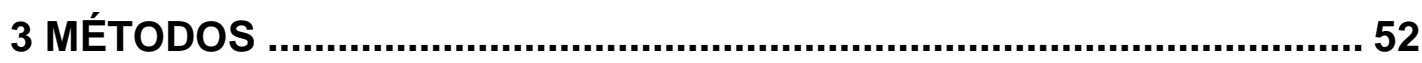

3.1 CRITÉRIOS DE INCLUSÃO ............................................................. 54

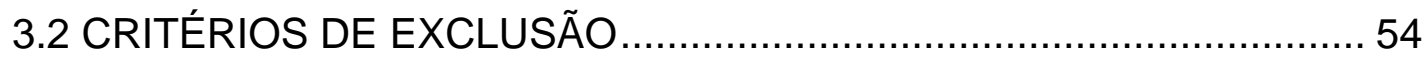

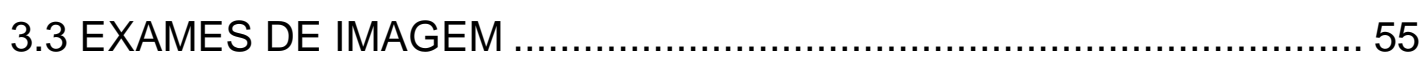

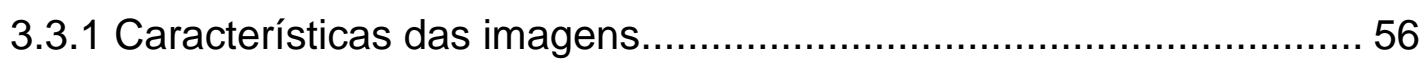

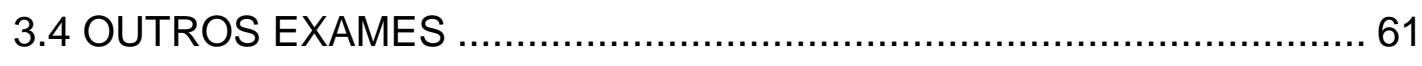

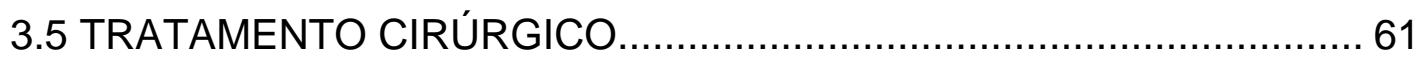

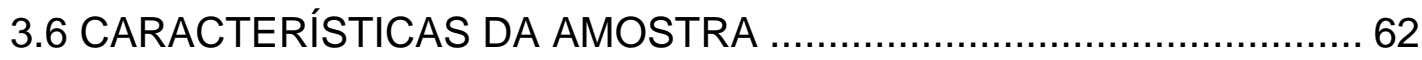

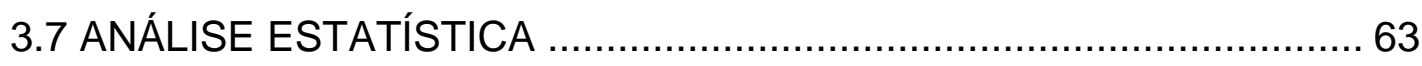

4 RESULTADOS

4.1 ALTERAÇÕES PÓS-OPERATÓRIAS IMEDIATAS .............................. 65

4.2 CORRELAÇÃO DO EXAME PÓS-OPERATÓRIO IMEDIATO COM

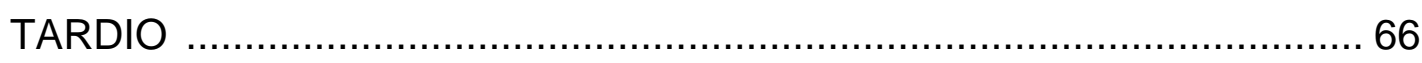

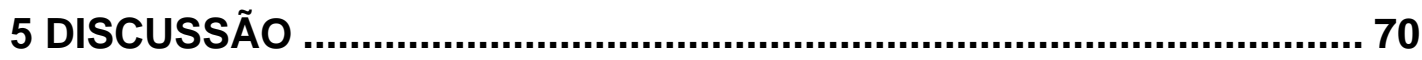

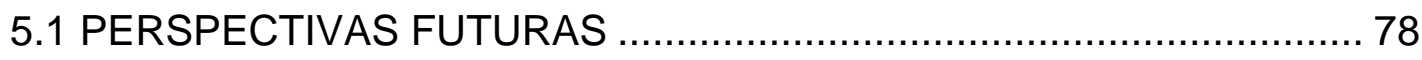

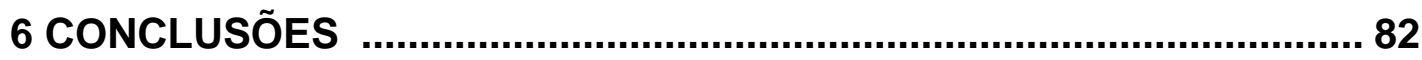

7 ANEXO

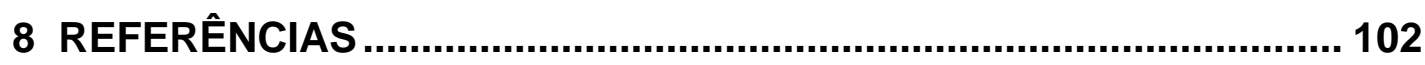


LISTAS 


\section{Abreviaturas, Símbolos e Siglas}

$\begin{array}{ll}\text { a. (AA.) } & \text { artéria (s) } \\ \text { ACTH } & \text { Hormônio adrenocorticotrófico } \\ \text { ADH } & \text { Hormônio antidiurético } \\ \text { CETAC } & \text { Centro de Tomografia Computadorizada de } \\ \text { DDAVP } & \text { Curitiba } \\ \text { et al. } & \text { Acetato de desmopressina } \\ \text { EUA } & \text { e outros } \\ \text { Fo.e. } & \text { Estados Unidos da América } \\ \text { FSE } & \text { Fast spin-echo } \\ \text { FSH } & \text { Gadolínio Ácido Dietileno Triamino Penta Acético } \\ & \text { Hormônio folículo-estimulante } \\ & \end{array}$


IGF-1

INC

LH

$\mu \mathrm{m}$

$\mathrm{mL}$

mmol

ng

NC III

NC IV

$\mathrm{NC} \mathrm{V}_{1}$

$\mathrm{NC} \mathrm{V}_{2}$

$\mathrm{NC} \mathrm{V}_{3}$

NC VI

OXY

PRL

RM
Somatomedina C (insuline-like growth factor)

Instituto de Neurologia de Curitiba

Hormônio luteinizante

micrômetros

mililitros

milimoles

nanogramas

Terceiro nervo craniano - nervo oculomotor

Quarto nervo craniano - nervo troclear

Primeira divisão do quinto nervo craniano - nervo

oftálmico

Segunda divisão do quinto nervo craniano - nervo

maxilar

Terceira divisão do quinto nervo craniano - nervo

mandibular

Sexto nervo craniano - nervo abducente

Ocitocina

Prolactina

Ressonância magnética 
S

$\mathbf{T}$

TC

TR

TSH

v. (vv.)

$\%$ segundos

Tesla

Tomografia computadorizada

Tempo de relaxamento

Hormônio estimulador da tireóide

veia (s)

percentual 


\section{FIGURAS}

Figura 1 - Relação anatômica da hipófise com os seios cavernosos e seus conteúdos

Figura 2 - Divisão anatômica da hipófise

Figura 3 - $\quad$ llustração de corte axial da hipófise com os locais de predomínio de produção de cada tipo hormonal

Figura 4 - O sistema portal hipofisário.

Figura 5 - $\quad$ Clasificação de Hardy modificada por Wilson para extensões tumorais suprasselares

Figura 6 - Classificação de Knosp et al para extensões tumorais parasselares

Figura 7 - $\quad$ Fotogragia de aparelho de Ressonância Magnética ....

Figura 8 - "Sinal do tufo"

Figura 9 - $\quad$ Acesso microcirúrgico endonasal ao seio esfenoidal....

Figura 10 - RM pós-operatória com padrão tipo $1 \ldots \ldots \ldots \ldots \ldots \ldots \ldots \ldots \ldots . . . .58$

Figura 11 - $\quad$ RM pós-operatória com padrão tipo $2 \ldots \ldots \ldots \ldots \ldots \ldots \ldots \ldots \ldots . . .58$

Figura 12 - RM pós-operatória com padrão tipo $3 \ldots \ldots \ldots \ldots \ldots \ldots \ldots \ldots \ldots . . . . . . .59$

Figura 13 - RM pós-operatória com padrão tipo $4 \ldots \ldots \ldots \ldots \ldots \ldots \ldots \ldots \ldots \ldots . . .59$

Figura 14 - Presença de material hiperintenso intrasselar ............ $\quad 60$

Figura 15 - Descolocamento lateral da haste hipofisária................ 60

Figura 16 - Sequência de exames de RM de paciente com macroadenomas não-secretor 
Figura 17 - Padrão de captação nodular evoluindo com crescimento de resto tumoral

Figura 18 - Esquema demonstrando método outside de RM intraoperatória 80

Figura 19 - Macrodenoma não-secretor com extensão suprasselar ressecado com auxílio de RM dinâmica intraoperatória 


\section{QuADROS}

Quadro 1 - Padrões de captação de contraste em ressonâncias magnéticas pós-operatórias imediatas................... 57 


\section{TABELAS}

Tabela 1 - $\quad$ Tipos de adenomas e suas características ................ 27

Tabela 2 - Características dos estudos de RM pós-operatória em

tumores hipofisários

78 
RESUMO 
Milano JB. Estudo das alterações em exames de ressonância magnética de pacientes em pós-operatório imediato de ressecção de tumores hipofisários por via transesfenoidal [tese]. São Paulo: Faculdade de Medicina, Universidade de São Paulo; 2010. 119p

Exames pós-operatórios de cirurgias intracranianas são difíceis de serem interpretados por apresentarem alterações morfológicas que simulam situações patológicas, como edema e tumores residuais. Com o advento de métodos de ressonância intraoperatória essa interpretação ganhou maior importância, pelo risco de re-intervenções desnecessárias. $O$ presente estudo objetivou estabelecer as características de exames pós-operatórios normais após remoção de tumores hipofisários pela via transesfenoidal endonasal, bem como estabelecer parâmetros de remoção tumoral radical para otimização de exames intraoperatórios. Foram estudados 40 pacientes (22 microadenomas e 18 macroadenomas) operados consecutivamente no Instituto de Neurologia de Curitiba, portadores de adenomas hipofisários, pela via transesfenoidal endonasal, e que realizaram exame de ressonância magnética (RM) dinâmica no pré-operatório, pós-operatório imediato (primeiras 24horas após o término da cirurgia) e após três meses.Foram utilizadas sequências ponderadas em $\mathrm{T} 1$, com cortes coronais de $3 \mathrm{~mm}$ antes da injeção de contraste (gadopentetato dimeglumina - Gd-DTPA) e a cada 90 segundos após a injeção rápida do mesmo. Os achados de RM dinâmica no pós-operatório imediato foram analisados quanto ao deslocamento da haste hipofisária, presença de material hiperintenso intrasselar, deslocamento do diafragma selar superiormente (caracterizado pela classificação de Hardy para extensões suprasselares) e quanto ao padrão de captação de contraste na RM dinâmica. Os padrões de captação foram classificados como: 1 . ausência de captação de contraste, 2 . realce anelar periférico, 3. captação nodular e 4. padrão misto (periférico e nodular coexistentes). No exame pós-operatório tardio, ênfase foi dada na presença de tumor residual, confirmada por alteração hormonal ou re-operação com histopatologia.As alterações de imagem foram descritas em termos de prevalência de ocorrência (porcentagem), e correlacionadas com a existência ou não de tumores residuais no pós-operatório tardio. Observouse deslocamento da haste hipofisária em $95 \%$ dos casos $(90,9 \%$ dos microadenomas e $100 \%$ dos macroadenomas). Material hiperintenso intrasselar ocorreu em $77,3 \%$ dos microadenomas e $100 \%$ dos macroadenomas ( $87,5 \%$ do total). $O$ deslocamento cranial do diafragma selar manteve inalterado em 16 dos 18 casos $(88,9 \%)$. A padrão de captação de contraste foi o tipo 1 em $90,9 \%$ dos microadenomas, com apenas 2 casos $(9,1 \%)$ com captação periférica (tipo 2) neste grupo. Nos macroadenomas, $66,7 \%$ foram tipo $1,5,5 \%$ tipo $2,16,7 \%$ tipo 3 e $11,1 \%$ tipo 
4. No pós-operatório tardio, o material hiperintenso desapareceu em todos os casos, com a haste hipofisária retornando à posição habitual em $81,8 \%$ dos casos. Cinco pacientes apresentavam tumores residuais, confirmados por alteração hormonal em dois casos e reoperação em três. Destes, três apresentavam padrão tipo 4 de captação de contraste, e dois do tipo 3. A correlação entre o padrão de captação nodular, isolado ou combinado, com a presença de tumor residual foi de $100 \%$. Todos os outros achados devem ser considerados normais no pós-operatório.

Descritores: 1.Adenoma hipofisário/cirurgia 2.Imagem por ressonância ressonância magnética 3.Período pós-operatório 4.Neoplasia residual 5.Recidiva 
SUMMARY 
Milano JB. Analysis of postoperative findings on dynamic magnetic resonance imaging of patients operated for pituitary tumors by transsfenoidal endonasal approach [thesis]. São Paulo: "Faculdade de Medicina, Universidade de São Paulo"; 2010. 119p.

Imaging after intracranial surgeries is difficult to evaluate because usual changes often simulates pathological findings, such as edema and residual tumors. Emerging technologies of intraoperative magnetic resonances lead to a greater interest on understanding usual findings, in order to avoid unnecessary revisions. The objective of this study was to establish normal postoperative findings on dynamic magnetic resonance imaging (dMRI) after resection of pituitary tumors through endonasal transsphenoidal approach, as well as determine parameters of radical resection, thus optimizing intraoperative images. Forty patients (22 microadenomas and 18 macroadenomas) operated on the "Instituto de Neurologia de Curitiba" for pituitary adenomas through endonasal transsphenoidal approach were evaluated by dMNRI before, within the first 24 hours and after three months of the surgery. T1-weighted images on coronal plane, $3 \mathrm{~mm}$ slices were performed before and on every 90 seconds after rapid injection of the paramagnetic contrast (gadopentetate dimeglumine - GdDTPA). Findings analyzed at early postoperative dMRI were: lateral displacement of the pituitary stalk, hyperintense intraselar material, position of the diafragma selae (as classified by Hardy, for supraselar extensions) and the pattern of contrast enhancement: 1. no enhancement, 2. peripheral ring, 3. nodular enhancement and 4. combined peripheral and nodular. At late postoperative $\mathrm{MRI}$, the regression of early findings was noted, as well as the presence of a residual tumor. This late was confirmed by hormonal essay or hystopathological examination (reoperation). Findings were first described as prevalence $(\%)$, and then related to the presence or not of a residual tumor at late postoperative MRI. Displacement of the pituitary stalk was noted in $95 \%$ of cases $(90,9 \%$ in microadenomas, and $100 \%$ in macroadenomas). Hyperintense intraselar material was found in $77,3 \%$ of microadenomas and $100 \%$ of macroadenomas $(87,5 \%$ of all cases). Supraselar extension remained unaltered in 16 of 18 cases $(88,9 \%)$. Pattern of enhancement was type 1 in $90,9 \%$ of the microadenomas, with only two cases $(9,1 \%)$ with peripheral ring. Of the macroadenomas, $66,7 \%$ had type 1 pattern, 5,5\% type 2, 16,7\% type 3 and $11,1 \%$ type 4 . At late postoperative $\mathrm{MRI}$, the hyperintense material disappeared in all cases, with the pituitary stalk returning to the midline in $81,8 \%$ of the cases. Five patients had residual tumors, confirmed by hormonal essay in two cases, and re-operated (with hystopathological confirmation) in three. Of these, three had type 4 pattern of enhancement, and two had type 3 . When the nodular 
enhancement, alone or combined, was correlated with the presence of a residual tumor, the association was of $100 \%$. The other findings described should be considered normal findings.

Descriptors: 1.pituitary adenoma/surgery 2.magnetic resonance imaging 3.postoperative period 4.residual tumor 5.recurrence 
INTRODUÇÃO 


\section{INTRODUÇÃO}

Os adenomas hipofisários representam cerca de $10 \%$ de todas as neoplasias intracranianas operadas ${ }^{1}$. Entretanto, sua prevalência chega a $16,7 \%$ dos indivíduos adultos, de forma assintomática ("incidentalomas") ${ }^{2}$. Os adenomas tornam-se sintomáticos devido a produção excessiva de hormônios ou por apresentarem efeito expansivo, comprimindo estruturas adjacentes $^{3}$. Uma vez sintomáticos, os adenomas hipofisários requerem tratamento. $\mathrm{O}$ tratamento clínico está indicado principalmente nos tumores produtores de prolactina ("prolactinomas"), com índices de resposta que chegam a cerca de $90 \%{ }^{4}$ com agonistas dopaminérgicos. Nas outras formas de tumores (hormonalmente inativos, produtores de ACTH, GH ou TSH), ou nos prolactinomas sem resposta às terapias, o tratamento cirúrgico é o preconizado $^{3}$

O acesso cirúrgico pela via transesfenoidal é utilizado na quase totalidade das operações para tumores hipofisários ${ }^{5-6}$. A evolução dos 
instrumentos cirúrgicos, associada a refinamento técnico, tem possibilitado índices de cura cada vez maiores, com redução da morbidade e mortalidade do procedimento ${ }^{7}$. Apesar disso, a localização da hipófise na base do crânio, suas relações anatômicas e a infiltração do tumor a estruturas adjacentes pode dificultar a remoção radical de tumores ${ }^{8}$. Os índices de cura, tanto imaginológica como endocrinológica, dependem substancialmente do grau de ressecção tumoral obtido com o tratamento cirúrgico. Na acromegalia, espera-se cura entre 50 a $70 \%$ dos tumores operados ${ }^{9}$, enquanto na doença de Cushing, os índices variam entre 50 e até $90 \%$ dos casos ${ }^{10-12}$.

A fim de se aumentarem os índices de remoção tumoral radical, novas tecnologias vêm sendo desenvolvidas e empregadas no tratamento cirúrgicos dos adenomas hipofisários. Sistemas de neuronavegação auxiliam na localização de tumores baseada em exames pré-operatórios, tornando o procedimento mais preciso ${ }^{13-14}$. Durante o procedimento, entretanto, o deslocamento das estruturas manipuladas torna necessária a atualização dos dados, reduzindo-se o benefício do método no que diz respeito à remoção tumoral radical ${ }^{15}$. Mais recentemente, a utilização de ressonâncias magnéticas durante o procedimento cirúrgico trouxe imagens atualizadas durante o procedimento ${ }^{16}$. O cirurgião passou a ver o resultado operatório em tempo real; resíduos tumorais que teriam passado despercebidos passaram a ser identificados durante a operação, e removidos prontamente. Nas primeiras publicações do método, grupos com grande experiência no tratamento de tumores hipofisários revelaram necessidade de se continuar a remoção tumoral em três de cada cinco pacientes ${ }^{17}$; outros grupos 
revelaram necessidade de re-intervenções em metade a dois terços dos casos ${ }^{18-19}$. O custo de se ter um aparelho de ressonância magnética dentro do centro cirúrgico passou a ser o principal fator limitador. Para minimizá-los, alguns grupos começaram a utilizar o mesmo aparelho de exames de fora do centro cirúrgico para realização de exames intra-operatórios. Esta experiência precursora no Brasil foi recentemente publicada ${ }^{20}$.

O maior desafio passou a ser a interpretação dos exames intraoperatórios, pois a própria manipulação cirúrgica gera alterações nos exames de imagem que pode gerar interpretações errôneas do grau de ressecção tumoral ${ }^{18}$. Em algumas publicações, uma imagem sugestiva de tumor residual levou a re-intervenções desnecessárias em cerca de $20 \%$ dos casos, pois no local onde a ressonância sugeria a presença de tumor, havia só coágulos e fibrina ${ }^{19}$. Tornou-se imprescindível uma melhor interpretação dos achados de imagem pós-operatórios.

A manipulação cirúrgica promove alterações nos exames de imagem pós-operatórias que podem simular tumores ${ }^{21-22}$, mesmo em cirurgias não oncológicas ${ }^{23-24}$. Nos tumores hipofisários, o diafragma da sela mantém-se elevado após a remoção tumoral na grande maioria dos $\operatorname{casos}^{25-27}$. Ainda, captação de contraste ocorre precocemente, simulando tumores e dificultando a análise das imagens ${ }^{28-29}$. O estudo do padrão de captação de contraste baseado em sequência dinâmica de ressonância magnética aperfeiçoa esta avaliação ${ }^{29}$; entretanto, o único estudo até hoje realizado com ressonância magnética dinâmica no pós-operatório de tumores hipofisários utilizou-se de exames realizados durante os primeiros três dias 
na maioria dos pacientes, e em até sete dias em outros ${ }^{29}$; tais achados não podem ser extrapolados para ressonâncias intra-operatórias, pois o principal fator determinante da captação de contraste pós-operatório é o tempo decorrido do fim da operação até a realização de exames de imagem ${ }^{30-32}$. No único estudo até hoje realizado em que todos os pacientes realizaram exames de ressonância magnética nas primeiras 24 horas, não foi utilizada a sequência dinâmica durante a injeção de contraste, prejudicando a reprodutibilidade dos achados, subjetivos em muitos aspectos ${ }^{27}$.

\subsection{OBJETIVOS}

O presente estudo teve como objetivos:

i) Determinar as alterações pós-operatórias em ressonâncias magnéticas de pacientes com tumores hipofisários operados pela via transesfenoidal endonasal que podem ser consideradas normais, diferenciando-as de complicações pós-operatórias e tumores residuais.

ii) Estabelecer padrões de imagem indicativos de tumores residuais em exames precoces, otimizando-se possíveis reintervenções. 
REVISÃO DA LITERATURA 


\section{REVISÃO DA LITERATURA}

A hipófise é uma pequena glândula, com apenas cerca de $1 \mathrm{~cm}$ de diâmetro, e pesando não mais do que $1 \mathrm{~g}^{33}$. Apesar das diminutas dimensões, a hipófise controla, através da secreção de seus hormônios, a atividade das outras glândulas endócrinas do corpo humano. Os principais hormônios secretados são oito: 1. Hormônio do crescimento (GH - Growth Hormone), que promove o crescimento do corpo como um todo, atuando na síntese de proteínas, na multiplicação e diferenciação celulares. 2. Corticotropina (ACTH - adrenocorticotropic hormone), que controla a secreção de hormônios do córtex das glândulas suprarrenais, afetando o metabolismo da glicose, das proteínas e gorduras. 3. Tirotropina, ou hormônio tireoestimulante (TSH - thyroid-stimulating hormone), através do qual a hipófise controla a velocidade de secreção de tiroxina pela tireóide (que, por sua vez, controla o metabolismo celular através de alteração na velocidade da maioria das reações químicas do organismo). 4. Prolactina 
(PRL), que promove o desenvolvimento das glândulas mamárias. 5. Hormônio folículo-estimulante (FSH - follicle-stimulating hormone) e 6 . Hormônio luteinizante (LH - luteinizing hormone), os hormônios gonadotrópicos, que controlam o crescimento das gônadas e suas atividades reprodutivas. 7. Ocitocina (OXY), hormônio que facilita a liberação do leite da mama para os mamilos durante lactação - além de ter importante participação no trabalho de parto, no final da gravidez. 8. Hormônio antidiurético, ou vasopressina (ADH - antidiuretic hormone), através do qual a controla a excreção de água pelos rins.

O controle endócrino da hipófise, entretanto, está subordinado ao hipotálamo, porção mais ventral do diencéfalo, com o qual a hipófise apresenta estreita relação anatômica, inclusive de contiguidade, como será descrito a seguir. O hipotálamo produz os hormônios e fatores que controlam a secreção dos hormônios da hipófise. Através da secreção de hormônios de liberação, o hipotálamo estimula a hipófise a produzir a maioria dos seus hormônios, como GH, TSH, ACTH e gonadotropinas. O controle de produção de PRL, entretanto, está subordinado a um fator inibidor, a dopamina. Através desta, o hipotálamo exerce inibição (controle negativo) da produção de PRL. Já a vasopressina e a ocitocina são na verdade produzidas no hipotálamo, nos seus núcleos supraóptico e paraventricular, e levadas por fibras especiais até o lobo posterior da hipófise, onde são liberados para posterior secreção ${ }^{34}$. 


\subsection{ANATOMIA RELEVANTE}

\subsubsection{Localização}

O osso esfenóide forma o centro da base do crânio. Observado de cima, apresenta no centro do seu corpo uma cavitação denominada sela turca. É dentro da sela turca, ou seja, embaixo do cérebro e na parte mais central da base do crânio que a hipófise está localizada, ocupando a fossa hipofisal $^{35}$. É coberta por uma reflexão da dura-máter, o diafragma da sela, que forma o teto da sela turca. De formato na maioria das vezes retangular e côncavo, o diafragma apresenta variações em sua espessura, forma e integridade $^{8}$. É perfurado em sua porção central pelo pedúnculo ou haste hipofisária, através da qual a hipófise se conecta ao hipotálamo. Pode, no entanto, apresentar aberturas bem maiores, e até mesmo ser inexistente ${ }^{36}$. Nestes casos não forma qualquer barreira anatômica para o acesso transesfenoidal, aumentando o risco de lesões das vias visuais e de fístulas liquóricas. É aderido anteriormente ao tubérculo da sela e posteriormente à porção anterior do processo clinóide posterior ${ }^{37}$. O tecido glandular é coberto por uma camada simples de tecido conjuntivo, denominada por Ciric de cápsula da hipófise ${ }^{37}$. Ocasionalmente, pode ser substituída por aracnóide.

A sela turca é limitada anteriormente pelos processos clinóides de cada lado e pelo tubérculo da sela na porção mediana. Posteriormente, pelos processos clinóides posteriores de cada lado e pelo dorso da sela na porção mediana. Seu assoalho é formado pelo seio esfenoidal, enquanto 
lateralmente a sela limita-se com o assoalho da fossa média do crânio e seios cavernosos.

Protegida anatomicamente, a hipófise, dentro da fossa hipofisal, apresenta difícil acesso do ponto de vista cirúrgico, visto que por qualquer lado que se objetive acessá-la, um longo trajeto anatômico precisa ser percorrido. A fossa hipofisal dista, em média, $60 \mathrm{~mm}$ do limite anterior da fossa crainiana anterior na calvária, $65 \mathrm{~mm}$ da parede lateral da fossa média, $65,5 \mathrm{~mm}$ da margem posterior do forame magno, e $70,8 \mathrm{~mm}$ do ponto subespinhal (abaixo da espinha nasal inferior, início do acesso transesfenoidal $)^{37}$.

\subsubsection{Relações anatômicas}

Dentro da sela turca, a hipófise apresenta importantes relações anatômicas que serão determinantes do ponto de vista patológico e cirúrgico. A primeira (e talvez mais importante) é a relação da fossa hipofisal com os seios cavernosos. Localizados lateralmente à sela turca e ao seio esfenoidal, os seios cavernosos são estruturas venosas formados pelos folhetos interno e externo da dura-máter, revestidos internamente por endotélio $^{38}$, denominados seios venosos. Drenam as estruturas da órbita através da v. oftálmica superior, que chega até eles pela fissura orbitária superior, além de receber o plexo basilar, a partir da porção basilar do osso occipital. Ainda, comunicam-se com os seios transversos de cada lado através dos seios petrosos superiores; com o bulbo da v. jugular interna, de 
cada lado, através dos seios petrosos inferiores; com os hemisférios cerebrais, através das vv. cerebrais inferior e média; e com a retina, através da v. central da retina. Os dois cavernosos apresentam comunicações entre si através dos seios intercavernosos anterior, posterior e inferior, além do seio basilar. Em relação à hipófise, o seio intercavernoso anterior passa anterior e superiormente, o posterior, posterior e superiormente, e o inferior, inferiormente ${ }^{39}$. Estes seios podem existir juntos ou separados; quando os seios intercavernosos anterior e posterior, junto com os seios cavernosos de cada lado, formam um círculo venoso ao redor do diafragma da sela, é chamado de seio $\operatorname{circular}^{40}$, de grande importância por dificultar (e até mesmo impedir) o acesso à hipófise pela via transesfenoidal. O mesmo ocorre quando a distância entre os seios intercavernosos inferior e anterior é muito pequena, restringindo o acesso inferior à sela turca.

Os seios cavernosos possuem em seu interior importantes estruturas anatômicas. As artérias carótidas internas trafegam no seu interior, formando uma curvatura interna conhecida como sifão carotídeo. Da parte cavernosa da a. carótida interna emergem o tronco meningohipofiseal, o tronco inferolateral e a a. capsular (conhecida com artéria de McConnell), como será descrito a seguir. Cada seio cavernoso possui em seu interior três compartimentos venosos, denominados de acordo com sua relação com a a. carótida interna: medial, anteroinferior e posterossuperior ${ }^{39}$. É no compartimento medial que eles se relacionam com a hipófise. A distância entre a a. carótida interna e a hipófise neste compartimento é, em média, de $2,3 \mathrm{~mm}$, podendo atingir até $7 \mathrm{~mm}^{35,40,41}$. Entretanto, em até $25 \%$ dos casos, 
este espaço pode ser ocluído por uma tortuosidade da a. carótida interna, causando uma impressão sobre a hipófise ${ }^{8,41}$. Este achado pode dificultar e até mesmo impossibilitar o acesso transesfenoidal a adenomas hipofisários. A distância entre as aa. carótidas internas, de cada lado, também apresenta variações anatômicas importantes. Segundo Renn e Rhoton ${ }^{42}$, a distância mínima ocorre acima dos processos clinóides em $82 \%$ dos casos, porém dentro dos seios cavernosos, ao lado da sela turca, em $14 \%$, e em $4 \%$ dentro do próprio seio esfenoidal.

Ainda, os seios cavernosos possuem em seu interior, de cada lado, os nervos oculomotor (NC III), troclear (NC IV), a raiz oftálmica no nervo trigêmio $\left(\mathrm{V}_{1}\right)$ e o nervo abducente $(\mathrm{NC} \mathrm{VI})$, nesta ordem de superior para inferior $^{39}$. Os NC III, IV e V1 localizam-se na parte interna da parede lateral, enquanto o VI localiza-se propriamente dentro do seio, medialmente ao $\mathrm{V}_{1} \mathrm{e}$ aderente a este, além de aderir à porção cavernosa da a. carótida interna, medialmente (Figura 1). Na junção das lâminas interna e externa da duramáter, lateralmente, localiza-se a raiz maxilar do nervo trigêmio $\left(V_{2}\right)$. 


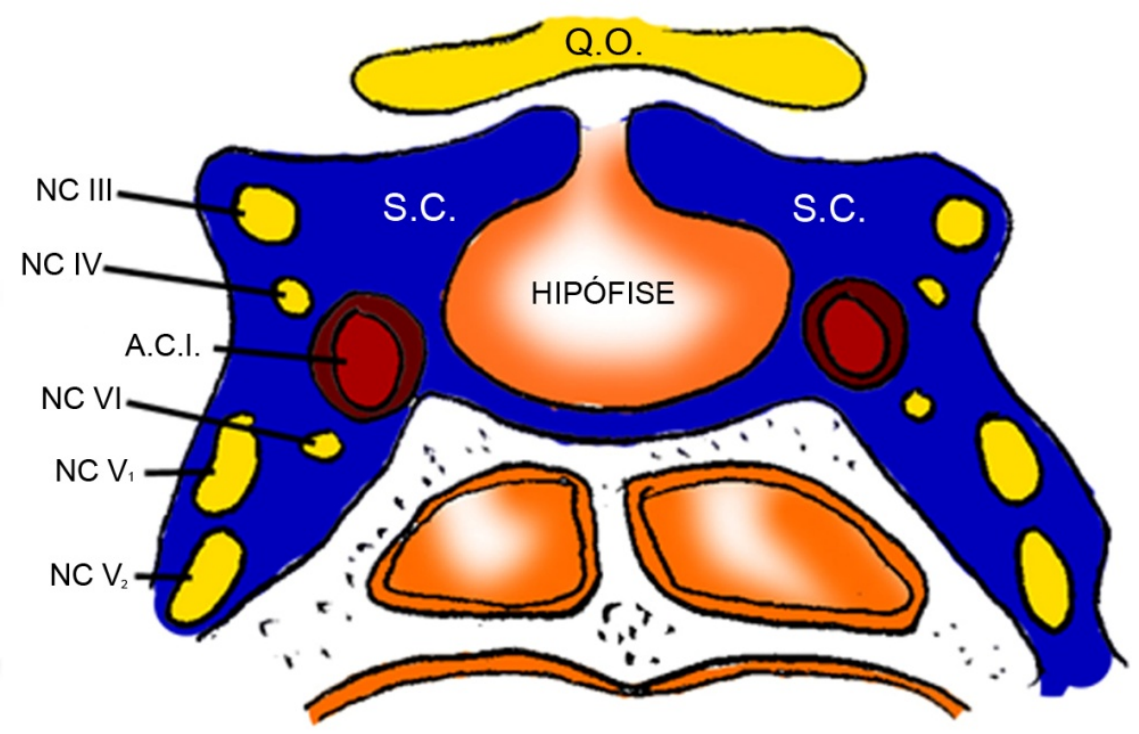

Figura 1: Relação anatômica da hipófise com os seios cavernosos e seu conteúdo. ACl: a. carótida interna. QO: quiasma óptico. SC: seio cavernoso.

De grande importância patológica e cirúrgica é o estudo da parede medial dos seios cavernosos. Segundo Yilmazlar ${ }^{43}$, a parede medial dos seios cavernosos é constituída pela dura-máter, sendo mais delgada posteriormente; ainda, foi demonstrado que inferiormente a parede medial é mais delgada que superiormente ${ }^{44}$. Yasuda et $\mathrm{al}^{45}$ descreveram a parede medial dividida em dois segmentos. O primeiro, selar, separa a fossa hipofisal do compartimento medial do seio cavernoso; o segundo, esfenoidal, acompanha a dura-máter no sulco carótico, no corpo do osso esfenóide. Semelhante aos outros autores, demonstraram a parede medial do seio cavernoso mais delgada inferior (segmento selar) que superiormente (parte esfenoidal); entretanto, é sempre composta de uma lâmina contínua de duramáter, diferentemente da parede lateral, que apresenta duas lâminas. A espessura da parede medial dos seios cavernosos variou entre 10 e $180 \mu \mathrm{m}$ 
(média $85 \mu \mathrm{m}$ ) no estudo de Peker et al ${ }^{46}$, com variações inclusive entre os dois lados do mesmo espécime; não foram encontrados defeitos durais nos espécimes. De forma contrária, o estudo em ressonância magnética realizado por Dieteman et al ${ }^{47}$ não foi capaz de encontrar tecido dural na parede medial dos seios cavernosos. Sejam defeitos durais, sejam áreas de fragilidade, uma expansão do tecido hipofisário lateralmente pode invadir o seio cavernoso deste lado, conforme demonstrado em 22 a $29 \%$ dos casos, em diversos estudos ${ }^{8,35,42}$.

Inferiormente, o assoalho da sela turca é formado pelo seio esfenoidal, sendo esta a base para os acessos cirúrgicos extracranianos, uma vez que a cavidade nasal, na sua porção superior, o encontra. Apresenta formato e pneumatização variáveis entre os indivíduos e de acordo com a idade de um mesmo indivíduo ${ }^{8}$, sendo o seio da face que mais variações apresenta. Durante os primeiros anos de vida, o seio esfenoidal não apresenta pneumatização, sendo formado por pequenas cavidades dentro do osso esfenóide. Com o passar do tempo, essas cavidades tendem a aumentar e unirem-se, formando um seio único durante a adolescência. No adulto, três tipos de seio esfenoidal podem ser encontrados ${ }^{35}$. De acordo com sua pneumatização, o seio esfenoidal é denominado conchal quando a área abaixo da sela turca apresenta um bloco ósseo sem ar; pré-selar quando a pneumatização não ultrapassa a linha vertical da parede anterior selar; e selar quando a pneumatização extende-se através do corpo do osso esfenóide, envolvendo a sela e alcançando o clivo. O tipo conchal é raro em adultos, sendo comum em crianças abaixo de 12 anos; a espessura do osso 
entre o assoalho da sela turca e o seio esfenoidal supera $10 \mathrm{~mm}$. O seio tipo pré-selar apresenta-se em cerca de $24 \%$ dos $\operatorname{casos}^{42}$, e dificulta sobremaneira o acesso transesfenoidal (assim como, e mais ainda, o seio tipo conchal). Felizmente, o tipo selar é o mais comum, presente em mais de $80 \%$ dos adultos.

Logo acima do diafragma da sela está localizado o quiasma óptico, região de cruzamento parcial das vias ópticas oriundas das retinas através dos nervos ópticos ${ }^{35}$. A expansão suprasselar de um adenoma hipofisário pode comprimir o quiasma óptico, gerando déficits visuais variáveis. Classicamente, a compressão centroquiasmática causa perda das funções das vias ópticas cruzadas no quiasma óptico, a saber, aquelas originadas das retinas mediais (portanto, trazendo a visão dos campos laterais), causando quadro conhecido como hemianopsia bitemporal ${ }^{48}$. Entretanto, diversos tipos de déficits visuais podem ocorrer, decorrendo não só do local da compressão, mas também de variações na localização do quiasma óptico; estas variações também têm importâncias cirúrgicas. Um quiasma óptico em posição anatômica normal repousa sobre o diagrama da sela e sobre a hipófise (o que ocorre em $70 \%$ dos casos segundo Renn e Rhoton ${ }^{42}$ ) Entretanto, o quiasma óptico pode situar-se em cima do tubérculo da sela (denominado quiasma pré-fixado) ou mais posteriormente, sobre o dorso da sela (denominado quiasma pós-fixado); estas duas situações ocorrem mais ou menos na mesma proporção ${ }^{35}$. Durante acessos cirúrgicos intracranianos, um quiasma óptico pré-fixado dificulta sobremaneira a exposição da fossa hipofiseal. Aberturas indevidas no diafragma da sela pela 
via transesfenoidal podem causar danos ao quiasma óptico. Logo acima do quiasma óptico, o terceiro ventrículo apresenta uma dilatação denominada recesso supraquiasmático. Tumores com extensão suprasselar ainda maiores podem deslocar e invadir o terceiro ventrículo, alcançando até mesmo o forame interventricular, causando hidrocefalias não-comunicantes.

\subsubsection{Partes da hipófise}

As divisões anátomo-funcionais da hipófise são motivo de discussão. Anatomicamente, a hipófise é constituída de dois lobos bem definidos, o lobo anterior e o lobo posterior ${ }^{35}$. Entre estes dois, entretanto, existe uma porção pouco desenvolvida nos humanos, mas maior e mais desenvolvida em animais inferiores, denominada parte intermédia ${ }^{33}$, quem em preparados anatômicos em geral é destacada junto com o lobo anterior, e por isso agrupada com as outras partes deste ${ }^{35}$. Como fisiologicamente a parte intermédia guarda relações com o lobo posterior, muitos fisiologistas preferem agrupá-la com o mesmo ${ }^{49}$. Em edição recente da Nomina Anatomica, traduzida para a língua portuguesa, definiu-se a divisão da hipófise em duas partes: a adenohipófise, constituída pela parte tuberal, parte intermédia e parte distal, e a neurohipófise, formada pela parte nervosa e pelo infundíbulo hipofisial, que contém a haste infundibular e a eminência mediana $^{50}$ (Figura 2). 


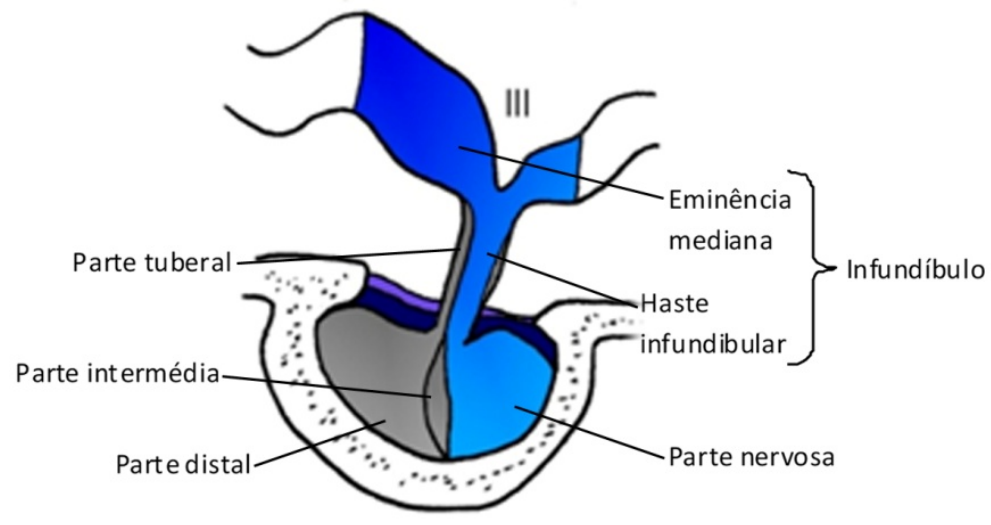

Figura 2: Divisão anatômica da hipófise. Em azul, a neurohipófise; em cinza, a adenohipófise. III = terceiro ventrículo

Embriologicamente, a adeno e a neurohipófise tem origens diferentes $^{33}$. A adenohipófise é derivada da bolsa de Rathke, invaginação embrionária do epitélio da faringe, o que explica a natureza epitelióide de suas células. Já a neurohipófise deriva de evaginação do hipotálamo, justificando o grande número de células gliais no seu interior. Conforme relatado anteriormente, a produção hormonal da hipófise está subordinada a ação hipotalâmica. Enquanto os homônios da adenohipófise (PRL, GH, TSH, ACTH, e FSH/LH) são produzidos dentro do próprio parênquima hipofisário, a produção de vasopressina e de ocitocina é realizada no próprio hipotálamo (núcleos supraóptico e paraventricular). Os longos neurônios hipotalâmicos trafegam pelo infundíbulo hipofisário e secretam os hormônios diretamente na neurohipófise. As células gliais dentro da neurohipófise, denominadas 
pituícitos, não têm função de secreção, atuando apenas como tecido de sustentação.

Dentro da adenohipófise, há diferenças regionais na quantidade de células produtoras de cada hormônio (Figura 3). As células lactotróficas e somatotróficas predominam nas porções mais laterais, enquanto as tireotróficas e gonadotróficas têm localização central. As células corticotróficas também têm localização central, porém mais próximas à parte intermédia ${ }^{51}$. Isso justifica a maior prevalência de determinado tipo tumoral em cada localização da hipófise ${ }^{52}$.

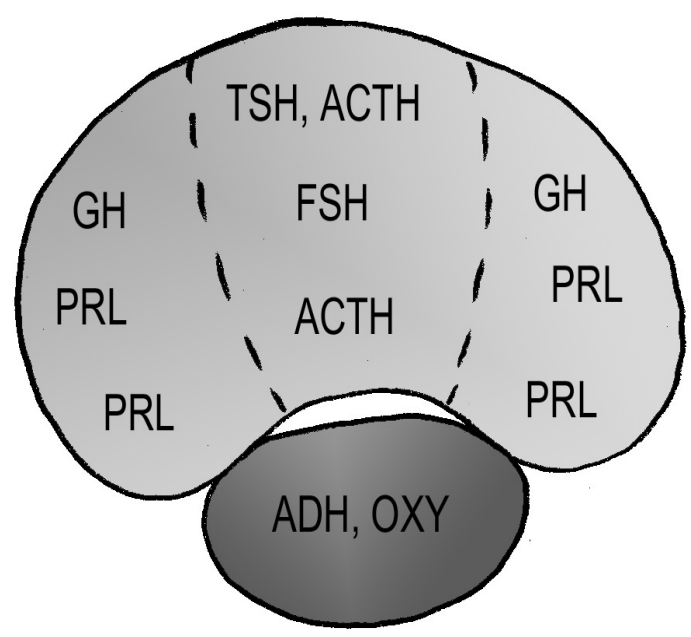

Figura 3: Ilustração de corte axial da hipófise com os locais de predomínio de produção cada tipo hormonal. Em cinza claro, a adenohipófise. Em escuro, a neurohipófise. 


\subsubsection{Vascularização}

A hipófise é vascularizada por ramos oriundos das aa. carótidas internas. Após penetrar no crânio pelo canal carótico, a a. carótida interna de cada lado percorre pequeno trajeto dentro do osso temporal, para então adentrar na fossa média do crânio no forame lacerado ${ }^{38}$, iniciando-se sua parte cavernosa. Dentro do seio cavernoso a a. carótida interna realiza uma sequência de curvas que se inicia com uma porção vertical, à qual se segue o joelho posterior, a porção horizontal, o joelho anterior e finalmente outra porção vertical para sair do seio cavernoso, invadindo o compartimento intradural (parte cerebral ${ }^{50}$ ). Essa região, conhecida como sifão carótico, tem como função diminuir o impacto das pulsações arteriais oriundas do pescoço $^{38}$

O ramo mais proximal da a. carótida interna na parte cavernosa é o tronco meningohipofisário, que se origina próximo da primeira curvatura da artéria $^{39}$. Junto ao teto do seio cavernoso, ele trifurca-se dando origem à a. tentorial (conhecida como artéria de Bernasconi-Cassinari, que se dirige posteriormente acompanhando a margem livre da tenda do cerebelo), à a. meníngea dorsal (que se dirige posteriormente em direção ao clivo) e à a. hipofisária inferior. Esta é o ramo mais infreqüente da parte cavernosa da a. carótida interna, ocorrendo em cerca de $80 \%$ das vezes ${ }^{39}$. Dirige-se medialmente em direção ao lobo posterior da hipófise e à parte posterior da cápsula da hipófise, suprindo então a dura-máter do assoalho da sela turca, para então anastomosar-se com sua oposta homônima. Em geral, é a 
responsável pelo suprimento dos adenomas hipofisários ${ }^{39}$, e pode ser ramo direto da a. carótida interna.

A a. inferior do seio cavernoso (conhecida como tronco inferolateral) é o segundo ramo da a. carótida interna na parte cavernosa. Dá ramos para a parede medial do seio cavernoso e não participa da irrigação da hipófise.

O último e menos constante ramo desta parte é a a. capsular (conhecida como a. de McConnell), que está presente em cerca de um quarto dos $\operatorname{casos}^{39,41}$, e tem trajeto variável, podendo dirigir-se medialmente para irrigar o assoalho da sela turca e parte do lobo anterior da hipófise, anastomosando-se com a a. hipofisária inferior.

Após emergir do seio cavernoso, a a. carótida interna de cada lado inicial sua parte cerebral, descrita por Rhoton ${ }^{53}$ como segmento oftálmico. Nesta primeira porção intradural, a a. carótida interna dá origem a vários ramos denominados hipofisários superiores, em número de um a quatro (em média, dois ${ }^{37}$ ). O maior destes ramos é chamado de a. hipofisária superior ${ }^{53}$. Junto com ramos chamados infundibulares (em menor número, emergindo tanto da a. carótida interna como da a. comunicante posterior, mais superiormente), as aa. hipofisárias superiores formam uma rede de anastomoses ao redor da haste hipofisária, denominado plexo circuminfundibular. Deste plexo originam-se ramos ascendentes (que irrigarão o tuber cinério, a eminência mediana e a superfície inferior do quiasma óptico) e descendentes. Os ramos descendentes, por sua vez, podem ser superficiais, que perfuram a aracnóide em direção ao lobo anterior, ou os 
denominados ramos curtos, que perfuram a haste hipofisária dando origem ao sistema portal hipofisário ${ }^{37,53}$.

\subsubsection{Sistema portal hipofisário}

Os ramos curtos que partem do plexo circum-infundibular, oriundo principalmente da a. hipofisária superior, penetram na estrutura da eminência mediana, porção da haste hipofisária que se continua superiormente com o hipotálamo. Nesta região, estes ramos apresentam a importante característica de serem permeáveis a certas substâncias secretadas por neurônios especiais do hipotálamo. Estes neurônios, originários de diversas regiões do hipotálamo, possuem axônios especiais que não terminam fazendo sinapse com outro neurônio, mas sim liberam hormônios e fatores diretamente na região da eminência mediana, em sinusoides do chamado sistema portal primário ${ }^{33}$ (Figura 4). Após receberem estas substâncias, os pequenos vasos emergem do parênquima da eminência mediana e dirigem-se inferiormente, desaguando direta e livremente na parte distal (adenohipófise), em sinusoides do sistema portal secundário. Assim, os hormônios e fatores reguladores do hipotálamo exerceram sua influência sobre a adenohipófise, controlando a secreção de seus hormônios. Esta característica particular da vascularização da hipófise é particularmente importante no diagnóstico dos processos patológicos que a acometem. O tecido hipofisário apresenta, nos exames de imagem, intensa captação de contraste endovenoso, da mesma forma que tumores. 
Entretando, a captação do contraste se dá muito precocemente, diferentemente de outros tecidos normais e de neoplasias, sendo este conhecimento a base para os exames dinâmicos de RM.

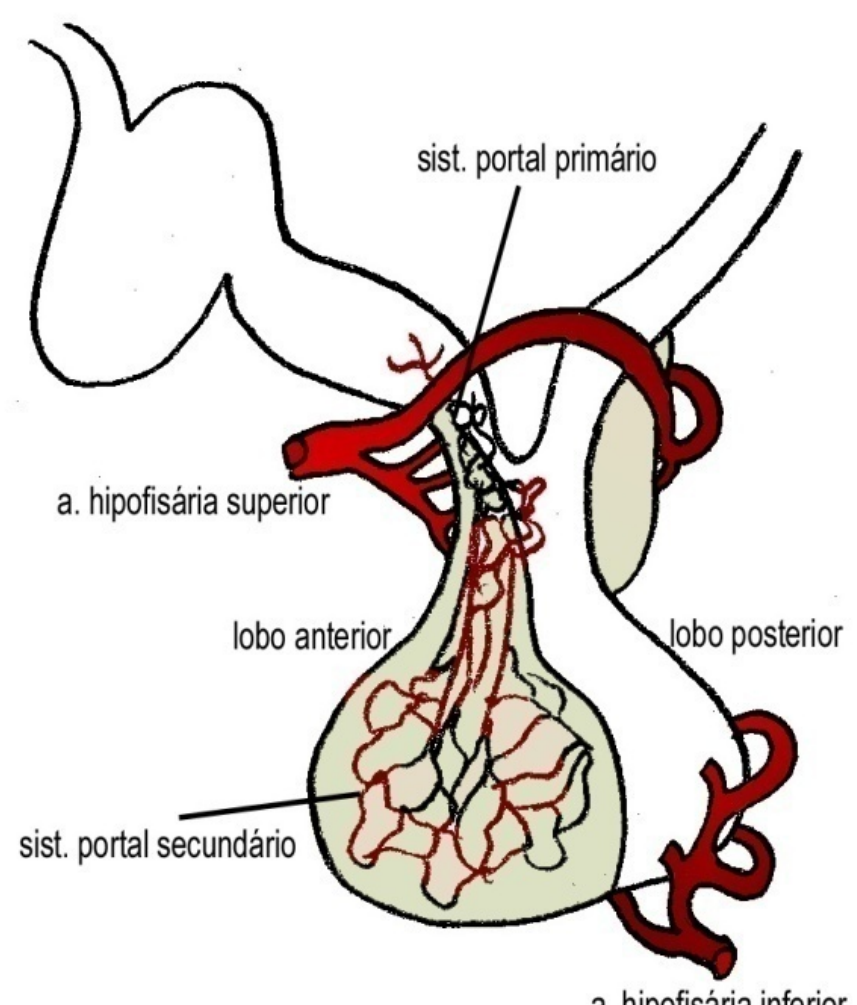

a. hipofisária inferior

Figura 4: O sistema portal hipofisário

\subsection{OS ADENOMAS HIPOFISÁRIOS}

A epidemiologia dos adenomas hipofisários é assunto de grande discussão, uma vez que podem ser encontrados de forma assintomática (os chamados "incidentalomas"). Em uma revisão sistemática recente, Ezzar et $\mathrm{al}^{2}$ identificaram prevalência de $14,4 \%$ dos indivíduos em autópsia, e 22,5\% 
em estudos de imagem (TC ou RM). Na média, 16,7\% dos indivíduos apresenta achado assintomático de adenomas hipofisários. Entretanto, análise de imunohistoquímica revelou que 25 a $41 \%$ dos tumores identificados em autópsias são produtores de prolactina, levando à suspeição de que se tratam de tumores clinicamente significativos não teriam recebido o devido diagnóstico. Cerca de $10 \%$ de todos os tumores intracranianos operados são adenomas hipofisários ${ }^{1,54,55}$. Por definição, são tumores benignos originários da adenohipófise. Tumores originários da neurohipófise são raros e de menor importância clínica; tumores histologicamente malignos da adenohipófise são denominados carcinomas, sendo também raros e motivo de discussão até sobre sua real existência ${ }^{55}$, não sendo objeto deste estudo.

Os adenomas causam sintomas basicamente em duas situações ${ }^{3}$ : quando atingem volumes grandes o suficiente para comprimir ou deslocar as estruturas anatômicas ao redor, ou quando suas células produzem hormônios cujo excesso se manifesta clinicamente. O deslocamento da haste hipofisária pode interferir no transporte de dopamina do hipotálamo para a hipófise. A dopamina é o mais importante inibidor da produção de prolactina; portanto, macroadenomas podem produzir hiperprolactinemia secundária mesmo sem serem hormonalmente ativos ${ }^{4}$. Os sintomas mais comuns decorrentes de aumento de volume tumoral são perda de campos visuais (classicamente, hemianopsia bitemporal) e cefaléia ${ }^{4}$. A causa atribuída à cefaléia, mesmo em microadenomas, é o aumento da pressão intrasselar ${ }^{56}$, e o volume tumoral não parece ser fator determinante ${ }^{56,57}$; 
outros fatores como história familiar de cefaléia e atividade hormonal parecem ter relação mais importante que o volume tumoral ${ }^{57,58}$.

\subsubsection{Classificação}

Embora haja diversos esquemas de classificação para adenomas hipofisários, na prática são úteis dois parâmetros: a presença ou não de alterações hormonais (determinante na decisão terapêutica) e o tamanho/extensão tumoral.

\subsubsection{Quanto ao tamanho/extensão}

Classicamente, os adenomas hipofisários são dividos em microadenomas, lesões que medem menos de $10 \mathrm{~mm}$ em seu maior diâmetro, e macroadenomas, com mais de $10 \mathrm{~mm}$.

Tão determinante quanto tamanho da lesão per se, a extensão selar extrasselar dos tumore hipofisários foi classificada por Hardy, em seu clássico trabalho sobre tumores hipofisários ${ }^{59}$. O grau de erosão selar foi classificado como Grau 0 (presença de tumor, com sela turca normal), I (mudanças focais discretas na sela), III (erosão focal do assoalho selar) e IV (erosão extensa da sela com destruição da base do crânio). Ainda, a expansão extrasselar é denominada $A$ quando não ultrapassa os limites do diafragma da sela, B, quando a extensão atinge a cisterna supraquiasmática, 
e $C$, se atinge o terceiro ventrículo, e D, para tumores com extensão acima de $30 \mathrm{~mm}$ ("gigantes"). Adicionada posteriormente, se o crescimento se faz lateralmente, invadindo o seio cavernoso, classifica-se com grau $\mathrm{E}^{5}$.

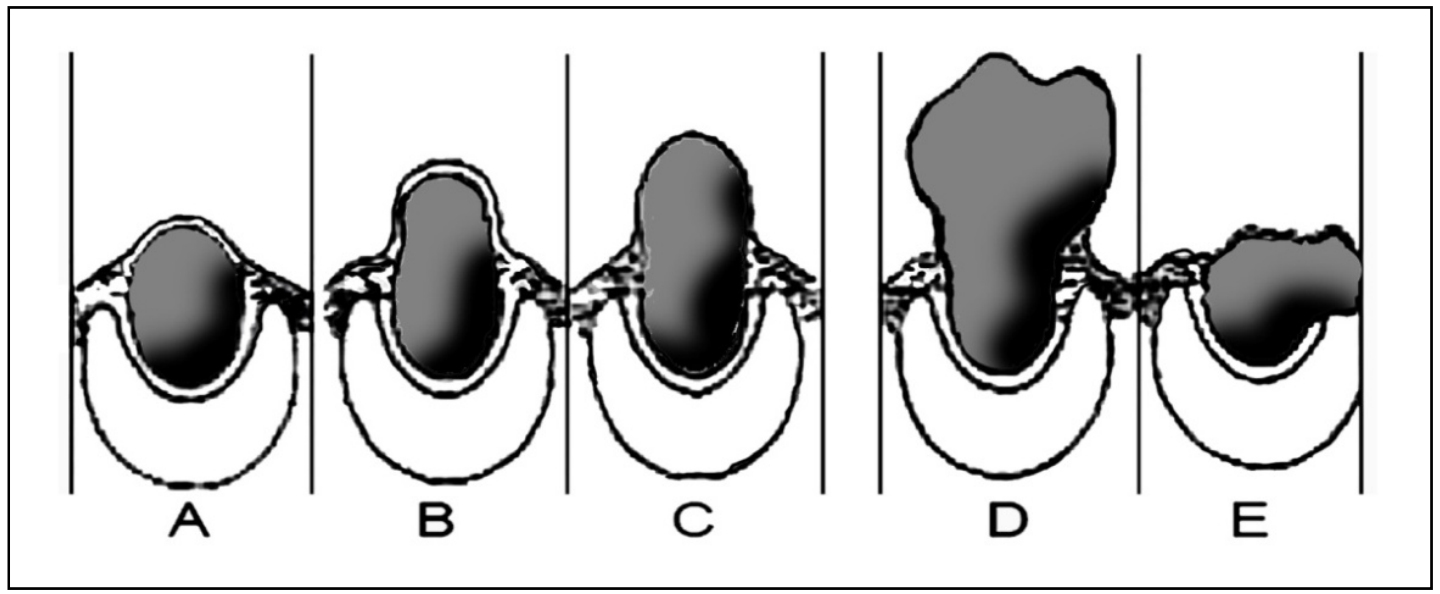

Figura 5: Classificação de Hardy, modificada por Wilson ${ }^{5}$, para extensões tumorais suprasselares. A. Extensão suprasselar até $10 \mathrm{~mm}$ da cisterna supraquiasmática. B. Até $20 \mathrm{~mm}$ acima da sela túrcica, empurrando recesso infundibular do III ventrículo. C. Expansão até $30 \mathrm{~mm}$ acima da sela túrcica, atingindo 0 nível do forame interventricular. D. Expansão maior que $30 \mathrm{~mm}$, com hidrocefalia obstrutiva ("gigantes"). E. expansão lateral infraclinóidea/seio cavernoso

Atenção especial ao envolvimento do seio cavernoso foi dada por Knosp et $\mathrm{al}^{60}$., que propuseram uma classificação baseada em exame de RM exclusivamente na extensão lateral dos tumores hipofisários. Em corte no plano coronal ao nível da sela turca, identificam-se os segmentos supra e intracavernosos da a. carótida interna. Considera-se grau 0 se uma linha tangenciando a parede medial dos dois segmentos da a. carótida interna não atinge o tecido tumoral; grau I, se o tumor não ultrapassa uma linha que 
passa que passa pelo centro dos segmentos da artéria; grau II se não ultrapassa linha que tangencia a parede lateral das carótidas; grau III se ultrapassa esta mesma linha lateral, e IV para tumores que envolvem totalmente o segmento cavernoso da artéria.

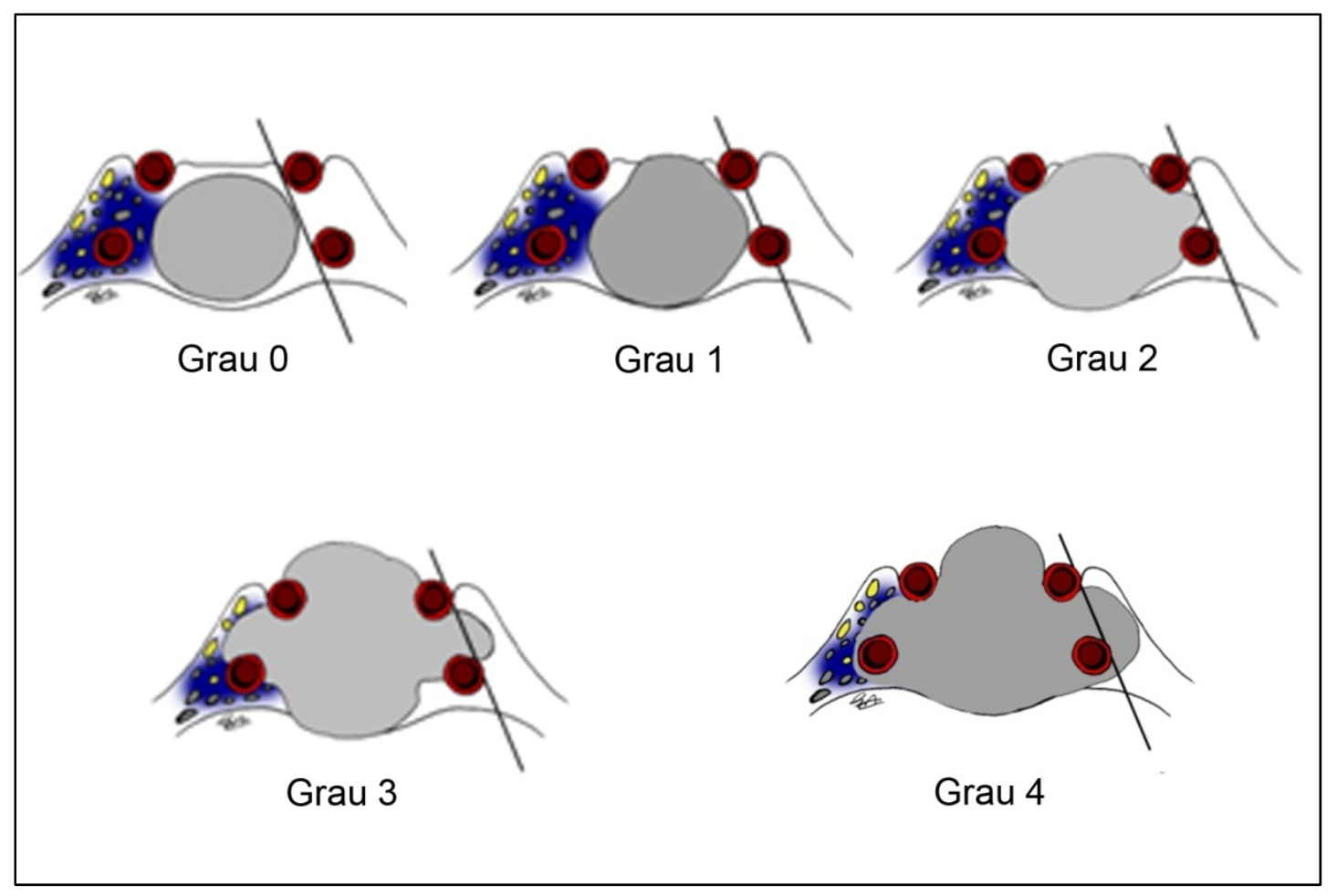

Figura 6 Classificação de Knosp et al $^{60}$ para extensões tumorais parasselares. Grau 0: sem invasão. Grau 1: invasão tumoral ultrapassa linha tangente medial às aa. carótidas internas. Grau 2: invasão ultrapassa linha intercarotídea mas não a tangente lateral das aa. carótidas internas. Grau 3: tumor além da tangente carotídea externa. Grau 4: envolvimento completo $\left(360^{\circ}\right)$ da a. carótida interna.

\subsubsection{Classificação hormonal}

Os sintomas mais comuns dos adenomas hipofisários são hipersecretórios, perfazendo até $70 \%$ do total ${ }^{61}$. O tipo de hormônio 
secretado (e consequentemente o tipo celular envolvido) determina o tratamento a ser realizado.

Os tumores hipofisários são classificados de acordo com seu comportamento hormonal conforme demonstrado na Tabela 1; os tipos mais comuns e mais importantes na prática clínica são a seguir descritos.

Tabela 1: Tipos de adenomas e suas características ${ }^{3,51}$

\begin{tabular}{|c|c|c|}
\hline Tipo de adenoma & Prevalência & Característica \\
\hline $\begin{array}{l}\text { Secretor de } \\
\text { prolactina }\end{array}$ & $27 \%$ & $\begin{array}{l}\text { "prolactinoma"; } \\
\text { galactorréia/amenorréia em } \\
\text { mulheres; diminuição da libido em } \\
\text { homens }\end{array}$ \\
\hline Secretor de GH & $13 \%$ & $\begin{array}{lcc}\text { Gigantismo } & \text { em } & \text { crianças; } \\
\text { acromegalia } & \text { em } & \text { adultos; } \\
\text { infiltrativos e agressivos } & \end{array}$ \\
\hline $\begin{array}{l}\text { Secreção mista (GH } \\
\text { e PRL) }\end{array}$ & $8 \%$ & $\begin{array}{l}\text { Variante mamossomatotrófica } \\
\text { crescimento lento,predomina GH. } \\
\text { Variante acidófila: agressiva, } \\
\text { predomina PRL }\end{array}$ \\
\hline Corticotrófico & $10 \%$ & $\begin{array}{l}\text { Pequenos; secretam ACTH causa } \\
\text { doença de Cushing }\end{array}$ \\
\hline $\begin{array}{l}\text { Corticotrófico } \\
\text { silencioso }\end{array}$ & $5 \%$ & $\begin{array}{l}\text { Morfologia de corticotrófico; } \\
\text { secreta pró-opiomelanocortina } \\
\text { outros fragmentos de ACTH. } \\
\text { Tendência de serem invasivo }\end{array}$ \\
\hline Tireotrófico & $1 \%$ & $\begin{array}{l}\text { Secreta TSH e subunidade } \alpha-1 \text { do } \\
\text { TSH; causa hipertireoidismo }\end{array}$ \\
\hline Plurihormonal & $1 \%$ & $\begin{array}{l}\text { Tipicamente: TSH, GH e PRL; } \\
\text { sintomas dependem do hormônio } \\
\text { predominante }\end{array}$ \\
\hline $\begin{array}{l}\text { Células "nulas" e } \\
\text { oncocitomas }\end{array}$ & $26 \%$ & $\begin{array}{lc}\text { "Não-funcionantes"; na verdade, } \\
\text { secretam subunidades } \\
\text { fragmentos } \\
\text { clinicamente } \\
\text { geralmente macroadenomas ao } \\
\text { diagnóstico }\end{array}$ \\
\hline
\end{tabular}




\subsection{Prolactinomas}

Representam os mais comuns na prática clínica, perfazendo entre 25 a $40 \%$ dos $\operatorname{casos}^{55}$. São mais comuns em mulheres que em homens, numa proporção de 4:1. Em mulheres causam sintomatologia de amenorréia e galactorréia (classicamente conhecida como síndrome de Forbes-Albright), decorrente da hiperprolactinemia; no sexo masculino, o aumento da prolactina causa diminuição da libido e impotência, sintomas menos conspícuos que no sexo feminino; os tumores tendem a serem diagnosticados de forma mais tardia, quando já geram efeito de massa e compressão das estruturas adjacentes.

Outras causas de hiperprolactinemia incluem uso de medicações, insuficiência renal, hipotireoidismo e exercício físico. Considerando-se valores normais de prolactina sérica até $20 \mathrm{ng} / \mathrm{ml}$, situações patológicas que não prolactinomas podem gerar aumentos de até $150 \mathrm{ng} / \mathrm{ml}$. Ainda, como comentado anteriormente, macroadenomas podem causar hiperprolactinemia por compressão da haste hipofisária; nestes casos, níveis de até $400 \mathrm{ng} / \mathrm{ml}$ são possíveis. Em geral, consideram-se níveis superiores a $200 \mathrm{ng} / \mathrm{ml}$ como fortemente indicativos de tumores produtores de prolactina ${ }^{55}$ 


\subsection{Adenomas corticotróficos}

Correspondem entre 10 e $15 \%$ dos adenomas hipofisários ${ }^{55}$. A produção excessiva de ACTH pelos tumores gera hiperfunção e hipertrofia das glândulas suprarrenais, com aumento dos níveis circulantes de cortisol endógeno.

O excesso de cortisol de qualquer origem promove uma série de alterações clínicas conhecidas em conjunto como síndrome de Cushing, sendo denominada doença de Cushing quando causada por um adenoma hipofisário. Caracteriza-se por uma endrocrinopatia das mais graves, com sintomatologia atingindo diversos aparelhos e sistemas. A mudança do aspecto físico típica consiste de obesidade centrípeta, depósito de gordura supraclavicular e face de lua-cheia. Mudança da pigmentação da pele e hirsurtismo são comuns. Alterações mais severas são relacionadas aos efeitos metabólicos, como hipertensão arterial, intolerância a glicose e osteoporose.

Os tumores costumam ser pequenos, menores que $5 \mathrm{~mm}$, e os exames diagnósticos podem ser inconclusivos. 


\subsection{Adenomas produtores de $\mathrm{GH}$}

A produção excessiva de $\mathrm{GH}$ produz efeitos sistêmicos através de estímulo ao aumento da secreção hepática da somatomedina - C (ou IGF 1- insuline-like growth factor ${ }^{4}, 62$. Seu efeito sobre ossos, articulações e tecido conjuntivo é facilmente notado. Em adultos, causa síndrome característica de acromegalia, com alterações faciais como aumento da bossa frontalm prognatismo e má-oclusão dentária, alem de aumento das extremidades (pés e mãos). Caso a doença de manifeste antes do fechamento da epífise dos ossos longos, pode ocorrer gigantismo.

Além das deformidades estéticas, o aumento da densidade óssea e hipertrofia das articulações causa degeneração articular precoce e estenose do canal vertebral. Neuropatias periféricas (síndrome do túnel do carpo e outras neuropatias compressivas são comuns ${ }^{63}$. Porém, de maior gravidade são as anormalidade cardíacas (insuficiência cardíaca congestiva e hipertensão severas) e metabólicas (desde intolerância a glicose até diabete melito grave), que aumenta significativamente o risco de vida dos acometidos.

\subsection{Adenomas tireotróficos}

Classicamente, representam menos de $1 \%$ dos adenomas hipofisários. Entretanto, novos métodos laboratoriais têm identificado número crescente de $\operatorname{casos}^{64}$. Mindermann e Wilson ${ }^{65}$ demonstraram proporção 
próxima de $3 \%$. O quadro clínico não difere daquele do hipertireoidismo primário:

\subsection{Adenomas não-funcionantes}

Perfazem cerca de 25 a $40 \%$ de todos os adenomas, e caracterizam-se por não produzirem endocrinopatia clínica; seis sintomas são devidos ao seu aumento de volume e compressão de estruturas adjacentes. Conforme comentado anteriormente, podem produzir aumento dos níveis de prolactina devido a compressão da haste hipofisária.

Três tipos morfológicos diferentes de tumores são agrupados nesta classificação. Os adenomas compostos por "células nulas" são os mais comuns ( $17 \%$ de todos os adenomas); são células cujas características morfológicas e imunohistoquímicas não correspondem a nenhum dos outros cinco tipos celulares. Os oncocitomas perfazem cerca de $6 \%$ do total, e nada mais são dos que células nulas cujo citoplasma apresenta-se preenchido por mitocôndrias dilatadas; não há qualquer diferenciação clínica, oncológica ou terapêutica entre os dois tipos. Ainda, situam-se entre os adenomas nãofuncionantes os adenomas gonadotróficos. Embora sejam na verdade secretores de hormônios, devido a sua apresentação em pacientes mais idosos, já com função gonadal interrompida, seus sintomas são raramente perceptíveis. 
Mais raramente, tumores não-funcionantes podem produzir subunidades de hormônios glicopeptídeos (TSH, FSH) e formas "silenciosas" de hormônios geralmente ativos (ACTH, GH). Embora endocrinologicamente benignos, estes tumores podem apresentar agressividade biológica e comportamento anatomicamente mais invasivo ${ }^{51}$.

\subsubsection{Diagnóstico por imagem}

Além dos sintomas clínicos e exames laboratoriais, um diagnóstico anatômico preciso de uma adenomas hipofisário é necessário, especialmente quando se planeja algum tipo de tratamento cirúrgico. Exames de tomografia computadorizada (TC) promoviam imagens de difícil interpretação, especialmente pelos artefatos ósseos da região, e tumores menores eram frequentemente invisíveis ao método.

Diferentemente da TC, o exame através de RM não é baseado em raios-X, portanto não emite radiação ionizante; para se evitarem confusões, o termo anteriormente utilizado, ressonância nuclear magnética, deve ser evitado, dada a conotação radiológica que o termo nuclear apresenta. Ressonância magnética é propriedade física que os núcleos de determinados elementos têm de emitirem sinal ao serem submetidos a um campo magnético forte; este sinal pode ser captado por uma antena ou receptor e ser transformado em imagem. O núcleo mais simples é o do átomo de hidrogênio, possuindo um único próton; é capaz de emitir o maior sinal de todos os núcleos estáveis. Além disso, apresenta-se em abundância 
nos tecidos, sendo que a somatória destes fatores resulta na obtenção de sinal mil vezes maior que de qualquer outro elemento presente nos tecido animais, razão de sua utilização nos exames atuais. Uma vez excitados pelo campo magnético do aparelho, cada núcleo de hidrogênio torna-se instável e "vibra" ao retornar a seu estado inicial a uma freqüência na faixa das ondas de rádio. $\mathrm{O}$ equipamento detecta essas ondas e determina a posição no espaço e a intensidade da energia. Essa intensidade é mostrada como "brilho" na imagem, sendo utilizada a nomenclatura "intensidade de sinal". As primeiras aplicações médicas da ressonância magnética datam dos anos $1970^{66}$, sendo seu uso atual mundialmente difundido (Figura 7). Os estudos no campo da ressonância magnética e suas aplicações na imaginologia moderna renderam a Paul Lauterbur (EUA) e Peter Mansfield (Grã-Bretanha) o Prêmio Nobel de Fisiologia e Medicina do ano de 2003. 


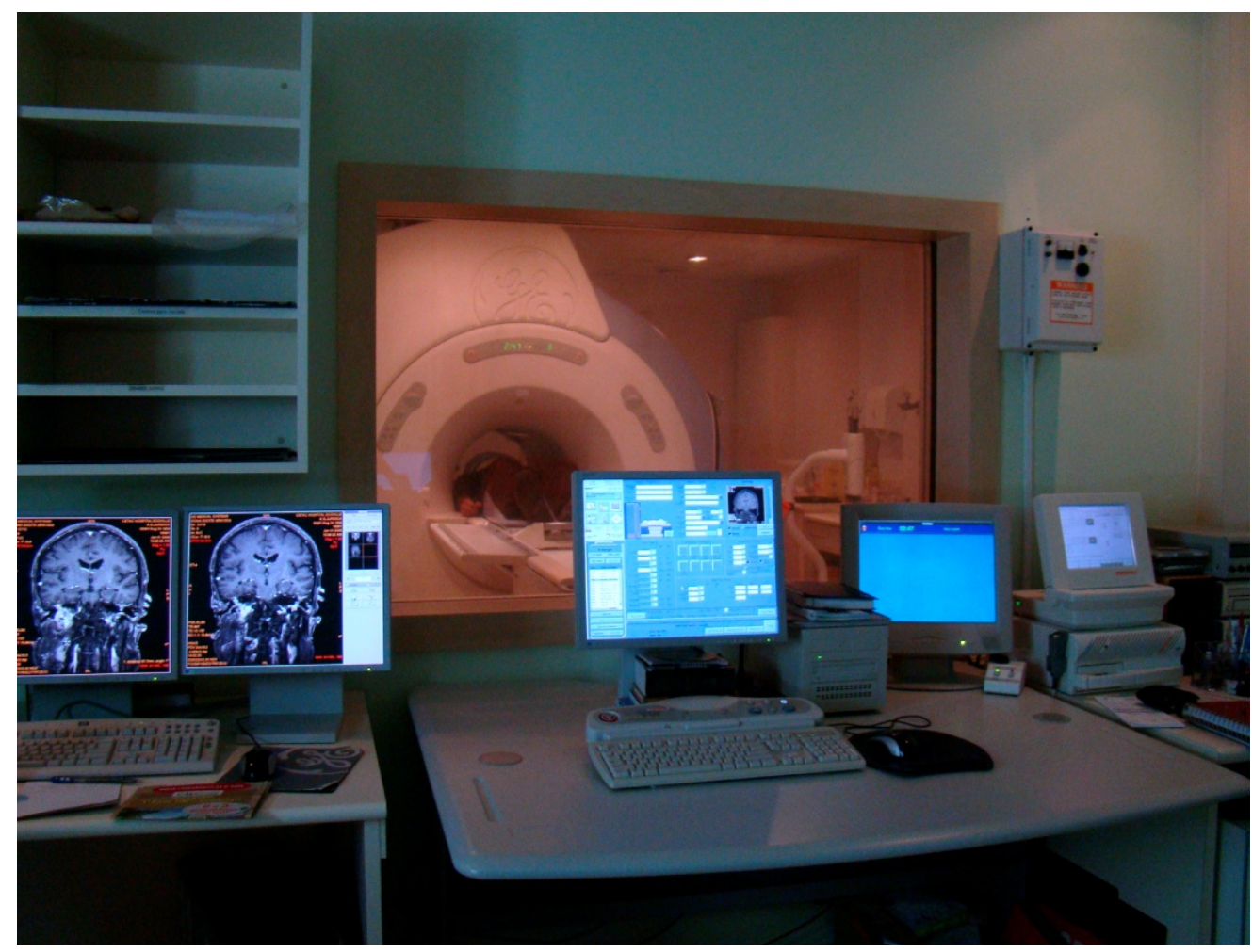

Figura 7: Fotografia de aparelho de ressonância magnética durante exame, visto de dentro da sala de controle com a estação de trabalho

O advento da RM modificou sensivelmente o diagnóstico e o planejamento cirúrgico dos adenomas hipofisários ${ }^{67}$. Além de possibilitar a demonstração de tumores menores, a invasão de tecidos adjacentes como os seios cavernosos pode ser mais bem demonstradas ${ }^{68}$. Nos macroadenomas, o maior benefício da RM foi a melhor identificação das relações entre o tumor e a estruturas vizinhas, em especial a. carótida interna, posição do quiasma óptico, e as extensões suprasselares e parasselares $^{69}$.

A utilização de substâncias endovenosas para obtenção de imagens contrastadas veio a melhorar a sensibilidade dos exames de RM. A captação 
de contrastes paramagnéticos decorre de dois processos ${ }^{70-71}$. $O$ primeiro, denominado intravascular, pode ocorrer devido a neovascularização, vasodilatação ou hiperemia, e nada mais é do que o próprio agente de contraste dentro do vaso sanguíneo. Após determinado período, o contraste tende a se difundir pelos espaços perivasculares para o interstício, em decorrência de gradiente através da membrana capilar endotelial. No sistema nervoso central, a barreira hematoencefálica não é permeável ao contraste, fazendo com que não haja tal difusão para o interstício, e a intensidade da captação do contraste vai depender basicamente do fluxo e do volume sanguíneos locais. Para que ocorra o segundo processo, denominado intersticial, a barreira hematoencefálica precisa sofrer alguma alteração, seja anatômica, seja funcional. A chamada "quebra" da barreira ocorre em diversas situações patológicas, como inflamações, desmielinização, infecções e tumores.

O diagnóstico de neoplasias hipofisárias melhorou significativamente com a utilização de contraste paramagnético ${ }^{51}$. Por outro lado, a intensa captação de contraste que o tecido hipofisário normal exibe devido ao seu sistema portal muitas vezes acaba por confundir o diagnóstico ${ }^{72}$. Diversas doses do contraste paramagnético foram utilizadas para se tentar minimizar este efeito ${ }^{73}$. 


\subsubsection{Ressonância Magnética dinâmica}

Já na década de 1980 , Hemminghytt ${ }^{74}$ relatou que a detecção de um microadenoma hipofisário em tomografias computadorizadas era tempodependente após a injeção de contraste. A circulação porta-hipofisária, como relatado anteriormente, faz com que o sangue arterial (e consequentemente o contraste injetado) deságue imediatamente no parênquima hipofisário, sem passagem por capilares ${ }^{75}$. Com isso, o parênquima hipofisário, em especial a porção proximal do lobo anterior, exibe captação precoce do contraste, enquanto um adenoma exibe captação mais tardia. A hipófise normal apresenta um pico de captação do contraste paramagnético cerca de 60 a 90 s após sua injeção ${ }^{75}$, enquanto os adenomas apresentam captação mais $\operatorname{tardia}^{76}$. Ou seja, se uma imagem for adquirida precocemente, a hipófise exibirá captação do contraste, enquanto o tumor exibirá uma falha na captação. Bonneville et al, ainda em exame de tomografia computadorizada, chamaram a atenção para esta característica, denominando-a "sinal do tufo",77 (Figura 8). 


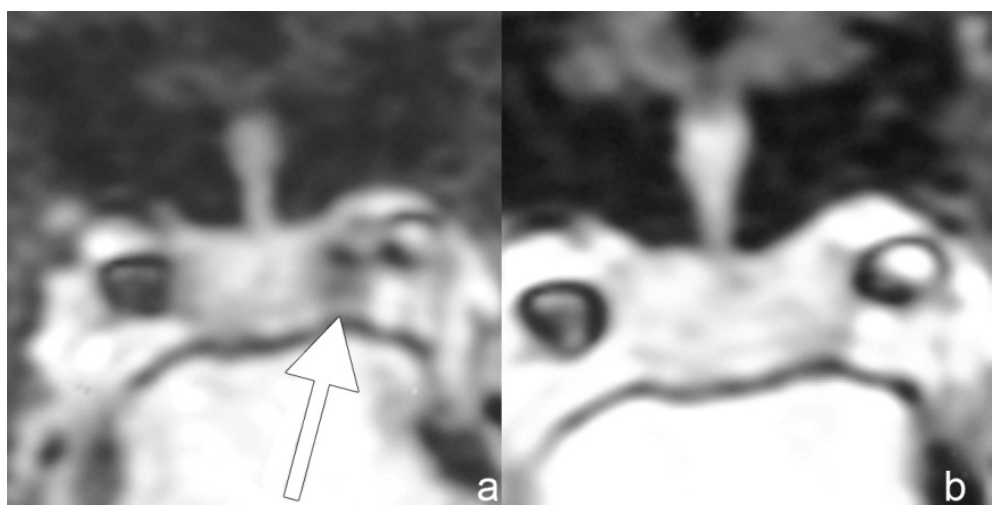

Figura 8: "Sinal do tufo". A. Imagem precoce de RM dinâmica, no plano coronal, demonstrando falha de preenchimento no local do adenoma (seta). B. Imagem tardia demonstrando captação quase homogênea do tecido intrasselar, dificultando detecção da lesão.

Miki et al ${ }^{72}$ analisaram o padrão de captação da hipófise e de adenomas em razão do tempo para aquisição da imagem após a injeção de contraste. Dos dez pacientes analisados, quatro apresentaram pico de captação na primeira imagem (primeiro minuto) e seis na segunda (segundo minuto), enquanto os adenomas exibiram captação na sequências mais tardias (terceiro ao quinto minuto). A diferenciação entre a glândula e o tumor foi mais bem verificada nas duas primeiras sequências. Ainda, os autores chamam a atenção para a importância da RM dinâmica mesmo nos macroadenomas, uma vez que o tecido hipofisário normal pode ser visualizado na borda de um tumor volumoso nas sequências precoces. A RM dinâmica aumenta a detecção de microadenomas em relação às sequências contrastadas padrão ${ }^{78-80}$. A avaliação dos seios cavernosos também merece atenção especial. Sua intensa captação do contraste paramagnético dificulta sobremaneira a avaliação de exames da região ${ }^{76}$. Estudos com RM 
dinâmica demonstraram um maior diferenciação entre o tecido conectivo normal dos seios cavernosos e tumores invasivos, modificando sobremaneira a estratégia cirúrgica após este conhecimento ${ }^{76,81}$.

\subsubsection{Tratamento}

Uma vez diagnosticado um adenoma hipofisário, seu tratamento, se necessário, necessitará ser individualizado dentro de seu contexto clínico. Tumores não-funcionantes e assintomáticos (i.e., sem efeito de massa comprimindo estruturas adjacentes - "incidentalomas") podem inclusive ser seguidos com exames de imagem, sem qualquer tratamento.

Uma vez indicado o tratamento, este deve objetivar ${ }^{61,69}$ :

1. Reversão da endocrinopatia e restauração da função hipofisária normal.

2. Remoção da massa tumoral e restauração da função neurológica normal.

3. Eliminar ou minimizar a possibilidade de recorrência tumoral

4. Obter diagnóstico histológico definitivo 


\section{Prolactinomas}

Controle farmacológico é a modalidade inicial de tratamento da maioria dos prolactinomas. Conforme referido anteriormente, a liberação hipofisária de PRL encontra-se sob influência inibitória do hipotálamo, através da secreção de dopamina. O uso de agonista dopaminérgicos apresenta sucesso elevado no controle da secreção hipofisária de PRL, com

diminuição do volume tumoral e regressão dos déficits visuais ${ }^{4,}{ }^{82}$. Normalização dos níveis de PRL chega a $75 \%$ dos casos com bromocriptina e $87 \%$ com pergolide. Diminuição do volume tumoral em pelo menos $50 \%$ do tamanho original é atingida em $65 \%$ dos pacientes tratados com bromocriptina, e $85-90 \%$ com pergolide ou cabergolide ${ }^{82}$.

Quadros resistentes a tratamento farmacológico (seja pela ausência de resposta ou por efeitos colaterais insuportáveis) ou com efeito massa muito significativo são candidatos a tratamento cirúrgico ${ }^{61}$; mulheres com desejo de engravidas podem tentar outras modalidades farmacológicas, mas os índices de resposta são muito inferiores e a opção cirúrgica acaba sendo a mais eficaz ${ }^{3}$.

\section{Adenomas corticotróficos}

O tratamento dos pacientes com Doença de Cushing é cirúrgico, se condições clínicas não o permitirem. A cirurgia é curativa em até $90 \%$ dos 
microadenomas e em cerca de $65 \%$ dos macroadenomas e tumores invasivos $^{4,61}$.Tratamentos farmacológicos em geral são ineficazes a longo prazo, e podem ser utilizados em conjunto com adrenalectomia bilateral nos casos mais agressivos.

\section{Adenomas secretores de $\mathbf{G H}$}

À semelhança dos adenomas corticotróficos, os adenomas secretores de $\mathrm{GH}$ são tratados inicialmente com ressecção tumoral ${ }^{4}$; entretanto, isoladamente o tratamento cirúrgico é curativo em índices menores que nos outros tipos funcionais. Espera-se cura após ressecção tumoral em 50 a $70 \%$ dos casos, e varia de acordo com o volume tumoral (até $91 \%$ dos microadenomas e cerca de $50 \%$ dos macroadenomas 4 . Agonistas dopaminérgicos podem ser usados como terapia adjuvante, mas os análogos das somatostatina (octreotide, lanreotide) e antagonistas de receptores de $\mathrm{GH}$ (pegvisomant) apresentam melhores resultados. Tanto o custo das medicações como o perfil de efeitos colaterais são limitantes destas terapias.

\section{Adenomas tireotróficos}

Devido a sua baixa prevalência em relação aos outros adenomas, há dificuldade de se estabelecerem protocolos de tratamento; entretanto, sem 
dúvida o tratamento cirúrgico é escolhido na maioria dos casos. Análogos da somatostatina entre outros medicamentos são considerados experimentais, e reservados para ressecções parciais ${ }^{64}$.

\section{Adenomas não funcionantes}

Diferentemente dos adenomas funcionantes, nos quais o controle endócrino pode ser obtido com medicamentos, sejam isolados ou associados a operações, nos adenomas não-funcionantes não há terapia farmacológica eficaz disponível ${ }^{61}$. Assim sendo, o tratamento cirúrgico passa a ser o escolhido nos pacientes que exibem sintomas de efeito de massa.

Pacientes cuja ressecção parcial e tumores invasivos podem se beneficiar de radioterapia ${ }^{83}$. Isso se aplica também a tumores funcionantes nos quais tentativas cirúrgicas e farmacológicas não produzem controle hormonal. Entretanto, seus efeitos deletérios por vezes superam os benefícios. A irradiação do quiasma óptico, devido a sua proximidade anatômica, pode gerar déficits visuais irreversíveis em 2 a 5\% dos casos. Hipopituitarismo, doenças cerebro-vasculares, déficits cognitivos e até tumores induzidos por radioterapia são realidades a serem consideradas ao se indicar esta modalidade de tratamento $^{74}$. Com o advento de novas técnicas como a radiocirurgia, seu perfil de segurança deve melhorar significativamente, e sua aplicabilidade, tornar-se maior. 


\subsubsection{A cirurgia dos adenomas hipofisários}

Procedimentos cirúrgicos constituem a única modalidade terapêutica aplicável em todos os tipos de adenomas, dentro das particularidades de cada caso. As relações anatômicas da hipófise e da sela turca, como citado anteriormente, fazem da abordagem cirúrgica dos tumores hipofisários um desafio particular dos neurocirurgiões.

A separação da sela turca do seio esfenóide apenas por uma fina lâmina óssea faz com que a via transesfenoidal, com suas variações, seja a mais utilizada das abordagens das afecções intrasselares; para esse acesso, será dado importância maior.

A exposição subfrontal da região selar é facilmente obtida através de pequena craniotomia frontal unilateral. Tumores localizados acima do quiasma óptico podem ser abordados por esse acesso. Sua exposição envolve obrigatoriamente alguma retração do lobo frontal e dissecção microscópica das aa. carótidas internas no segmento intracraniano, manipulação do quiasma óptico, tornando o caminho até a sela turca mais longo e trabalhoso. Entretanto, nas ocasiões em que o seio esfenóide é do tipo conchal ou se a extensão suprasselar é tão extensa que não pode ser alcançada pela via transesfenoidal, este pode ser o acesso selecionado ${ }^{35}$.

Craniotomia pterional pode ser necessária se a área lateral ao processo clinóide anterior e segmento supraclinóide da a. carótida interna 
necessitam ser expostos; envolvimentos maiores dos seios cavernosos podem exigir exposições mais amplas, como um acesso órbito-zigomático ${ }^{35}$.

\subsubsection{O acesso cirúrgico transesfenoidal}

Embora o acesso cirúrgico transesfenoidal tenha sido inicialmente relatado a pouco mais de um século, foi após a introdução do microscópio cirúrgico e pelos trabalhos de Jules Hardy que o procedimento se popularizou. A grande maioria dos tumores hipofisários são hoje operados pela via transesfenoidal ${ }^{15,35}$. As variações do acesso são diversas, mas a abordagem do seio esfenóide é a via comum dos acessos inferiores.

O acesso sublabial foi outrora o mais utilizado. Promove ampla exposição do seio esfenoidal, sendo indicado principalmente para lesões mais extensas e que envolvem a destruição da fossa craniana anterior, sendo hoje raramente necessário das abordagens dos adenomas hipofisários.

A maioria dos cirurgiões utiliza a via transnasal com deslocamento parcial do septo nasal para alcançar o seio esfenoidal ${ }^{15}$. Utiliza-se uma pequena incisão na mucosa nasal e dissecção da mesma do septo ósseo, com posterior deslocamento lateral do mesmo e exposição da sua junção com a base do seio esfenoidal; parte dele é então ressecada junto à crista do vômer e todo o seio é exposto. Uma pequena variação deste acesso é o chamado endonasal, que consiste na exposição direta da junção do septo 
ósseo com o rostro esfenoidal, logo abaixo do óstio esfenoidal. A mucosa é incisada nessa junção, e o septo é deslocado para o lado oposto com espéculo, sem necessidade de ressecção da coana nasal (Figura 9).
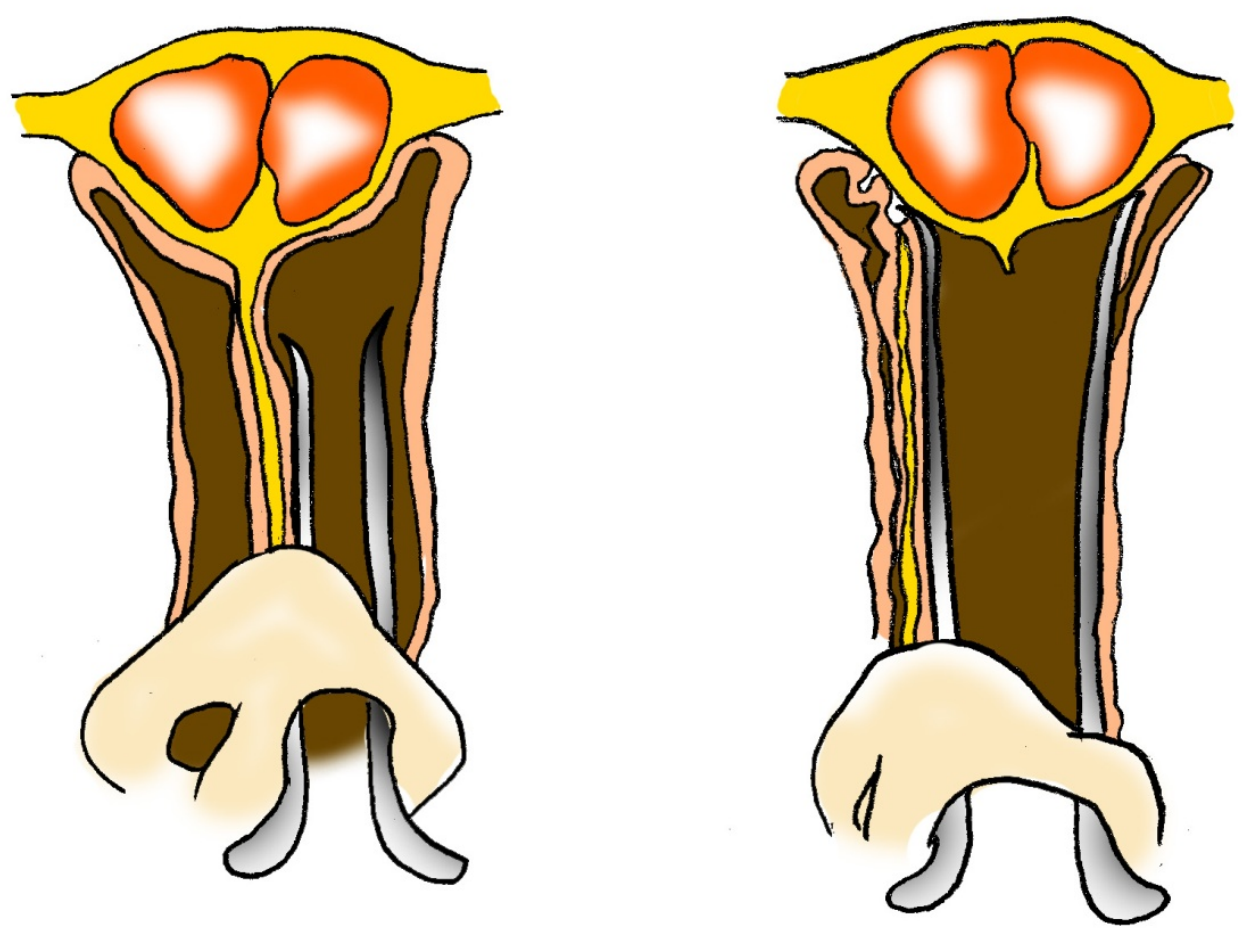

Figura 9: Acesso microcirúrgico endonasal ao seio esfenoidal

O acesso endonasal pode ser realizado desde seu início com auxílio de endoscópio, sendo que vários cirurgiões têm sido treinados com essa técnica. As vantagens são discutíveis, e os acessos são similares ${ }^{35}$. Após a abertura do seio esfenoidal, ampla visão do assoalho da sela turca é obtida, e o acesso a hipófise encontra sucesso. 
O objetivo das operações dos adenomas hipofisários é a ressecção radical com preservação da função hipofisária. Nem sempre esses objetivos são alcançados. Extensões suprasselares podem representar dificuldade cirúrgica nesse acesso. Embora a retirada da lesão intrasselar em geral permita que o tumor suprasselar prolapse no campo cirúrgico, manobras podem ser usadas para forçar sua exposição. Manobra forçada de Valsalva, compressão das veias jugulares e instilação de solução salina através de cateter lombar aumentam a pressão intracraniana, e forçam a descida da porção suprasselar à sela turca.

O uso de endoscópio neurocirúrgico veio a modificar o a abordagem dos tumores hipofisários. Extensões suprasselares e parasselares, inclusive para seios cavernosos, puderam ser melhor visibilizadas e manipuladas com segurança; ressecções mais radicais puderam ser alcançadas com complicações menores.

\subsubsection{RM intraoperatória}

O grau de ressecção tumoral estimado pelo cirurgião é superestimado, conforme referido já nos anos 1980 por Albert et al ${ }^{31}$. Neste clássico estudo, o número de pacientes com tumores residuais foi três vezes maior que o estimado pelo neurocirurgião, quando realizadas RM entre o primeiro e o terceiro dia de pós-operatório. No início dos anos 1990, alguns grupos idealizaram o chamado "Centro Cirúrgico do Futuro"83-84, no qual um 
cirurgião poderia realizar um procedimento com visualização imediata dos seus resultados, aumentando os índices de ressecção tumoral, outrora baseado em estimativas incertas. A implementação de aparelhos de RM dentro do cirúrgico, bem como o desenvolvimento de instrumentais cirúrgicos compatíveis com campo magnético foram desafios rapidamente suplantados $^{85}$. Menos de uma década depois, as primeiras publicações sobre o método trouxeram mais ânimo aos entusiastas. A RM intraoperatória passava a ser realidade, permitindo ao cirurgião visualizar, quase em tempo real, seus resultados operatórios, sem que com isso o tempo cirúrgico aumentasse significativamente, bem como sem aumento das taxas de complicações $^{19,86}$.

O aumento dos índices de ressecção tumoral foi identificado prontamente. Knauth et al ${ }^{87}$, em aparelho de $0,2 \mathrm{~T}$, demonstraram ressecção radical em apenas $36,6 \%$ dos casos quando utilizada neuronavegação apenas, com re-intervenções $44,8 \%$ dos casos para remoção adicional de tumores residuais. Ressecções adicionais necessárias foram relatadas em 50 a $92 \%$ dos casos em no tratamento de tumores intracranianos em geral ${ }^{88-}$ 91. Com aparelhos de alto campo magnético $(1,5 \mathrm{~T})$, imagens ainda mais fidedignas passaram a ser possíveis, otimizando-se o método ${ }^{92-93}$. Entretanto, significativa elevação nos custos limita o uso extensivo da técnica, e estudos de relação custo versus benefício são necessário ${ }^{94-95}$. No Brasil, a única série publicada baseia-se na redução dos custos utilizando-se aparelho de fora da sala cirúrgica ${ }^{20}$; com resultados promissores, pode representar uma solução para centros onde há limitação orçamentária. 
Nos tumores hipofisários, Martin et al $^{17}$ revelaram re-intervenções em três dos cinco primeiros casos operados. Em outra publicação, Bohinski et $\mathrm{al}^{18}$, com aparelho de 0,3T, realizaram re-intervenções em 66\% (19 de 29) dos pacientes, operados de tumores hipofisários, nos quais se julgava ter-se obtido ressecção total. Fahlbusch et al ${ }^{96}$, inicialmente com aparelho de 0,2T, realizaram ressecções adicionais em $34 \%$ dos casos. Entretanto, a revisão do leito operatório suspeito em nove casos (20\%) não revelou qualquer tumor, confirmando-se a ausência em RM pós-operatória três meses após. Artefatos e hematomas confundindo-se com tumores residuais foram citados por outros autores ${ }^{97}$ chegando a $30 \%$ das imagens em aparelhos de baixo campo $^{98}$. Com aparelhos de alto campo $(1,5 \mathrm{~T})$, os índices de remoção adicional aumentaram ainda mais ${ }^{92}$. Em publicação do mesmo grupo, desta vez com aparelho de 1,5T, remoção radical foi possível em $82 \%$ dos casos, enquanto apenas $58 \%$ tinham ressecção radical no momento do primeiro exame intraoperatório. Com melhores imagens, as re-intervenções desnecessárias e confusão com artefatos reduziram-se drasticamente, com apenas $6 \%$ de falsos positivos. Para aumentar a diferenciação entre artefatos e tumores residuais, cotonóides embebidos em contraste paramagnético (Gd-DTPA) podem ser utilizados, reduzindo-se os falsos positivos mesmo em aparelhos de baixo campo magnético ${ }^{99}$. RM dinâmica tem sido raramente utilizada, e pode colaborar na diferenciação de tecido hipofisário, tumor residual e artefatos paramagnéticos ${ }^{100}$. 


\subsubsection{Prognóstico e acompanhamento pós-operatório}

Embora dependa do tamanho, do tipo tumoral e de níveis hormonais pré-operatórios, o prognóstico dos tumores hipofisários depende diretamente do grau de ressecção tumoral. Os pacientes necessitam de controle clínico, laboratorial e de imagem constantes para se identificarem recidivas e crescimentos tumorais precoces, e otimizar-se a terapia.

Níveis hormonais precoces relacionam-se com controle tardio da doença, no caso dos tumores funcionantes ${ }^{4}$. Níveis plasmáticos de prolactina menores que $10 \mathrm{ng} / \mathrm{ml}$ no pós-operatório imediato relacionam-se com índices de cura tardia em até $100 \%$ nos microadenomas e de $93 \%$ nos macroadenomas. Os níveis de ACTH apresentam queda já no ato operatório $^{11}$, apesar de exame rápido não ser amplamente disponível. Critérios de remissão de tumores produtores de $\mathrm{GH}$, por outro lado, são extremamente discutíveis, incluindo a dosagem sérica do $\mathrm{GH}$, teste de supressão de GH pela glicose e níveis séricos de IGF-1 corrigidos. Já no caso de tumores não funcionantes, apenas exames de imagem pósoperatórios podem ser utilizados para controle evolutivo. A avaliação por RM completa a análise pós-operatória, também nos tumores funcionantes, especialmente quando critérios hormonais não são conclusivos. 


\subsubsection{RM pós-operatória}

Antes mesmo de a RM estar amplamente disponível, estudos com TC já alertavam para a dificuldade de se interpretarem exames realizados no período pós-operatório precoce, devido à persistência de massa ocupando o espaço da ressecção tumoral ${ }^{22,}{ }^{101}$. Ainda, captação de contraste foi notada mesmo na ausência de neoplasias. Em estudo experimental em cães, Jeffries et al demonstraram captação de contraste após ressecção de tecido cortical ocorrendo por volta do sétimo dia, coincidente com o aparecimento de neovascularização ${ }^{102}$. Estes achados foram replicados em estudos clínicos de exames seriados após procedimentos cirúrgicos. Cairncross et al ${ }^{32}$ estudaram pacientes submetidos a ressecções tumorais e lobectomias temporais para epilepsia, revelando captação de contraste devido a neovascularização no leito da ressecção após o quinto dia; captações que ocorressem antes do quinto dia seriam devidas a tumores residuais. Os autores recomendaram realização de exames de controle antes deste período para evitar confusões com tumores residuais. Laohaprasit et al demonstraram captações em cirurgias de epilepsia em período tão precoce como três dias $^{23}$; este período ficou inicialmente estabelecido como sendo o limite para realização de exames pós-operatórios para controle de ressecção tumoral.

Estudos com RM pós-operatória demonstraram captações de contraste ainda mais precoces. Testando a hipótese de que "toda captação 
de contraste nas primeiras 24 horas representa tumor residual, Oser et al ${ }^{21}$ realizaram RM em 43 crianças submetidas a ressecção de lesões expansivas nas primeiras 24 horas, e as acompanharam por dois anos. Encontraram captação de contraste em 33 (72\%) casos, sendo que 15 deles (35\%) não apresentavam tumores residuais no seguimento. De forma semelhante, Henegar et $\mathrm{al}^{24}$ estudaram pacientes submetidos a ressecção cortical para lesões não neoplásicas (principalmente epilepsia) e demonstraram em captação de contraste no leito da ressecção em $64 \%$ dos casos, em períodos tão precoces como 17 horas. Quebra da barreira hemato-encefálica, perfusão de luxúria (por perda da auto-regulação local) e hipervascularização (neovascularização) são implicadas como causas desta captação anômala.

No controle pós-operatório de tumores hipofisários outros achados dificultam a interpretação dos exames. O diafragma selar mantém-se elevado no período pós-operatório, simulando massa tumoral ${ }^{25-28, ~ 103, ~} 104$. Implantes utilizados como hemostáticos $\left(\right.$ Surgicell ${ }^{\circledR}$, Gelfoam $^{\circledR}$ ) ou tecidos autólogos como gordura e fáscias (utilizados como selantes para prevenção de fístulas liquóricas) apresentam-se com sinal hiperintenso espontâneo nas sequências ponderadas em T1, além de apresentarem captação de contraste de forma heterogênea e sem seguir um padrão temporal constante $25,26,29,105$.

As publicações disponíveis até hoje sobre RM pós-operatória em adenomas hipofisários mostram resultados semelhantes, porém análises conflitantes. Rodriguez et $\mathrm{al}^{103}$, ao encontrar alterações pós-operatórias 
que simulavam tumores residuais, concluem que a RM não tem utilidade no seguimento de tumores hipofisários, em especial nos microadenomas. Kremer et al ${ }^{28}$ sugerem que controles pós-operatórios de pacientes estáveis clinicamente sejam realizado apenas três meses após o procedimento cirúrgico, após a queda do diafragma selar e absorção dos materiais implantados. A mesma interpretação foi dada por Rajaraman et $\mathrm{al}^{26}$, que sugerem exames após quatro meses se não houver complicações no pós-operatório. De forma contrária, Bonneville et al ${ }^{105}$ utilizam RM no pós-operatório precoce (quarto dia) para, entre outros motivos, identificar a presença de tumor residual (embora não determine um padrão exato que o sugira). Kiliç et al ${ }^{27}$ demonstraram a capacidade de se identificar, nas primeiras 24 horas, as estruturas anatômicas normais e a presença de tumores residuais. Em sua discussão, os autores imputam ao tempo decorrido a partir do fim do procedimento a utilidade do exame, discordando das opiniões anteriores.

A fim de se padronizar a análise das RM pós-operatórias, Yoon et $\mathrm{al}^{29}$ utilizaram a sequência dinâmica de RM. Determinaram quatro padrões de captação de contraste e verificaram a utilidade desta classificação na identificação de tumores residuais. Entretanto, uma parte dos pacientes realizou exames durante os primeiros três dias de pós-operatório, e outros após até sete dias. Tais achados não podem ser extrapolados para ressonâncias intra-operatórias, pois o principal fator determinante da captação de contraste pós-operatório é o tempo decorrido do fim da operação até a realização de exames de imagem ${ }^{30-32}$. 
MÉTOdos 


\section{MÉTODOS}

O presente estudo baseia-se na análise prospectiva Dos exames ressonâncias magnéticas pós-operatórias de pacientes operados de tumores hipofisários pela via transesfenoidal endonasal, no Instituto de Neurologia de Curitiba (INC), de julho de 2007 a junho de 2008.

Quarenta pacientes operados consecutivamente foram incluídos no estudo. Todos assinaram termo de consentimento livre e esclarecido para se submeterem ao estudo.

O projeto foi submetido ao Comitê de Ética e Pesquisa em Seres Humanos (CEP) do Instituto de Neurologia de Curitiba, aprovado em 23/07/2007, bem como à Comissão de Ética para a Análise de Projetos de Pesquisa (CAPPesq) do Hospital de Clínicas da Faculdade de Medicina da Universidade de São Paulo, sob o protocolo 0712/07. 


\subsection{CRITÉRIOS DE INCLUSÃO}

- Pacientes com tumores hipofisários com indicação de tratamento cirúrgico pela via transesfenoidal endonasal.

\subsection{CRITÉRIOS DE EXCLUSÃO}

- Pacientes portadores de marcapasso cardíaco ou qualquer sistema biológico com possibilidade de alteração funcional na proximidade de campo magnético.

- Pacientes com contra-indicação relativa ou formal para infusão de contraste paramagnético (gadopentetato de dimegluminaGd-DTPA), tais como insuficiência renal, gestação ou puerpério, antecedentes alérgicos etc.

- Pacientes com instabilidade clínica que impossibilitasse realização de RM pós-operatória nas primeiras 24 horas.

- Pacientes submetidos a cirurgia intracraniana anteriormente, pelo acesso transesfenoidal ou não.

- Pacientes que não realizassem os exames pré-, pós-operatório imediato ou pós-operatório tardio de acordo com os critérios abaixo descritos. 


\subsection{EXAMES DE IMAGEM}

Tanto no pré- como no pós-operatório, todos os pacientes realizaram RM dinâmica seguindo-se o mesmo protocolo. Foi utilizada unidade supercondutora de 1,5T (Signa 1,5 T, MR Excite, GE Inc, USA) com bobina de crânio circular polarizada. Inicialmente, sequências no plano sagital ponderadas em T1 foram realizadas para orientação dos cortes subsequentes. A seguir, cortes coronais com TR (tempo de relaxamento) longo eram realizadas com técnica FSE (fast spin-echo): cortes de $3 \mathrm{~mm}$ de espessura, intervalo de $1 \mathrm{~mm}, 3500-4000 / 95-100$, matriz de $256 \times 256$ pixels, e campo de visão (field of view - FOV) de $18 \mathrm{~cm}$. O protocolo de RM dinâmica consistiu em sequências ponderadas em T1, 425/14 - 16/1 (TR/TE/excitação), matriz retangular de $192 \times 256$, FOV de $20 \mathrm{~cm}$, cortes de $3 \mathrm{~mm}$ de espessura, sem intervalo. Antes da injeção do contraste (Magnevistan $®$, gadopentetato de dimeglumina - Gd-DTPA - Schering do Brasil), eram obtidos cortes no plano coronal; o contraste era então injetado de forma rápida $(2 \mathrm{~mL} / \mathrm{s}, 0,1 \mathrm{mmol} / \mathrm{kg}$ de peso corporal, equivalente a 0,2 $\mathrm{ml} / \mathrm{kg}$ de peso corporal), e as imagens dinâmicas eram obtidas a cada 80 90 segundos, com cortes no plano coronal a cada 3-4 minutos. Depois da imagem dinâmica, imagens de rotina FSE ponderadas em T1 eram obtidas.

O mesmo protocolo era realizado nas primeiras 24 horas após o procedimento cirúrgico, e então repetido após três meses. Todos os exames foram realizados no mesmo aparelho, no Centro de Tomografia 
Computadorizada de Curitiba (CETAC), nas dependências do próprio INC, sem qualquer deslocamento dos pacientes para fora do hospital no período pós-operatório.

\subsubsection{Característica das imagens}

As imagens pré-operatórias foram avaliadas de forma a se obter o diagnóstico preciso da lesão, bem como análise de suas características morfológicas. Os tumores foram inicialmente classificados como microadenomas $(<10 \mathrm{~mm})$ ou macroadenomas $(>10 \mathrm{~mm})$. Os macroadenomas foram ainda classificados quanto à sua extensão extrasselar de acordo com as classificações de Hardy ${ }^{52}$ modificada por Wilson $^{5}$ (Figura 5) para extensões suprasselares (deslocamento cranial do diafragma selar), e de Knosp ${ }^{60}$ (Figura 6) para extensões parasselares (envolvimento do seio cavernoso).

A análise das imagens pós-operatórias imediatas foi realizada com ênfase especial no padrão de captação de contraste paramagnético. Utilizaram-se os parâmetros descritos por Yoon et $a^{29}$ segundo os quais quatro padrões podem ser observados (Quadro 1). Dois radiologistas interpretavam as imagens e depois as discutiam com o neurocirurgião responsável pelo estudo; consenso quanto ao padrão de captação ocorreu em todos os casos. 
Quadro 1: Padrões de captação de contraste em ressonâncias pósoperatórias imediatas.

\begin{tabular}{ll}
\hline Padrão de captação & Descrição \\
\hline $\mathbf{1}$ (sem captação) & Ausência de captação de contraste no \\
& local onde previamente havia o tumor \\
& (Figura 10) \\
$\mathbf{2}$ (anel periférico) & Captação de contraste na periferia da \\
& massa hipofisária pós-operatória \\
& (Figura 11) \\
$\mathbf{3}$ (nodular) & Captação nodular de contraste \\
& demonstrada na massa hipofisária \\
& (Figura 12) \\
& Coexistência dos padrões nodular e \\
& anelar (Figura 13)
\end{tabular}




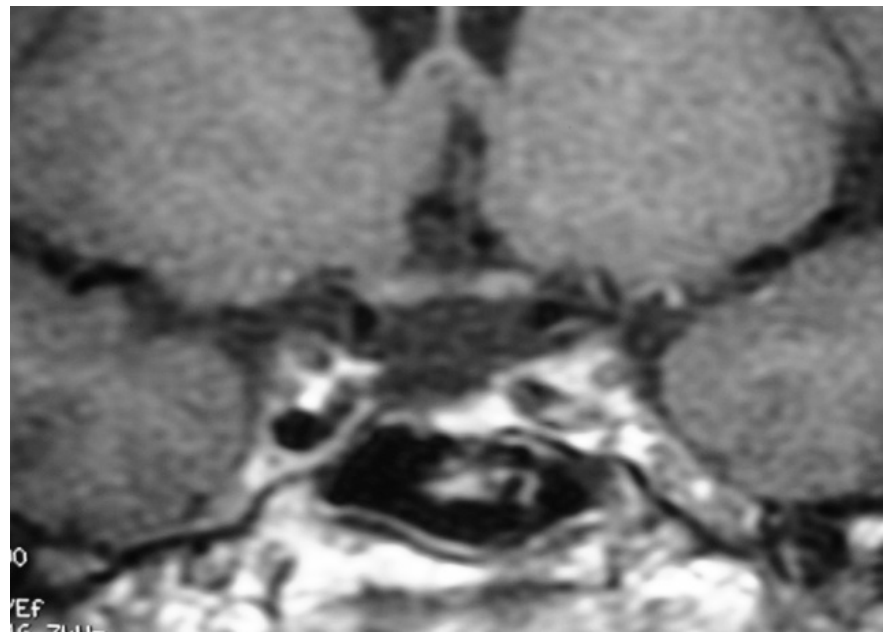

Figura 10: RM pós-operatória com padrão tipo 1 (sem captação)

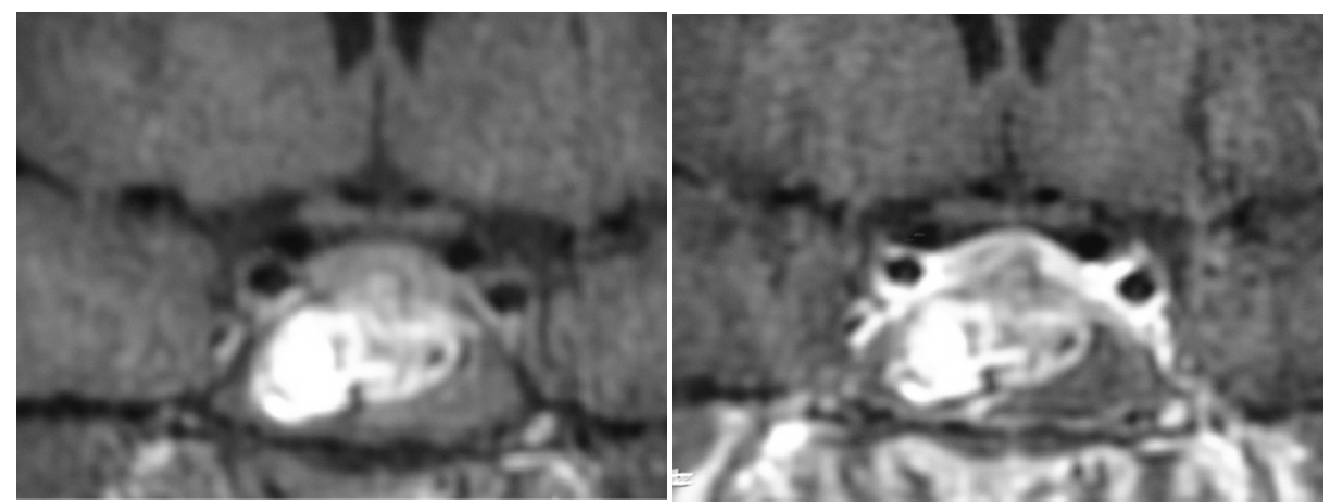

Figura 11: RM pós-operatória com padrão tipo 2 (anel periférico). A. Sequência pré-contraste. B. Sequência pós-contraste tardia 

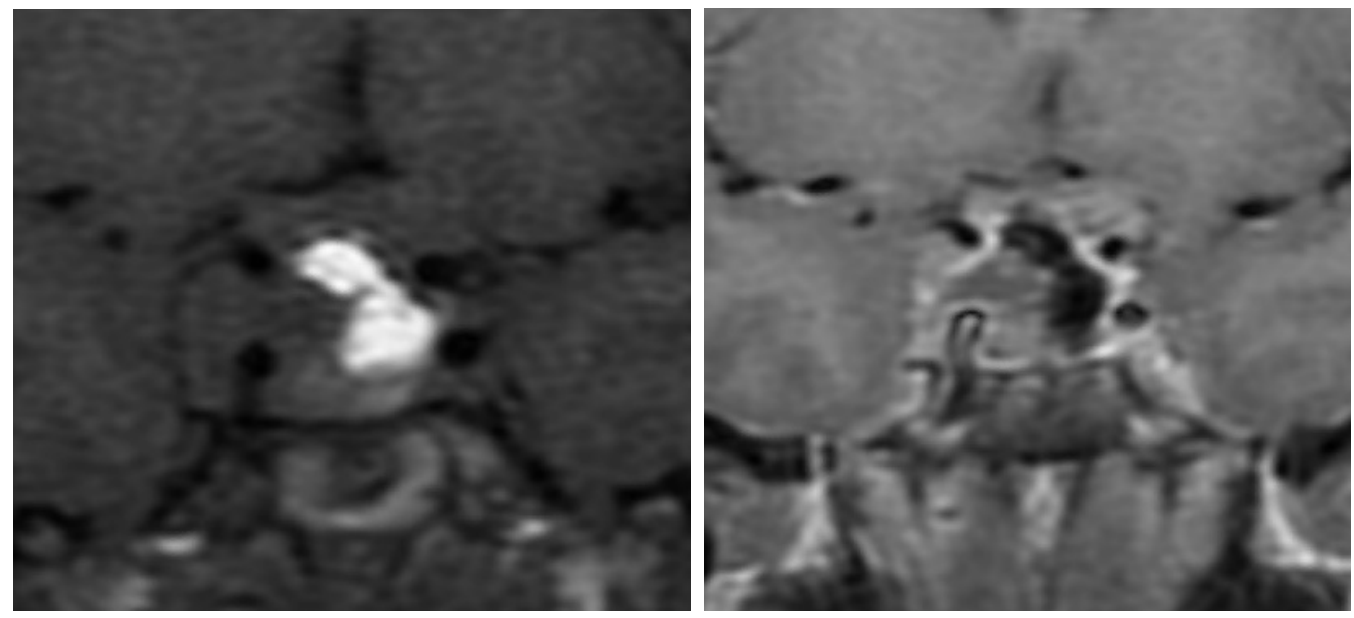

Figura 12: RM pós-operatória revelando captação de contraste tipo 3 (nodular). A porção lateral à a. carótida interna havia sido deixada intacta intencionalmente

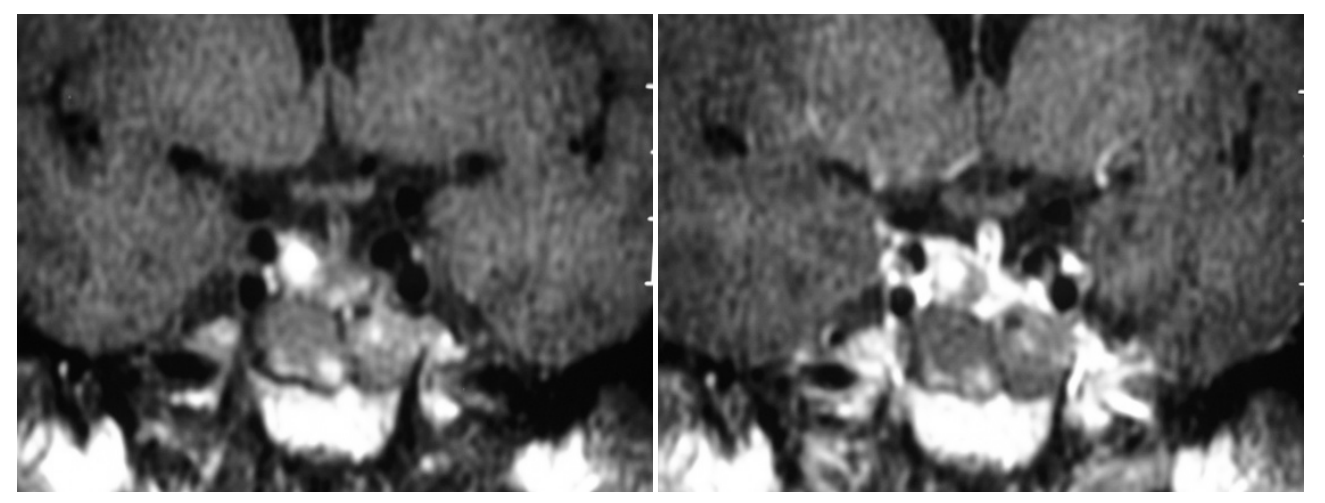

Figura 13: RM pós-operatória com padrão tipo 4 (combinado, nodular mais anel periférico). A. Sequência pré-contraste. B. Sequência póscontraste tardia

Além da captação de contraste, as imagens pós-operatórias foram classificadas de acordo com a presença ou não de material espontaneamente hiperintenso intrasselar (Figura 14), deslocamento da haste hipofisária da linha mediana (Figura 15) e retorno do diafragma selar à posição original (diminuição da pontuação na classificação de Hardy). 


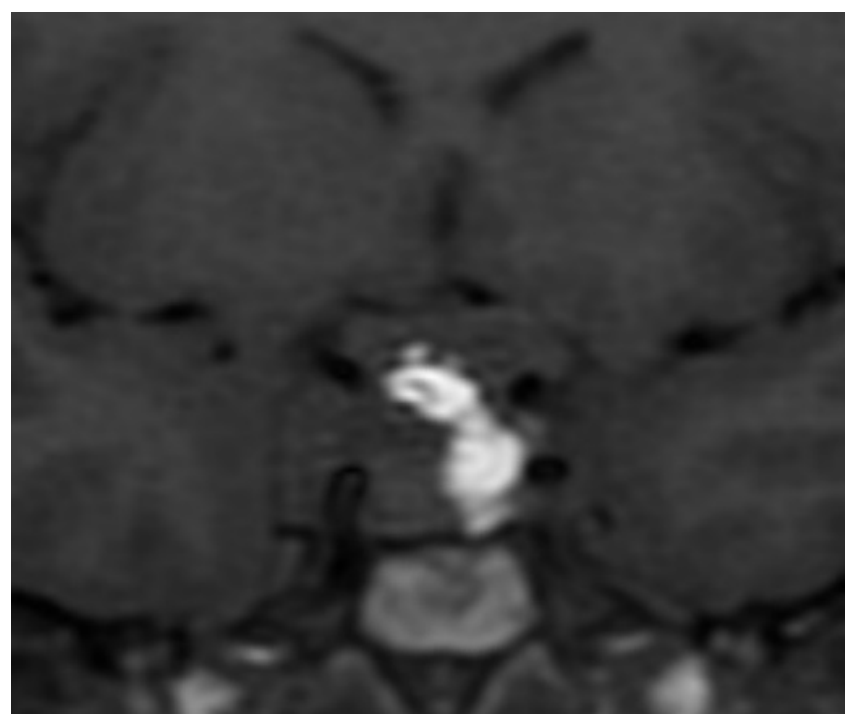

Figura 14: Presença de material hiperintenso intrasselar

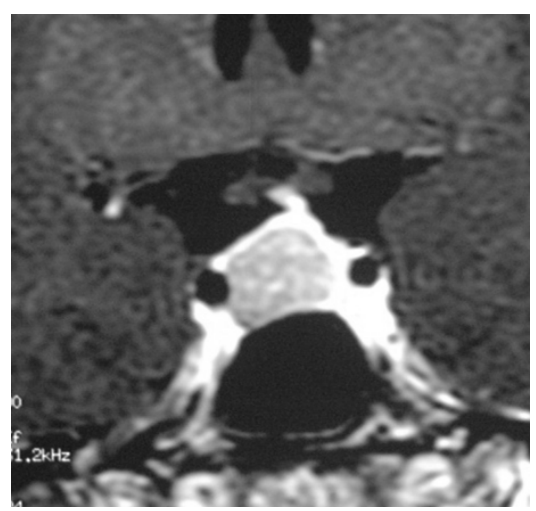

Figura 15: Deslocamento lateral da haste hipofisária 


\subsection{OUTROS EXAMES}

De acordo com protocolo de tumores hipofisários do INC, todos os pacientes realizaram avaliação oftalmológica pré- e pós-operatória, bem como perfil hormonal para caracterização da funcionalidade do tumor (tumor funcionante versus não-funcionante).

A confirmação de presença de tumor residual foi obtida através de testes endocrinológicos para tumores funcionantes, e padrão de crescimento na RM tardia, quando então re-operação foi indicada, tanto para tratamento como para confirmação histopatológica de tumor residual.

\subsection{TRATAMENTO CIRÚRGICO}

Todos os pacientes foram submetidos a remoção tumoral através de acesso transesfenoidal endonasal com magnificação microscópica, com técnica cirúrgica padronizada ${ }^{15}$. Nos macroadenomas, inspeção endoscópica da cavidade tumoral foi realizada à procura de possível tumor residual. Todos os procedimentos foram realizados sob a supervisão do coorientador da tese (RR), neurocirurgião com mais de 500 casos de tumores hipofisários operados. Houve aparente remoção completa em todos os casos, exceto dois, nos quais havia infiltração do seio cavernoso com envolvimento completo da a. carótida interna (Knosp grau 4) previamente conhecida, e deixada intacta intencionalmente. Após a remoção tumoral, a 
cavidade era coberta com celulose oxidada (Surgicel ${ }^{\circledR}$, Johnson \& Johnson Medical- Ethicon) e selante de fibrina (Beriplast ${ }^{\circledR}$, Aventis Behring). $O$ defeito do assoalho selar era reconstruído com pequeno fragmento ósseo retirado do septo nasal ósseo.Tampão nasal foi deixado apenas nos casos em que o sangramento da mucosa nasal foi muito significativo, e drenagem lombar externa, para prevenção de fístulas liquóricas, não foi utilizada preventivamente em nenhum caso.

\subsection{CARACTERÍSTICAS DA AMOSTRA}

Quarenta pacientes preencheram o protocolo completo. Foram incluídos 16 sujeitos do sexo masculino e 24 do sexo feminino. De acordo com o tamanho do tumor, 22 apresentavam microadenomas e 18 tinham macroadenomas. De acordo com a extensão suprasselar, quatro casos foram classificados como Hardy A (22,2\% dos macroadenomas), cinco $(27,8 \%)$ eram Hardy B, um (5,5\%) era Hardy C, e oito $(44,4 \%)$ era Hardy E. Nenhum caso foi classificado como Hardy D. Quanto à extensão parasselar (seio cavernoso), houve 4 casos de Steiner Grau zero $(22,2 \%)$, seis $(33,3 \%)$ Grau 1, quatro $(22,2 \%)$ Grau 2, dois $(11,1 \%)$ Grau 3 e dois $(11,1 \%)$ Grau 4. Quanto à função hormonal, 13 (32,5\%) tumores eram não-funcionantes e $27(67,5 \%)$ eram funcionantes. Destes, 15 eram prolactinomas, sete pacientes tinham doença de Cushing e houve 5 casos de acromegalia. 


\subsection{ANÁLISE ESTATÍSTICA}

Por se tratar de estudo descritivo, os achados de imagem do pósoperatório imediato foram inicialmente caracterizados apenas como porcentagem do total de casos em que a alteração foi encontrada (incidência).

$\mathrm{Na}$ comparação com os exames pós-operatórios tardios, as alterações foram avaliadas quanto a sua capacidade de diagnosticar um tumor residual precocemente, este confirmado por crescimento da lesão ou exame hormonal. Como "testes diagnósticos", os achados foram descritos em termos de sensibilidade (porcentagem dos casos confirmadamente patológicos em que a alteração ocorreu), especificidade (porcentagem de casos em que a alteração ocorreu que se confirmaram patológicos), valor preditivo positivo (VPP) (probabilidade de se confirmar patológica a alteração encontrada) e valor preditivo negativo (VPN) (probabilidade de se descartar doença uma vez ausente a alteração). Dada a co-existência dos padrões de captação (p.ex., padrão combinado é igual à co-existência dos padrões anelar e nodular), os mesmos foram reagrupados para teste individual. Assim, para avaliação do padrão anelar, os tipos 2 e 4 foram agrupados (ou seja, captação anelar com ou sem padrão nodular associado), e para avaliação do padrão nodular, agruparam-se os grupos 3 e 4 (ou seja, captação nodular associada ou não a captação anelar). 
RESULTADOS 


\section{RESULTADOS}

No pós-operatório, nenhum paciente apresentou complicações que impedissem a realização do exame de imagem de controle. A mediana de tempo para realização do exame foi de 18 horas a contar do término da cirurgia (1 hora a 24 horas). Não houve piora do déficit visual em nenhum caso no pós-operatório.

\subsection{ALTERAÇÕES PÓS-OPERATÓRIAS IMEDIATAS}

A presença de material hiperintenso intrasselar ocorreu no pós-

operatório em 17 dos 22 microadenomas $(77,3 \%)$ e em todos os 18 macroadenoma, ou seja, $87,5 \%$ de todos os casos.

A haste hipofisária manteve-se deslocada em 20 dos 22 microadenomas $(90,9 \%)$ e em todos os macroadenomas, ou seja, $95 \%$ de todos os casos. 
A posição elevada do diafragma selar, avaliada nos macroadenomas, manteve-se semelhante à do pré-operatório em 16 dos 18 casos $(88,9 \%)$. Um caso de Hardy tipo B regrediu para tipo A, enquanto o caso de Hardy C regrediu para Hardy B.

A extensão parasselar do tumor, avaliada pela classificação de Steiner, foi prejudicada pela presença de material hiperintenso no local onde previamente havia o tumor. Assim, alterações de imagem (patológicas ou não) ocorreram em todos os casos em que havia extensão para os seios cavernosos, não sendo possível a diferenciação pela classificação utilizada entre o pré- e o pós-operatório.

Nos microadenomas, 20 casos não demonstraram qualquer captação de contraste no pós-operatório imediato, e apenas dois casos $(9,1 \%)$ revelaram captação de contraste do tipo anelar. Já nos macroadenomas, 12 casos $(66,7 \%)$ não demonstraram qualquer captação anômala de contraste, enquanto um caso $(5,5 \%)$ apresentou captação anelar, além de dois casos $(11,1 \%)$ de captação tipo nodular e três casos $(16,7 \%)$ de padrão combinado.

\subsection{CORRELAÇÃO DO EXAME PÓS-OPERATÓRIO IMEDIATO COM O TARDIO}

Nos microadenomas, o material hiperintenso intrasselar desapareceu em todos os 17 casos; a captação de contraste anelar desapareceu em todos os três casos, enquanto a haste hipofisária retornou à linha mediana 
em 18 casos $(81,8 \%)$, mantendo-se desviada em quatro. Exames hormonais revelaram ausência de função anormal (i.e., tumor funcionante) em todos os casos.

Em cinco casos de macroadenomas a investigação tardia (3 meses) revelou presença de tumor residual. Em três casos esta foi evidenciada por crescimento da massa tumoral (re-operados, com confirmação histopatológica), e em dois deles (prolactinomas) exames hormonais confirmaram achados suspeitos em RM tardia.

Nos macroadenomas, material hiperintenso intrasselar desapareceu em todos os 18 casos; a haste hipofisária manteve-se desviada em sete dos 18 casos, cinco deles com confirmação de tumor residual. Como todos os casos apresentavam desvio no pós-operatório imediato, a especificidade do achado foi zero, e o VPN não pode ser aplicado. A sensibilidade foi de $100 \%$ e o VPP de $27,8 \%$.

O retorno do diafragma selar à posição normal ocorreu em 14 dos 17 casos alterados no pós-operatório imediato. Os dois casos em que houve regressão já no pós-operatório imediato (diminuição da classe de Hardy) não apresentaram tumores residuais no exame tardio (especificidade e VPP, 100\%; sensibilidade 15,4\%; VPN 21,4\%). (Figura 16). 


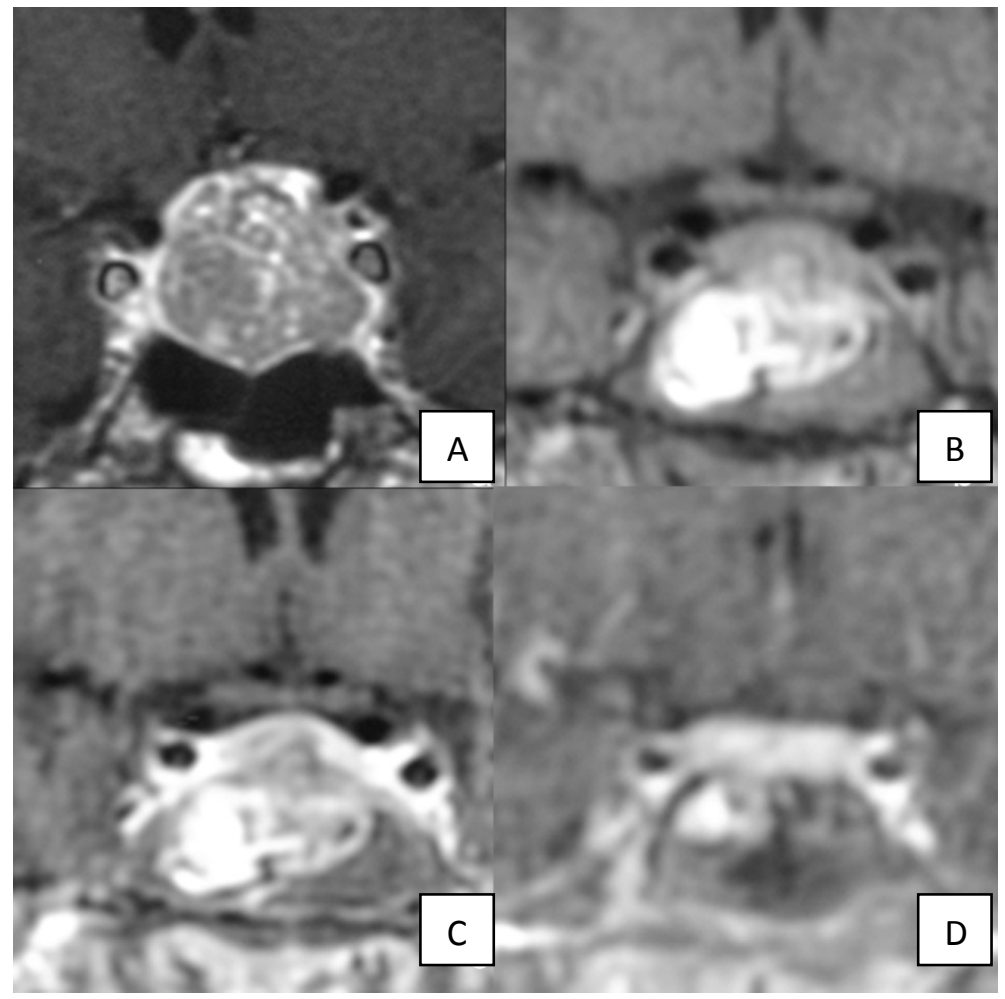

Figura 16: Sequência de exames de RM de paciente com macroadenoma não secretor. A. Pré-operatório, fase precoce. B. Pósoperatório imediato, sem contraste. Note-se redução da altura do diafragma selar (Hardy B para Hardy A). C. Pós-operatório imediato, fase tardia pós-contraste. Note-se padrão de anel periférico de captação (tipo 2). D. Pós-operatório tardio, sem qualquer tumor residual

Em relação ao padrão de captação de contraste, os 12 casos sem captação de contraste não revelaram tumor residual no pós-operatório tardio, assim como o caso de padrão anelar (Figura 16). Todos os três casos de padrão combinado e os dois casos de padrão nodular apresentavam tumor residual (Figura 17). Quando analisados os padrões individualmente, o padrão anelar esteve presente em quatro casos (um anelar isolado e três combinados),dos quais três apresentavam tumor residual, determinando sensibilidade de $60 \%$, especificidade de $92,3 \%$, VPN de $85,7 \%$ e VPP de $75 \%$. O padrão nodular esteve presente cinco 
casos (dois nodulares puros e três mistos), todos eles revelando tumores residuais. A sensibilidade, a especificidade, o VPP e o VPN foram de $100 \%$.

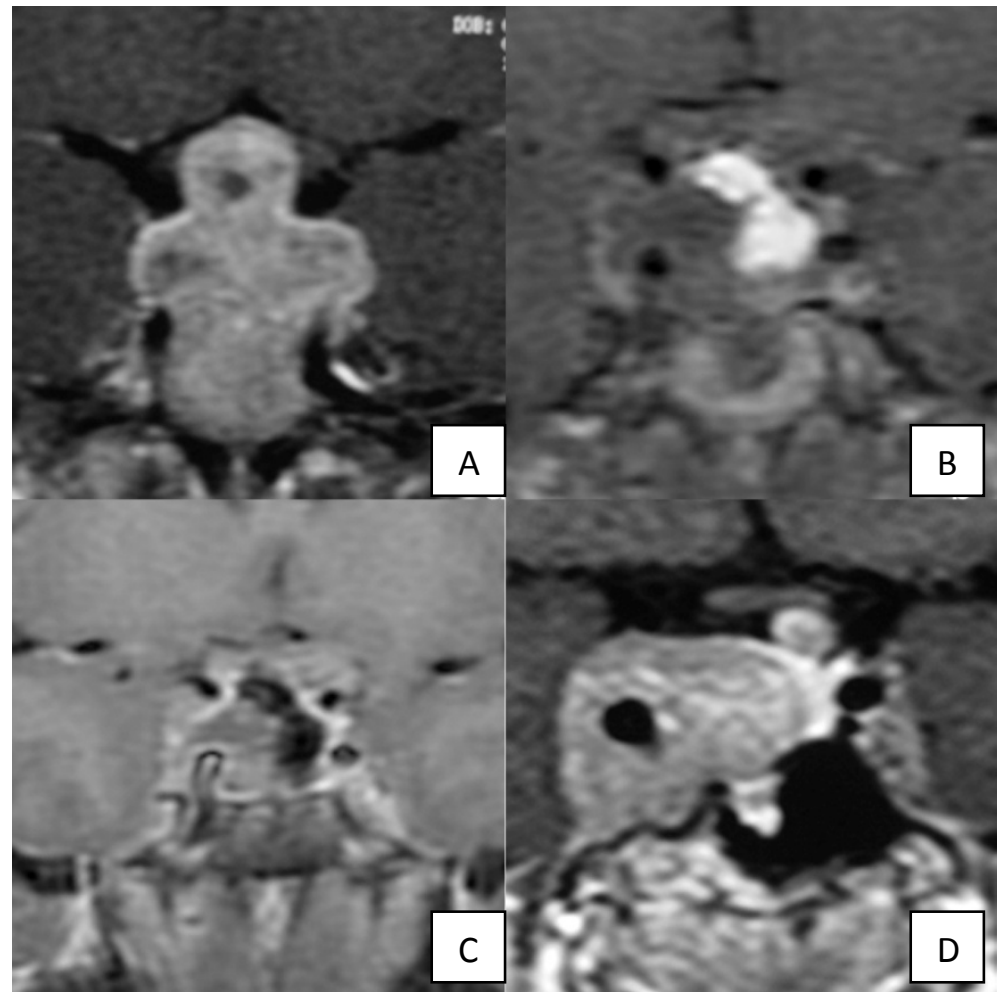

Figura 17: Padrão de captação nodular evoluindo com crescimento de resto tumoral. A. Pré-operatório. B. Pós-operatório imediato, sequência precoce. C. Pós-operatório imediato, sequência tardia, padrão nodular de captação. D. Pós-operatório tardio evidenciando crescimento da lesão parasselar. 
Discussão 


\section{DISCUSSÃO}

Ressecção cirúrgica é a principal terapia para a maioria dos tumores hipofisários. Em grande parte dos casos, o acesso pela via transesfenoidal endonasal é escolhido, proporcionando altos índices de ressecção radical ${ }^{102}$. Entretanto, o envolvimento do seio cavernoso, grandes extensões suprasselares e parasselares podem causar dificuldade em se obter ressecções mais amplas. Ainda, a visibilização obtida através da via transesfenoidal endonasal nem sempre é suficiente para se determinar o grau de ressecção durante o procedimento cirúrgico.

No período pós-operatório imediato, grande ênfase é dada para o manejo clínico dos pacientes (tanto endocrinológico como hidroeletrolítico), e exames de imagem (p. ex., ressonâncias magnéticas) são deixadas para um período mais tardio nos casos com evolução clínica satisfatória ${ }^{107}$. Entretanto, pacientes que apresentem quaisquer complicações neurológicas (perda visual, síndrome de hipertensão intracraniana, paralisia da 
motricidade ocular extrínseca) podem necessitar de exames de imagem para investigação de possíveis complicações operatórias. Ainda, diante da possibilidade de haver um tumor residual, a identificação precoce deste pode possibilitar uma re-intervenção precoce, permitindo remoção tumoral adicional que alterações pós-operatórias como aderências locais e fibrose venham a dificultar sobremaneira o procedimento. A interpretação destes exames, entretanto, é grandemente dificultada pelas alterações pósoperatórias normais decorrentes da manipulação cirúrgica e de implantes locais, gerando alterações nas imagens de RM que simulam complicações como edema e hematomas, e até tumores residuais ${ }^{25-26,103 .}$

A fim de se obterem dados para a melhor interpretação exames pósoperatórios, na última década houve uma série de publicações envolvendo a realização de RM no período pós-operatório imediato. Entretanto, o termo "imediato" necessita ser mais bem especificado, pois pode ser objeto de confusão. Os estudos anteriores com imagens pós-operatórias divergem muito no que seria "imediato". Yoon et $\mathrm{al}^{29}$ consideram imediatas imagens de ressonância obtidas entre três e sete dias; Dina et $\mathrm{al}^{25}$ realizaram exames entre o segundo e o oitavo dia; Kremer et $\mathrm{al}^{28}$ realizaram nos três primeiros dias, Rajamaran e Shoulder ${ }^{26}$ utilizaram entre os 14 primeiros dias e apenas Kiliç et al ${ }^{27}$ utilizaram exames nas primeiras 24 horas. Apesar de estes dados terem sido de extrema importância para o entendimento das alterações em imagens pós-operatórias, em concordância com Kiliç et $\mathrm{al}^{27}$ acreditamos que apenas as imagens realizadas nas primeiras 24 horas possam ser interpretadas de forma objetiva. As razões para esta crença são 
diversas. A segunda fase da resposta inflamatória inicia-se em cerca de 24 horas, e após este período a captação de contraste não pode mais ser utilizada como parâmetro confiável, pois pode aparecer espontaneamente na ausência de tumor residual, e até mesmo em cirurgias para desordens não neoplásicas ${ }^{23,31,32}$. Além disso, a degradação do coágulo na área cirúrgica começa a formar metemoglobina após 24 horas, e a intensidade de sinal nas sequências ponderadas em T1 se modifica progressivamente, num processo que não é uniforme a ponto de se conhecerem seu significado em todos os pacientes ${ }^{30}$. Ainda, implantes hemostáticos como celulose oxidada (Surgicell囚) e esponja de gelatina (Gelfoam $®$ ) tendem a ser mais difícil de ser diferenciados após este período ${ }^{24,30}$.

No estudo de Rajaraman e Shoulder ${ }^{26}$ grande ênfase foi dada ao volume da massa hipofisária/selar pós-operatória. A comparação foi realizada medindo-se a maior dimensão coronal do tumor (MCTD, maximal coronal tumor dimension) avaliada no pré-operatório, pós-operatório imediato (maioria dentro da primeira semana) e após 3 a 4 meses, em ressonância de 1,5T. O MCTD médio no pré-operatório foi de $30,3 \mathrm{~mm}$, variando de 11 a $59 \mathrm{~mm}$; no pós-operatório imediato, pouca ou nenhuma redução foi evidenciada na maioria dos casos $(7-49 \mathrm{~mm}$, média $23,5 \mathrm{~mm})$, inclusive com aparente aumento da massa em dois casos. Em todos os casos houve significativa redução no pós-operatório tardio, com MCTD médio de $12,7 \mathrm{~mm}$ (2 a $35 \mathrm{~mm}$ ), perfazendo redução de $58 \%$ do préoperatório. O número de pacientes foi baixo (quatorze) e não foi realizada qualquer correlação com a presença de tumor residual. Quatro pacientes 
realizaram ainda RM mais tardias (oito a doze meses de pós-operatório), e não houve redução adicional significativa em relação ao exame de três a quatro meses. Estudo com as mesmas características foi conduzido por Kremer et al $^{28}$, revelando a persistência de elevação do diafragma selar em $83 \%$ dos casos, apesar de melhora da função visual em $89 \%$ dos pacientes. Após três meses, notou-se redução de cerca de $50 \%$ do volume original. De forma semelhante, nosso estudo demonstrou a manutenção da posição do diafragma selar, classificado de acordo com Hardy, em 16 dos 18 macroadenomas $(88,9 \%)$. A relação estabelecida entre o retorno do diafragma já no pós-operatório imediato e a ausência de tumor residual foi clara (VPN de 100\%, bem como a especificidade). Entretanto, o número reduzido de casos em que tal alteração ocorreu foi muito baixo para ser utilizado isoladamente (VPN 21,4\%, sensibilidade 15,4\%).

$\mathrm{Na}$ maior casuística já publicada, Bonneville et al publicaram sua experiência de dez anos com exames pós-operatórios ${ }^{105}$. Com mais de 250 casos analisados, os autores descreveram as características de RM no quarto dia, entre dois e três meses e após um ano. Segundo os autores, o exame no quarto dia permite afastar complicações, verificar a qualidade da exérese, identificar a reserva de vasopressina (neurohipófise, hiperintensa espontaneamente), identificar implantes cirúrgicos (Surgicell ${ }^{\circledR}$, gordura), ocasionalmente suspeitar de tumor residual e raramente ver o tecido hipofisário sadio. Entretanto, quais achados seriam responsáveis pela suspeita de tumor residual, bem como a relação entre os achados ao quarto dia e tumor residual ao final de três meses, não são relatados. 
Em estudo bastante extenso, Kiliç et al ${ }^{27}$ analisaram 400 exames de 80 pacientes (25 microadenomas, 30 macroadenomas sem infiltração do seio cavernoso e 25 macroadenomas com infiltração do seio cavernoso). A avaliação dos achados pós-operatórios em exames realizados nas primeiras 24 horas, os autores caracterizaram o material hiperintenso intrasselar (gordura, Gelfoam ${ }^{\circledR}$ ou tecido de granulação), a preservação da hipófise e haste hipofisária, a altura do diafragma selar e a probabilidade de haver tumor residual. Baseado nestes achadas, os autores propõem algoritmo de seguimento após ressecção de adenomas hipofisários. Na ausência de tumor residual com "alto grau de confiabilidade", propõe-se a realização de exame de controle apenas após um ano. Em caso de achados questionáveis de RM pós-operatória imediata, novo exame em três meses. E na presença de tumor residual, tratamento imediato, com re-operação ou radiocirurgia. Entretanto, a avaliação da presença ou não de tumor residual foi baseada em um sistema de pontuação subjetivo, nos quais dois radiologistas e dois neurocirurgiões descreviam os achados como "Y" (sim) e "N" (não), seguido de pontuação em +++ para achado "definitivo", ++ para achado "altamente sugestivo" e + para "suspeito". Apesar de bastante correlacionado com os achados futuros, a subjetividade da descrição impede validação maior do método. Ainda, aparelhos diferentes foram utilizados para os exames (alguns de 0,5T), e exame dinâmico não foi realizado.

A sequência dinâmica de ressonância magnética é o método de escolha na detecção de adenomas hipofisários ${ }^{80-84}$. Sua grande vantagem é a diferenciação do parênquima hipofisário de tumores. Por causa de sua 
vascularização característica (sistema porta-hipofisário, citado anteriormente), a glândula apresenta captação precoce do contraste, enquanto a captação do tumor é mais tardia. Miki et al $^{72}$ demonstraram os padrões típicos de captação de contraste. A hipófise apresenta pico de captação após cerca de um minuto, com decaimento importante após três minutos, enquanto os adenomas atingem pico ao redor de três minutos, sem decaimento rápido. Assim, o tumor e a glândula podem ficar indistinguíveis após este período; a diferenciação entre os dois é máxima entre o primeiro e o segundo minuto. A sequência dinâmica é importante não apenas para o diagnóstico dos tumores (principalmente microadenomas), mas especialmente para a diferenciação entre o tumor e o tecido glandular residual. Partindo disso, acreditamos que esta sequência deva ser escolhida para a diferenciação de tumores residuais também em imagens pósoperatórias. Dos estudos realizados anteriormente com ressonâncias pósoperatórias, apenas o de Yoon et al ${ }^{29}$ utilizou esta sequência. Em sua descrição, os autores determinaram padrões de captação de contraste para a avaliação do conteúdo intra e extrasselar utilizada neste estudo.

No estudo de Yoon et $\mathrm{al}^{29}, 12$ dos 67 macroadenomas estudados apresentavam captação periférica (tipo 2) no pós-operatório imediato $(17,9 \%)$, proporção bem superior à encontrada no nosso estudo (apenas um dos 18 casos - 5,5\%). Acreditamos que esta discrepância seja devida ao tempo em que os exames pós-operatórios foram realizados (geralmente três, mas até sete dias, em contraposição de no máximo 24 horas em nosso estudo). O único caso de captação periférica não teve relação com tumor 
residual no pós-operatório tardio, em concordância com os dados de Yoon et al. Ainda, os padrões de captação nodular e combinado tiveram uma alta correlação com a presença de tumores residuais no pós-operatório tardio, assim como a ausência de captação correlacionou-se com a ausência de tumor residual.

A tabela abaixo demonstra os diferentes aspectos analisados em cada um dos estudos sobre RM pós-operatória em adenomas hipofisários. 
Tabela 2: Características dos estudos de RM pós-operatória em tumores hipofisários

\begin{tabular}{|c|c|c|c|c|c|c|c|}
\hline $\begin{array}{l}\text { Autor } \\
\text { (número) }\end{array}$ & $\mathbf{z}$ & 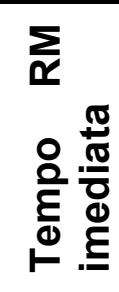 & 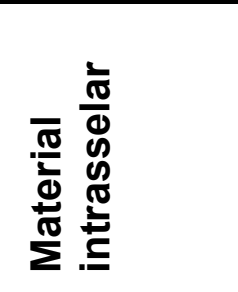 & 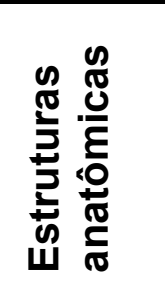 & 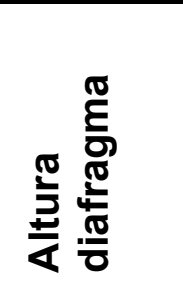 & 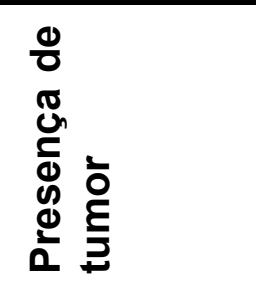 & 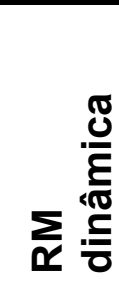 \\
\hline $\operatorname{Dina}^{25}$ & 10 & $2-8 d$ & Descritivo & $\bar{N} / \mathrm{A}$ & MCTD & $\mathrm{N} / \mathrm{A}$ & Não \\
\hline Kiliç $^{21}$ & 80 & $24 \mathrm{~h}$ & Descritivo & $\begin{array}{l}\mathrm{HH}, \\
\mathrm{QO}, \mathrm{GL}\end{array}$ & MCTD & $\begin{array}{l}\mathrm{Y} / \mathrm{N},+a \\
+++\end{array}$ & Não \\
\hline Kremer $^{28}$ & 50 & $3 d$ & Descritivo & $\begin{array}{l}\mathrm{HH}, \\
\mathrm{GL}\end{array}$ & Subj. & Subjetivo & Não \\
\hline Rajamaran $^{26}$ & 14 & $14 d$ & N/A & $\mathrm{N} / \mathrm{A}$ & MCTD & $\mathrm{N} / \mathrm{A}$ & Não \\
\hline Rodriguez $^{103}$ & 16 & $7 d$ & Sim/Não & $\begin{array}{l}\mathrm{HH}, \mathrm{GL} \\
\text { QO }\end{array}$ & $\begin{array}{l}\text { Contato } \\
\text { com } \\
\text { QO }\end{array}$ & Subjetivo & Não \\
\hline Steiner ${ }^{104}$ & 25 & $\begin{array}{l}3- \\
12 d\end{array}$ & Descritivo & $\begin{array}{l}\text { GL, } \\
\text { QO }\end{array}$ & Subj. & Subjetivo & Não \\
\hline Yoon $^{29}$ & 83 & $3-7 d$ & $\begin{array}{l}\text { Intensidade } \\
\text { de sinal }\end{array}$ & N/A & $\mathrm{N} / \mathrm{A}$ & $\begin{array}{l}\text { Padrão de } \\
\text { captação }\end{array}$ & Sim \\
\hline Milano & 40 & $24 \mathrm{~h}$ & Sim/Não & $\mathrm{HH}$ & Hardy & $\begin{array}{l}\text { Padrão de } \\
\text { captação }\end{array}$ & Sim \\
\hline
\end{tabular}

Nota: $\quad$ Milano refere-se ao presente estudo

$\mathrm{N}=$ número de pacientes; $\mathrm{d}=$ dias; $\mathrm{h}=$ horas; $\mathrm{N} / \mathrm{A}=$ não avaliado; $\mathrm{MCTD}=$ diâmetro tumoral coronal máximo (maximal coronal tumor diameter); $\mathrm{HH}=$ haste hipofisária; $\mathrm{GL}=$ glândula hipófise; $\mathrm{QO}=$ quiasma óptico; $\mathrm{Y} / \mathrm{N}$ : sim ou não.

\subsection{PERSPECTIVAS FUTURAS}

O resultado a longo prazo, em termos de controle tumoral ou endócrino, depende substancialmente do grau de ressecção tumoral obtido 
no ato operatório. A fim de se aumentarem os índices de ressecção radical, a ressonância magnética intraoperatória tem sido a ferramenta mais utilizada em países desenvolvidos na última década. Em sua primeira publicação, Martin et al $^{17}$ descreveram cinco casos operados de adenomas hipofisários nos quais a ressonância magnética intraoperatória foi utilizada. Após o cirurgião julgar o procedimento finalizado, acreditando ter obtido ressecção total das lesões, exame de ressonância magnética foi realizado revelando tumor residual em três casos, resultando em revisão da cavidade de ressecção e consequente remoção adicional de restos tumorais. A experiência obtida mundialmente com a utilização da ressonância magnética intraoperatória para tumores cerebrais e hipofisários revelou dados intrigantes. Bohinski et al ${ }^{18}$ realizaram re-intervenções em nove de dezesseis (56\%) pacientes operados de tumores hipofisários, nos quais se julgava terse obtido ressecção total. Entretanto, a dificuldade de se interpretarem as imagens obtidas foi objeto de re-análise do método. Nimsky et al 19 realizaram re-inspeções em 29 de 48 pacientes (60\%) após a ressonância intraoperatória. Entretanto, em dez desses casos não havia tumor residual na cavidade de ressecção objeto da suspeita, porém apenas materiais como cola de fibrina, sangue/coágulos e outros. Estas imagens eram espontaneamente hiperintensas nas sequências ponderadas em T1, causando confusão com tumores residuais. Após isso, os autores relatam mudança no seu protocolo de ressonância intra-operatória para sequências ponderadas em T2. De forma semelhante, Schwartz et al ${ }^{108}$, utilizando RM intraoperatória de baixo campo associada a técnica endoscópica, realizou 
re-intervenções baseadas na imagem intraoperatória em sete de 15 pacientes, encontrando tumor residual em apenas três destes. Os autores comentam a dificuldade de se analisarem as imagens intraoperatórias como a causa das re-intervenções desnecessárias em quatro pacientes.

Partindo da experiência com RM intraoperatória em cirurgias de gliomas $^{20}$, utilizamos os parâmetros pós-operatórios de ressecção tumoral, baseados no tipo de captação de contraste, para determinação de tumores residuais em dois casos pilotos. A técnica denominada outside de RM intraoperatória permite realização de imagens de alta boa definição, com aparelho de alto campo $(1,5 \mathrm{~T})$, sem os custos de implementação de aparelho dentro do centro cirúrgico (Figura 18).
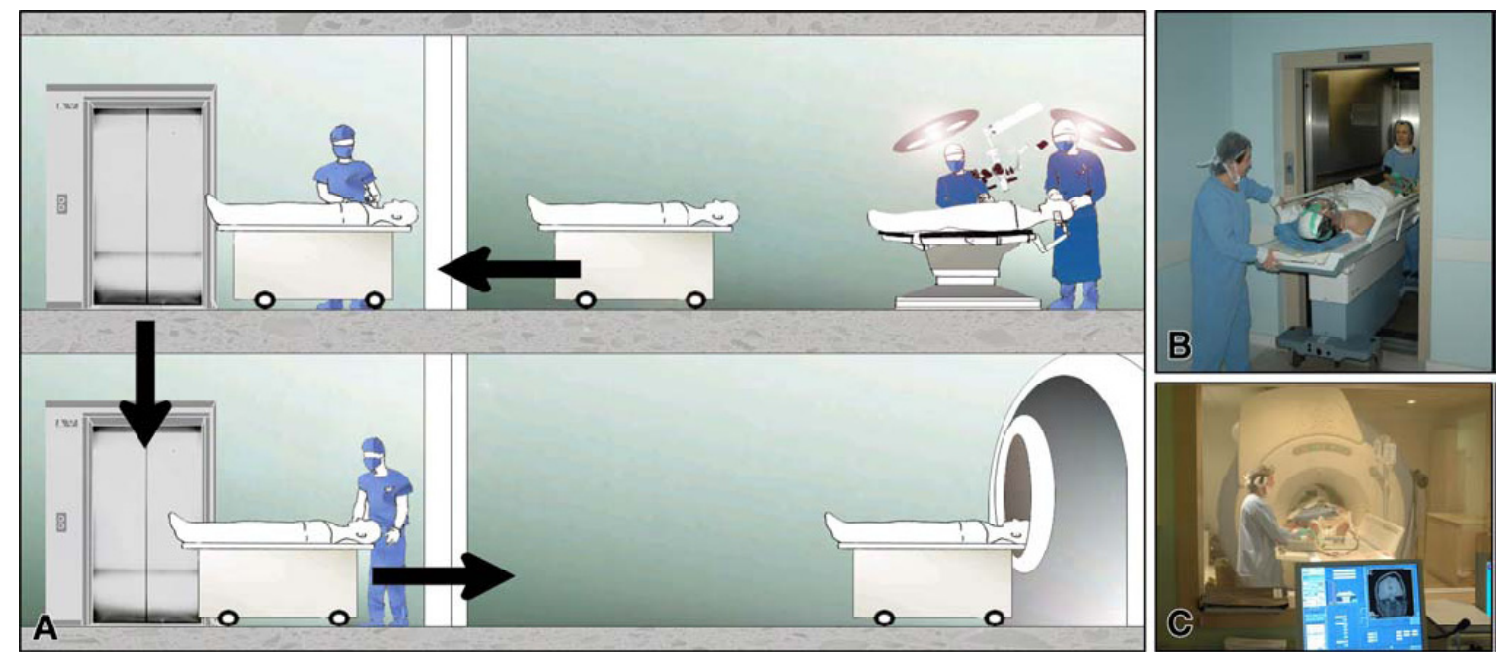

Figura 18: Esquema demonstrando método outside de RM intraoperatória. A. Transporte através de elevador estrategicamente posicionado ao lado da sala operatória. B. Foto da utilização do elevador específico. C. Paciente dentro do aparelho de ressonância acompanhado pelo anestesiologista.

Nos dois casos realizados, um demonstrou ressecção tumoral completa já no primeiro exame (padrão 1 - sem captação de contraste), e no 
outro houve a identificação de tumor residual junto ao seio cavernoso (padrão 3 - nodular), fora do campo de visão do cirurgião, possibilitando remoção imediata no mesmo tempo cirúrgico (Figura 19). A real utilidade dos parâmetros de ressecção radical, baseada na captação de contraste na RM dinâmica, em exames intraoperatórios necessita de estudos apropriados, sendo objeto atual de estudo do nosso grupo.

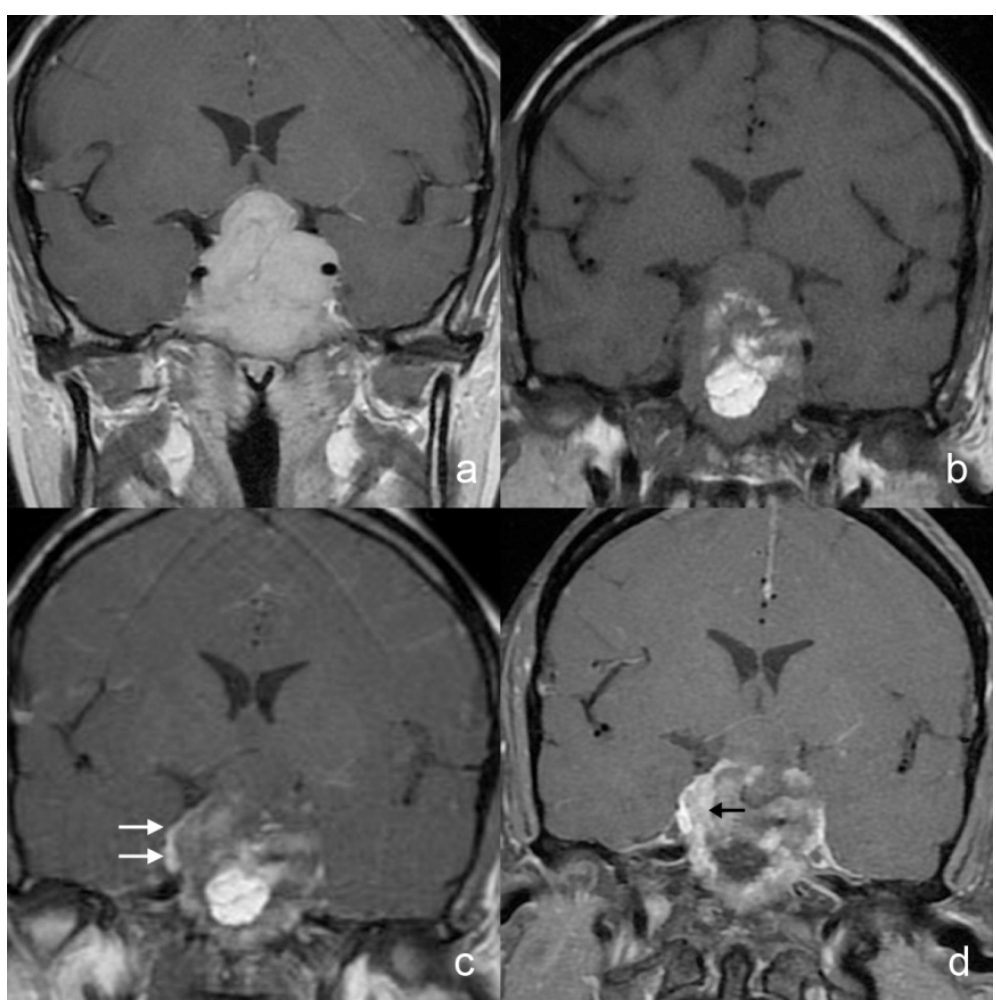

Figura 19: Macrodenoma não-secretor com extensão suprasselar ressecado com auxílio de RM dinâmica intraoperatória. a. Exame pré-operatório, sequência ponderada em T1, após injeção de contraste, no plano coronal. b-d: Imagens intraoperatórias aproximadamente no mesmo plano. b. Sequência antes da injeção de contraste, com discrete redução da altura do diafragma da sela. c. Sequência dinâmica precoce, demonstrando o tecido glandular residual com captação precoce do contraste (setas brancas). c. Sequência tardia, demonstrando captação de contraste de padrão nodular adjacente ao tecido glandular (seta preta). Re-intervenção imediata confirmou tumor residual, removido no mesmo ato operatório. 
Conclusões 


\section{CONCLUSÕES}

i) A presença de material hiperintenso intrasselar, o desvio persistente da haste hipofisária e a manutenção do deslocamento pré-operatório do diafragma selar são achados freqüentes no pós-operatório normal, sem relação com complicações ou tumores residuais; devem ser consideradas alterações normais no pós-operatório de tumores hipofisários pela via transesfenoidal endonasal.

ii) A presença de captação de contraste do tipo nodular, associada ou não a captação periférica (padrão misto) tem $100 \%$ de correlação com a presença de tumores residuais, devendo ser o parâmetro utilizado para a detecção destes. 
AnEXos 


\begin{abstract}
ANEXO A
Declaração da Comissão de Ética para Análise de Projetos de Pesquisa

(CAPPesq) de ciência da execução do projeto, previamente aprovado
\end{abstract}

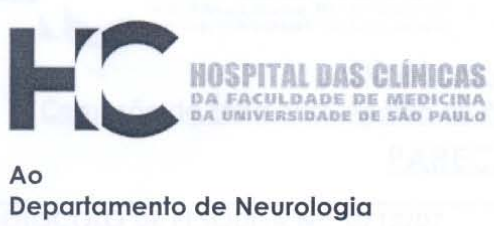

A Comissão de Ética para Análise de Projetos de Pesquisa - CAPPesq da Diretoria Clínica do Hospital das Clínicas e da Faculdade de Medicina da Universidade de São Paulo, em sessão de 03.10.07, tomou ciência da execução do Protocolo de Pesquisa $n^{\circ}$ 0712/07, intitulado: "ESTUdo DAS ALteraçÕES EM EXAME DE RESSONÂNCIA MAGNÉTICA DE PACIENTES EM PÓS-OPERATÓRIO IMEDIATO DE RESSECÇÃO DE TUMORES HIPOFISÁRIOS POR VIA TRANSESFENOIDAL".

No que tange sua parte empírica será desenvolvido no hOSPITAL ECOVILLE, tendo o Comitê de Ética do Instituto de Neurologia de Curitiba, aprovado o estudo em 23.07.07.

Pesquisador Responsável: PROF. DR. PAULO HENRIQUE PIRES DE AGUIAR Pesquisador Executante: DR. JERONIMO BUZETTI MILANO

CAPPesq, 11 de outubro de 2007.

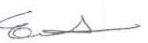

PROF. DR. EDUARDO MASSAD Presidente da Comissão Ética para Análise de Projetos de Pesquisa

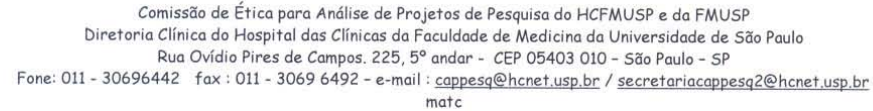




\section{ANEXO B \\ Cópia do manuscrito submetido para publicação no periódico Pituitary, dentro das normas para publicação no mesmo}

Editorial Manager(tm) for Pituitary

Manuscript Draft

Manuscript Number:

Title: Dynamic MRI findings in the first 24 hours after pituitary tumor surgery

Article Type: Original research manuscript

Keywords: pituitary adenoma; dynamic magnetic resonance imaging; postoperative period; resection.

Corresponding Author: Dr. Jerônimo Buzetti Milano, M.D.

Corresponding Author's Institution: Instituto de Neurologia de Curitiba

First Author: Jerônimo b Milano, M.D.

Order of Authors: Jerônimo b Milano, M.D.; Jerônimo Buzetti Milano, M.D.; Ronaldo P Vosgerau, M.D.; Alessandra B Nascimento, M.D.; Maurício Coelho Neto, M.D.; Sonival C Hunhevicz, M.D.; Erasmo B Silva, Jr, M.D.; Ricardo Ramina, M.D., PhD.; Paulo Henrique P Aguiar, M.D., PhD. 
Jerónimo Buzetti Milano, Ronaldo Pereira Vosgerau, Alessandra Bettega Nascimento, Mauricio Coelho Neto, Sonival Cândido Hunhevicz, Erasmo Barros da Silva, Jr, Ricardo Ramina, Paulo Henrique Pires de Aguiar

Dynamic MRI findings in the first $\mathbf{2 4}$ hours after pituitary tumor surgery

JBM, MCN, SCH, EBS Jr, RR: Departament of Neurosurgery, Instituto de Neurologia de Curitiba (INC), Curitiba, Brazil

RPV, ABN: Departament of Neurorradiology, Centro de Tomografia Computadorizada de Curitiba (CFTAC) Curitiha, Brazil

JBM, PHPA: Departament of Neurology, Faculdace de Medicina da Universidade de Sáo Paulo (FMUSP). São Paulo, Brazil

Address correspondence to: Jerônimo Buzetti Milano, Departament of Neurosurgery, Instituto de Neurologia de Curitiba. Rua Jeremias Maciel Perretto, 300. 81210-310. Curitiba-PR, Brazil. e-mail: milano@inc-neuro.com.br. Tel/fax: 554130288580.

\begin{abstract}
:
Imaging after intracranial surgeries often simulates pathological findings, such as edema and residual tumors. The objective of this study was to establish normal postoperative findings on dyramic magnetic resonance imaging (dMRI) after resection of pituitary tumors, as well as determine parameters of radical resection. Forty patients operated for pituitary adenomas through endonasal transsphenoidal approach were evaluated by dMRI before, within the first 24 hours and three months after the surgery. Findings analyzed at early postoperative dMRI were: displacement of the pituitary stalk, hyperintense intraselar material, identification of the pituitary gland, position of the diafragma selae and the pattern of contrast enhancement: 1. no enhancement, 2. peripheral ring, 3. nociular enhancement and 4. combined peripheral and nodular. Displacement of the pituitary stalk was noted in $95 \%$ of all cases. Hyperintense intraselar material was found in $87,5 \%$ of all cases. Diafragma position remained unaltered in 16 of 18 cases $(88,9 \%)$. From the microadenomas, the pattern of enhancement was type 1 in $90,9 \%$, with only two cases with peripheral ring. Of the macroadenomas, $66,7 \%$ had type $1,5,5 \%$ type $2,16,7 \%$ type 3 and $11,1 \%$ type 4. At late postoperative dMRI, the hyperintense material disappeared in all cases and the pituitary stalk returned to the midline in $81,8 \%$. Five patients had residual tumors. Of these, three had type 4 pattem of enhancement, and two had type 3. The association of a nodular enhancement, alone or combined. with a residual tumor was $100 \%$. Other findings should be considered normal.
\end{abstract}

Key words: pituitary adenoma, dynamic magnetic resonance imaging, postoperative period, resection 


\section{Introduction:}

Surgical resection is the most used treatment for pituitary tumors, with the exception of endoselar prolactine-producing acenomas; the transphenoidal approaches are widely accepted as the main route, achieving great rates of total resection [1]. In the early postoperative period, clinical and laboratorial assessment is mandatory, and radiological evaluation is often left to a late phase of the postoperative care [2]. However, early imaging may be necessary to rule cut complications is suspect cases, as well as to identify residual tumors when hormonally inactive, leading to the opportunity of an early reoperation before the development of adhesions and fibrosis. Interpretation of these images can be difficult bezause packing material, fibrosis and blood in the surgical field can simulate hemorrhage, residual tumors and other complications [3-4].

Early magnetic resonance imaging (MRI) in the postoperative period after pituitary tumors reseztion is the subject of some recent studies [5-8]; however, the definition of "early" must be discussed. It is generally accepted that "normal" contrast enhancement is most seen three days after brain surgeries $[9]$, even after non-tumor procedures [10]. This concept has been recently changed since several reports of earlier contrast enhancement were published. Oser et al [11], using MRI during the first 24 hours, reported abnormal contrast enhancement after tumor resection in $35 \%$ of the patients in the absence of a residual tumor (confirmed in late postoperative examinations); Henegar et al [12] showed enhancement in up to $65 \%$ of their patients, in period as earlier as 17 hours after epilepsy surgeries. Based on these findings, a reliable postoperative MRI to analyze a residual tumor should be done before 24 hours. Kiliç et al [5] studied 80 patients during the first 24 hours; this is the only publication using this timing. However, different MRI units were used $(0,5$ and $1,5 \mathrm{~T})$, and they did not used the dynamic MRI as a routine.

Dynamic magnetic resonance imaging (dMRI) is the method of choice for detection of pituitary adenomas. Its great advantage is the differentiation of the pituitary gland from the tumor, based on the pattern of contrast enhanecment [13]. Because of its unique blood supply (the portal system), the pituitary gland exhibits an early enhancement, while the tumor enhancement is later [14]. From the studies previously cited, only Yoon et al [8] performed dynamic MRI at the postoperative course, after 3 to 7 days after the surgery, and described parameters of contrast enhancement that can be used for evaluation of residual masses. 
This is the first study to describe the findings on dMRI during the first 24 hours afer resection of pituitary adenomas.

\section{Methods: \\ Subjects:}

Forty consecutive patients diagnosed with pituitary adenomas were studied between July 2007 and June 2008. There were sixteen males and twenty four females. Twenty-two presented microadenomas $(<10 \mathrm{~mm})$ and eighteen had macroadenoma; of those, four cases had supraselar extension classified as Hardy A ( $22 \%)$, five were Hardy B $27,8 \%)$, one Hardy C $(5,5 \%)$ and eight were Hardy E ( $44,4 \%)$; there were ro cases of Hardy D. Ophthalmologic and endocrinologic tests were performed in all patients. There were 13 non-functioning tumors, 14 prolactinomas, 7 patients with Cushirg disease and 5 cases of acrommegaly,

All patients underwent surgical removal of the tumor through an endonasal-transsphenoidal approach with microscope magnification. In macroadenomas, an endoscopic inspection of the cavity was performed atter the tumor resestion, searching for a residual tumor out of the line of sight of the operative microscope. All surgeries were performed under the supervision of the senior surgeon (RR). A complete removal was thought to be achieved in all but 2 cases, in which a cavernous sinus infiltration was previously known and was left untouched intentionally. After the resection, the cavity was covered oxygenated cellulose (Surgicell ${ }^{\star}$. Johnson \& Johnson Medical) and fibrin sealant (Beriplast ${ }^{\star 0}$. Avertis Behring). The sellar floor defect was reconstructed with a small bone fragment taken from the osseous nasal septum.

MRI protocol:

Preoperative, early (first 24 hours) and late ( 3 to 4 months) dMRI were performed in all patients following the same protocol. It was used a 1.5-T superconducting unit with a circular polarized head coil 
(Signa 1,5 T, MR Excite, GE Inc, USA). Dynamic MRI was performed using T1-weighted sequence with coronal $3 \mathrm{~mm}$-thick-slices with no interslice gap, before the gadopentetate dimeglumine, and then after a rapid injection $(2 \mathrm{ml} / \mathrm{s})$ of the contrast, with images obtained every 80 seconds for $3-4$ minutes.

The parameters studied were the presence of hyperintese material inside the sella, pituitary stalk dislocation, position of the diafragma selae (based on Hardy's classification for supraselar extension [1516]), the identification of the pituitary gland and patterns of contrast enhancement of the pituitary mass We used the parameters described by Yoon et al [8], who consider four possible patterns: 1, no enhancement (no enhancement in the postoperative pituitary mass where the pituitary tumor was located on the preoperative image after intravenous administration of contrast material); 2, peripheral rim (contrast enhancement in the periphery of the postoperative pituitary mass); 3 , nodular enhancement (nodular enhanc ement was demonstrated in the postoperative pituitary mass; 4 , combined (coexistence of both peripheral rim and nodular enhancement). A neurosurgeon (the first author - JBM) and two neuroradiologists ( $\mathrm{ABN}$ and RPV) interpreted the follow-up MR images; a consensus was achieved about the pattem of contrast enhancement in all cases.

All findings were compared with the late dMRI; confirmation of a residual tumor was done by endocrinological tests, growing pattem on late dMRI and a second operation when indicated.

Results:

At the early postoperative course, none of the patients had any complication that could impede the ex ecution of the early dMRI. The median time after the surgery was 18 hours (range: 1 to 24 hours). There was no additional visual loss in any patient.

Early dMRI findings:

Hyperintense material inside the sella was seen in 17 of 22 microadenomas $(77,3 \%)$ and in all cases of macroadenomas ( $87,5 \%$ of all cases).

The pituitary stalk remained displaced in 20 of 22 microadenomas $(90,9 \%)$ and in all cases of macroadenomas ( $95 \%$ of all cases ); in three cases it was not possible to identify the stalk, neither in preoperative dMRI nor in postoperative. 
Identification of the pituitary gland was possible in all cases of microadenomas, and in 15 of 18 macroadenomas $(83,3 \%)$ (Fig. 1). The three cases in which the gland was not seen are the same where the pituitary stalk was not seen as well.

The position of the diafragma selae, as classified according to Hardy's classification for supraselar extension, remained the same in 16 of 18 cases $(88,9 \%)$. There was one case of Hardy B that returns to a Hardy A (Fig. 2), and one case of Hardy C with falling of the diafragma position to Hardy B.

In microadenomas the postoperative dMRI showed no cortrast enhancement (type 1) in all but two cases, in which a peripheral rim (type 2) was seen $9,1 \%$ ). In macroadenomas, the type 1 was seen in 12 cases $(66,7 \%)$, type 2 in one case $(5,5 \%)$, type 3 - nodular - in thee $(16,7 \%)$ and type 4 (combined) in two $(11,1 \%)$.

Late dMRI findings:

The intraselar material disappeared in all cases of microadenomas, with full re-expansion of the gland. The pituitary stalk returned to the midline in 18 of 20 previous displaced cases $(90 \%)$. In all cases the endocrinologic test showed normal pituitary function (i.e., no functioning tumor), and no cases of recurrent/residual tumors were seen.

In the macrodenomas, the intraselar material also disappeared in all cases; the pituitary stalk remained displaced in seven cases, and it was still possible to identify the gland in the same 15 cases. The diafragma selae appears to have normal position in 14 of the 17 displaced in early postoperative dMRI.

Late dMRI findings showed recurrent'residual tumors in five cases. Those were confirmed by hormonal assay in two of them (prolactinomas) and by a second operation, with histopathological confirmation, in three. These cases were the same in which early dMRI showed type 3 or type 4 patterrs of enhancement (Fig. 3).

\section{Discussion}

Imaging patients after intracranial surgeries is oten necessary to rule out complications and to icentify residual tumors, as a baseline to follow up or to incicate an carly re-operation for additional removal. However, interpretation of such images is not easy, since postoperative normal findings can simulate complications, such as edema or hematomas [17], and even tumors [9, 18], leading to false 
interpretation and unnecessary re-interventions. This is also true for intraoperative MRI; Nimsky [19] performed second inspection in 29 of 48 patients after suspicion of a residual pituitary tumor; in ten of those no tumor was seen, but only materials such as fibrin glue, blood and others. A better description of what are the normal findings in postoperative MRI, as well as parameters of complete resection, is needed to optimize the application of intraoperative MRI.

Postoperative MRI in pituitary surgery is the subject of study of previous published papers [ $3-8$, 201, with different timing and parameters evaluated (Table 1). Although providing very useful data, the timing for imaging in those studies make some interpretations not so reliable. As inflammatory response begins after 24 hours, contrast enhancement after this period cannot be used as a reliable parameter $(9,18)$. Additionally, blood at the surgical area begins to form methemoglobin after 24 hours, and its intensity on T1-weight images tends to change in a non-uniform process [21]. As well, hemostatic implants such as Surgicell and Gelfoam are more difficult to be differentiated after this period [12,21]. The only publication on pituitary surgery in which an early image $i<24$ hours) was performed was that of Kiliç et al [5]. They studied 80 cases of pituitary aderomas ( 25 microadenomas, 30 macroadenomas without cavernous sinus infiltration and other 25 macroadenomas with cavernous sinus infiltration) with MRI performed after 24 hours and then every 3 months until one year after the operation. They described the usual finding after a surgery, the intensity of sign of package materials (fat or other absorbable synthetic material). Our findings are consistent with their data, showing disappearance of most materials atter 3 to 6 months. The size of the "pituitary mass" remained almost the same (as reported by others [3, 20]; we have seen, however, that when the diafragma selae retumed to a more normal position (reduction of Hardy's grade), there is a greater chance that the tumor was completed removed. They also showed that a residual tumor can be identified with a high specificity (only two of 80 examinations with falsepositive tumor). Unfortunately, they do not provide a reproductive parameter of complete removal, and dynamic MRI was rot used.

The only study which used dMRI in the postoperative analysis was that of Yoon et al [8]. They provide the patterns of contrast enhancement used by our group. It seems to be reproductive, since the interpretation by two radiologist and one neurosurgeon lead to a consensus in all cases. Our findings confirmed the ability of detection of a residual tumor when the nodular patern of enhancement, isolated or combined, is noted in the postoperative examination (Fig. 3). The greater difference noted was the number of case in which the peripheral ring (type 2) was seen. In their series, 13 of $67(19 \%)$ 
macroadenomas operated showed this pattern, while ours had only one case $(5,5 \%)$; this pattern was not associated to a residual tumor in our series too (Fig. 2). It is possible that the timing to perform the postoperative images (three to seven days) lead to this difference, since contrast enhancement tends to increase within the first days.

\section{Conclusion:}

After the resection of a pituitary adenoma, dynamic MRI performed within 24 hours show several findings that must be interpreted with caution. Hyperintensity inside the sella, pituitary stalk displacement and persistent elevation of the diafragma selae should be considered normal findings. The residual pituitary gland can be identified in most cases because of its early enhancement. When there is a nodular contrast enhancement, isolated or combined with a peripheral rim, a residual tumor is probably present. 
References

1. Jane JA Jr, Dumont AS, Sheehan JP, Laws ER Jr (2004) Surgical techniques transsphenoidal surgery: what is the standard of care in pituitary adenoma surgery? Curr O Endocrinol Diabetes 14:264-270

2. Ausiello JC, Bruce JN, Freda PU (2008) Postoperative assessment of the patient at transsphenoidal pituitary surgery. Pituitary $11: 391-401$. DOI 10.1007/s11102-008-0086-6

3. Dina TS, Feaster SH, Laws Jr ER, Davis DO (1993) MR of the pituitary gl: postsurgery: serial MR studies following transsphenoidal resection. AJNR Am J Neurorac 14(3): 763-769

4. Rodriguez O, Mateos B, de la Pedraja R, Villoria R, Hernando JI, Pastor A, Pompos Aurrecoechea J (1996) Postoperative follow-up of pituitary adenomas after trans-sphenoi resection: MRI and clinical correlation. Neuroradiology 38(8): 747-754

5. Kiliç T, Ekinci G, Șeker A, Elmaci I, Erzen C, Pamir MN (2001) Determining optir MRI follow-up after transsphenoidal surgery for pituitary adenoma: scan at 24 hours postsurg provides reliable information. Acta Neurochir (Wien) 143: 1103-1126

6. Kremer P, Forsting M, Ranaei G, Wüster C, Hamer J, Sartor K, Kunze S (20 Magnetic Resonance Imaging after Transsphenoidal Surgery of Clinically Non-Functio Pituitary Macroadenomas and its Impact on Detecting ResidualAdenoma. Acta Neuroc (Wien) 144: 433-443

7. Steiner E, Knosp E, Herold CJ, Kramer J, Stiglbauer R, Staniszewski K, Imhof (1992) Pituitary adenomas: Findings of postoperative MR imaging. Radiology 185(2): 521-52 8. Yoon PH, Kim DI, Jeon P, Lee SI, Lee SK, Kim SH (2001) Pituitary adenomas: e postoperative MR Imaging after transsphenoidal resection. AJNR Am J Neuroradiol 22:10 1104

9. Cairncross JG, Pexman JH, Rathbone MP, DelMaestro RF (1985) Postoperat contrast enhancement in patients with brain tumor. Ann Neurol 17(6): 570-572 
10. Laohaprasit V, Silbergeld DL, Ojemann GA, Eskridge JM, Winn R (1990) Postoperative CT contrast enharcement following lobectomy for epilepsy. J Neurosurg 73(3): $392-395$

11. Oser AB, Moran CJ, Kaufman BA, Park TS (1997) Intracranial tumor in children: MR imaging findings within 24 hours of craniotomy. Radiology 205(3):807-812

12. Henegar MM, Moran CJ, Silbergeld DL (1996) Early postoperative magnetic resonance imaging following nonneoplastic cortical resection. J Neurosurg 84: 174-179

13. Miki Y, Matsuo M, Nishizawa S, Kuroda Y, Keyaki A, Makita Y, Kawamura J (1990) Pituitary adenomas and normal pituitary tissue: enhancement patterns on gadopentetateenhanced MR imaging. Radiology 177(1): 35-38

14. Sakamoto Y, Takahashi M, Korogi Y, Bussaka H, Ushio Y (1991) Normal and abnormal pituitary glands: gadopentetate dimeglumire-enhanced MR imaging. Radiology 178(2): $441-445$

15. Hardy J, Vezina JL (1976) Transsphenoidal neurosurgery of intracranial neoplasm. In Thompson RA, Green JR (ed) Advances in Neurology, Raven Press, New York. pp. 261-275.

16. Wilson CB (1984) A desade of pituitary microsurgery. The Herbert Olivecrona lecture. J Neurosurg 61(5): 814-833

17. Teng MM, Huang CI, Chang T (1988) The pituitary mass after transsphenoidal hypophysectomy. AJNR Am J Neuroradiol 9(1):23-26

18. Albert FK, Forsting M, Sartor K, Adams HP, Kunze S (1994) Early postoperative magnetic resonance imaging ater resection of malignant glioma. Objective evaluation of residual tumor and its influence on regrowth and prognosis. Neurosurgery 34(1):45-61

19. Nimsky C, Ganslendt O, von Keller B, Romstöck J, Fahlbusch R (2004) Intraoperative high-field-strenght MR imaging: implementation and experience in 200 patients. Radiology $233: 67-78$

20. Rajaraman V, Schulder M (1999) Postoperative MRI appearance after transsphenoidal pituitary tumor resection. Surg Neurol 52(6): 592-598

21. Lanzieri CF, Larkins M, Mancall A, Lorig R, Duchesncau PM, Rosenbloom SA, Weinstein MA (1988) Cranial postoperative site: MR imaging appearance. AJNR Am J Neuroradiol 9: 27-34 
Table 1: Summary of publications on postoperative MRI after pituitary surgery

\begin{tabular}{|c|c|c|c|c|c|c|c|}
\hline $\begin{array}{l}\text { Author } \\
\text { [Reference] }\end{array}$ & 乙 & 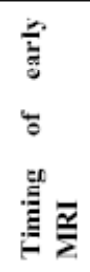 & 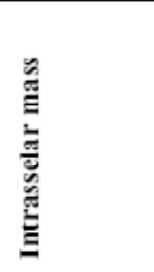 & 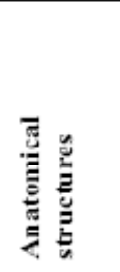 & 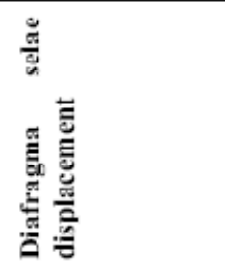 & 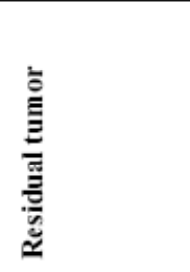 & 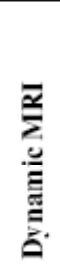 \\
\hline Dina [3] & 10 & $2-8 \mathrm{~d}$ & Descriptive & $\mathrm{N} / \mathrm{A}$ & MCTD & $\mathrm{N} / \mathrm{A}$ & No \\
\hline Kiliç [5] & 80 & $24 \mathrm{~h}$ & Descriptive & $\begin{array}{ll}\text { PS, OC } \\
\text { PG }\end{array}$ & MCTD & $\mathrm{Y} / \mathrm{N},+$ to $+1+$ & No \\
\hline Kremer โ6」 & 50 & $3 d$ & Descriptive & $\mathrm{PS}, \mathrm{PG}$ & Subjective & Subjective & No \\
\hline Rajamaran [20] & 14 & $14 \mathrm{~d}$ & $\mathrm{~N} / \mathrm{A}$ & $\mathrm{N} / \mathrm{A}$ & MCTD & $\mathrm{N} / \mathrm{A}$ & No \\
\hline Rodriguez [4] & 16 & $7 \mathrm{~d}$ & $\mathrm{Y} / \mathrm{N}$ & $\begin{array}{l}\text { PS,PG, } \\
O C\end{array}$ & OC Compression & Subjective & No \\
\hline Steiner [7] & 25 & $\begin{array}{l}3- \\
12 \mathrm{~d}\end{array}$ & Descriptive & $\begin{array}{l}\mathrm{GL} \\
\mathrm{OC}\end{array}$ & Subjective & Subjective & No \\
\hline Yoon [8] & 83 & $3 \cdot 7 \mathrm{~d}$ & $\begin{array}{l}\text { Intensity of } \\
\text { signal }\end{array}$ & $\mathrm{N} / \mathrm{A}$ & $\mathrm{N} / \mathrm{A}$ & $\begin{array}{l}\text { Enhancement } \\
\text { pattern }\end{array}$ & Yes \\
\hline Milans' & 40 & $24 \mathrm{~h}$ & $\mathrm{Y} / \mathrm{N}$ & $\begin{array}{l}\mathrm{OS}, \\
\mathrm{PG}\end{array}$ & Hardy & $\begin{array}{l}\text { Enhancement } \\
\text { pattern }\end{array}$ & Yes \\
\hline
\end{tabular}

$\mathrm{N}=$ number of patierts; $\mathrm{d}=$ days; $\mathrm{h}=$ hours; $\mathrm{N} / \mathrm{A}=$ not available; $\mathrm{MCTD}=$ maximal coronal tumor diameter; PS=pituitary stalk; $\mathrm{PG}=$ pituitary gland; $\mathrm{OC}=$ optic chiasm; $\mathrm{Y} / \mathrm{N}$ :YES or NO. 'Milano refers to this series. 


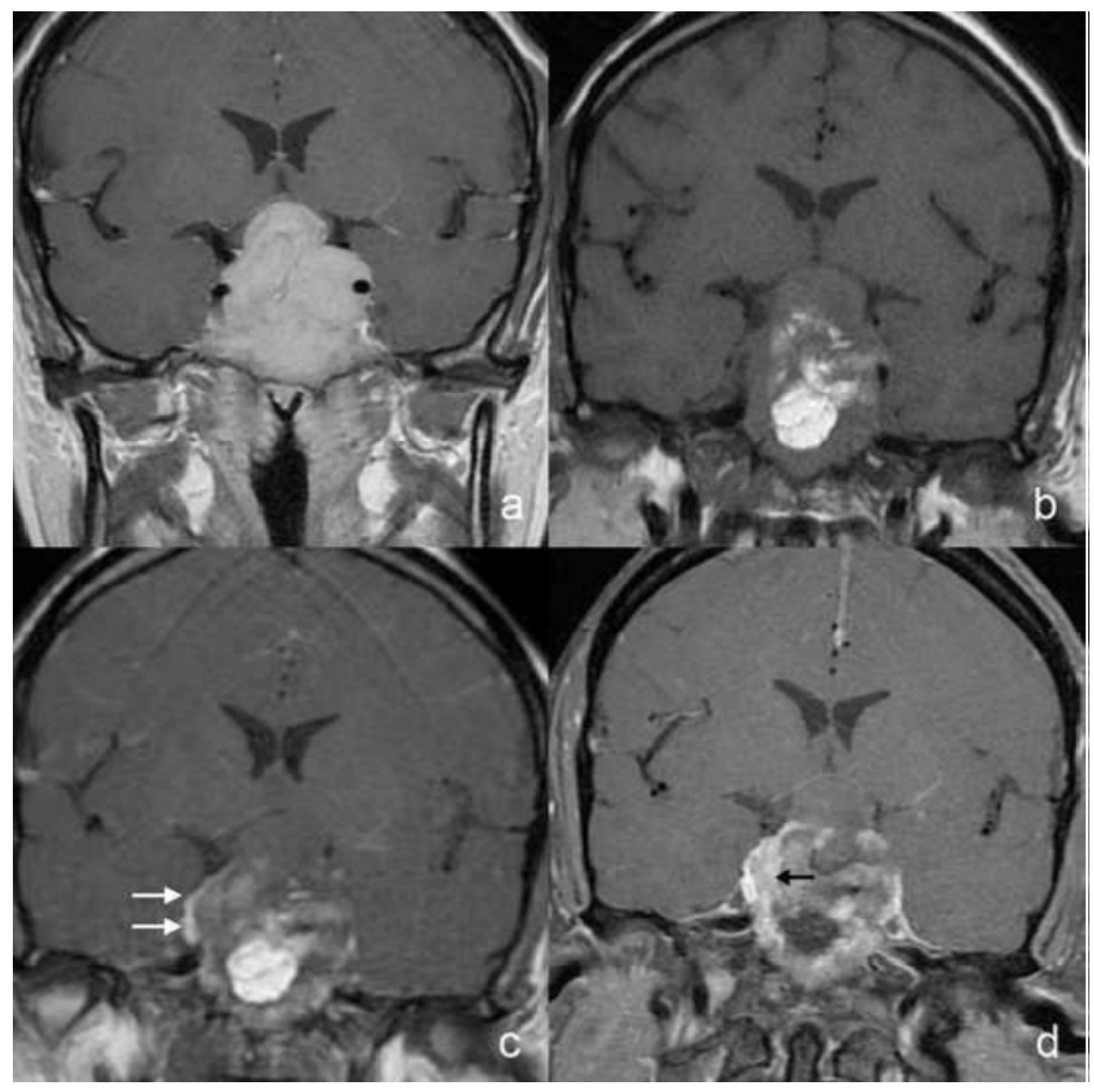




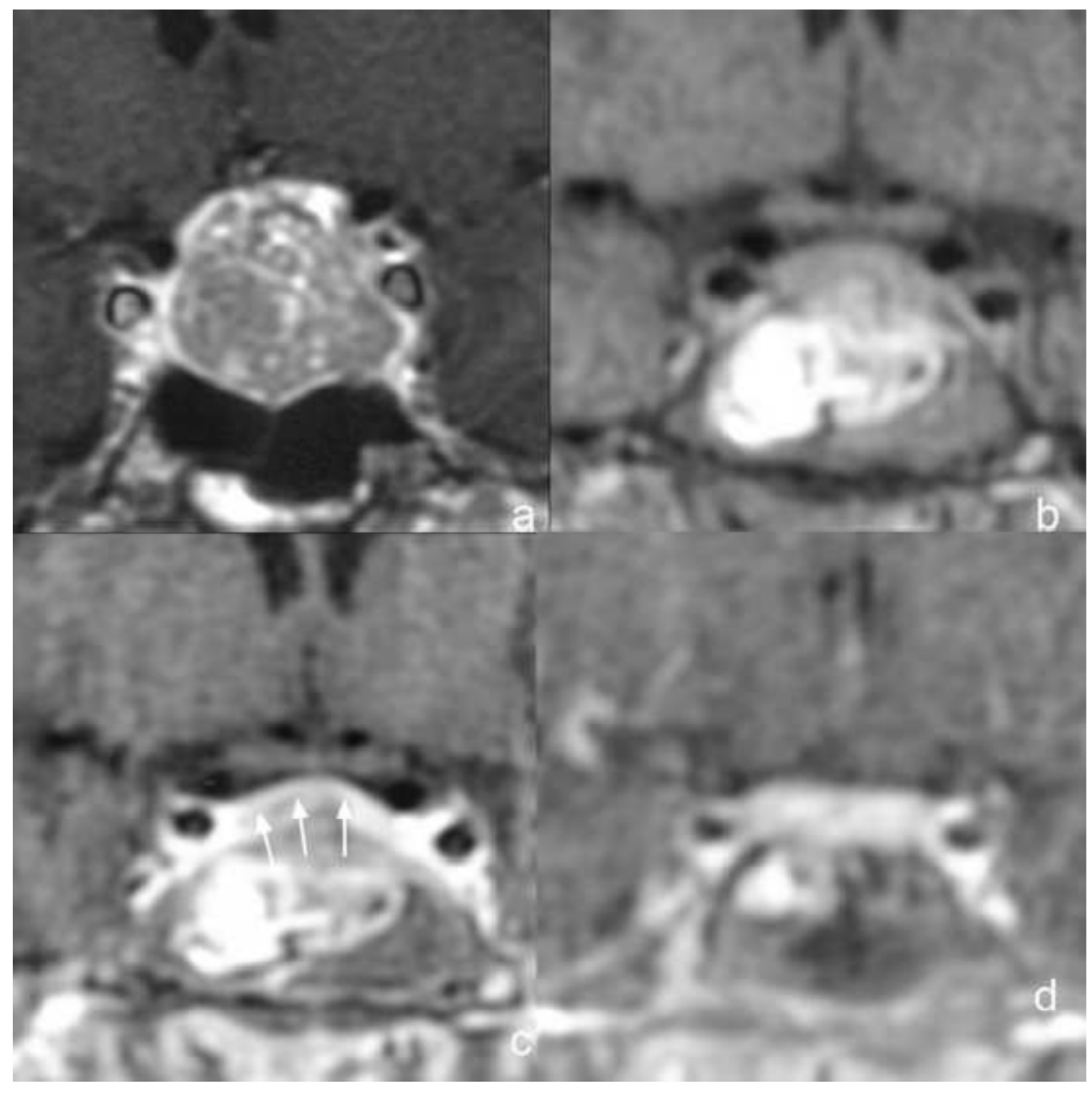




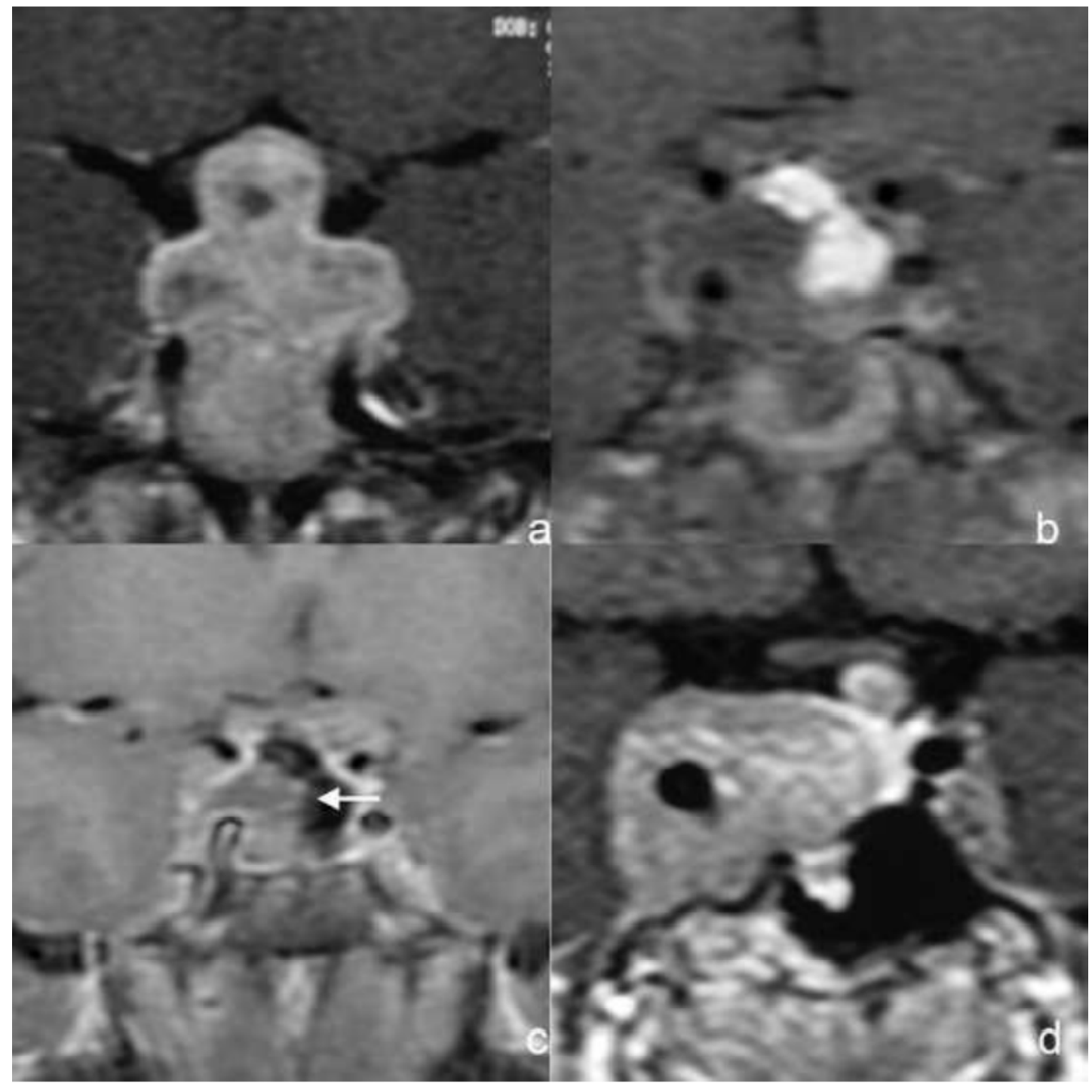


Figure 1: A large hormonally inactive pituitary adenoma with supraselar extension. a. Preoperative image. b-d: early postoperative dMRI. b. before contrast injection. The position of the diafragma selae remained almost the same, and an intraselar hyperintese material is seen. c. after contrast injection, early phase. The pituitary stalk as well as the gland can be identified with early contrast enhancement (white arrows). d. after contrast, late phase. Adjacent to the gland, a nodular enhancement is seen (black arrow).

Figure 2: Prolactinoma with no response to dopamine agonists. a. Preoperative image. b-c: early postoperative dMRI. b. before contrast injection. The position of the diafragma selae changed from Hardy B to Hardy A. c. after contrast injection. A type 2 (peripheral rim) pattern of enhancement is seen (white arrows). d. Late (3 months) MRI. No tumor is seen, the diafragma returned to its normal position, and the patient was hormonally normal.

Figure 3: A large hormonally inactive pituitary adenoma with supraselar extension. a. Preoperative image. b-c: early postoperative dMRI. b. before contrast injection. The position of the diafragma selae remained the same, and an intraselar hyperintese material is seen. c. after contrast injection. A type 4 (combined nodular and peripheral rim) pattern of enhancement is seen, near to the right cavernous sinus (white arrow). D. Late (3 months) MRI. A residual tumor with encasement of the right internal carotid artery is seen. 


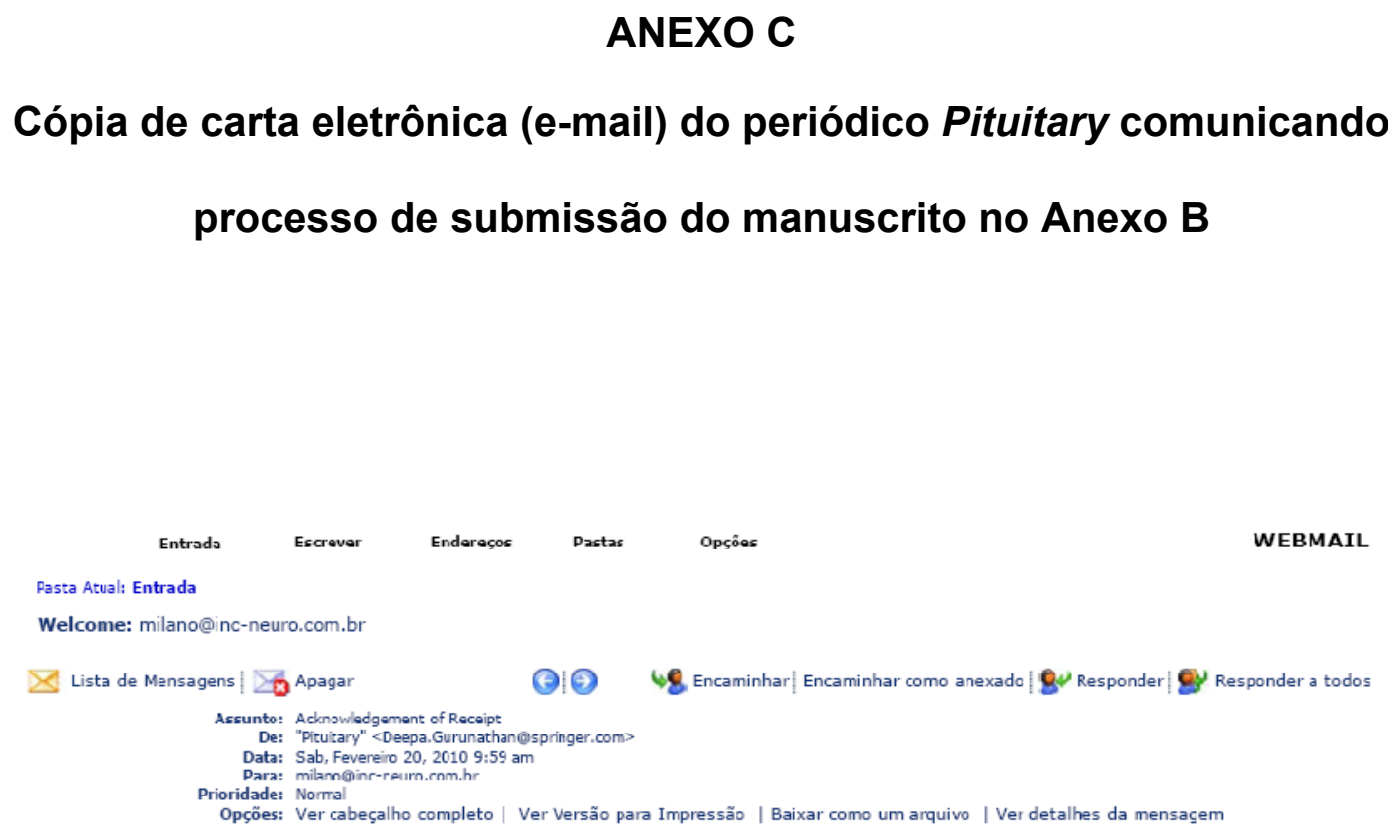

Dear Dr. Jer Ônimo Buzelli Milano:

Thank you for submitting your manuscript, "Dynamic MRI findings in the first 24

hours after pituitary tumor surgery", to Pituitary.

During the review process, you can keep track of the status of your manuscript by accessing the following web site:

http://pitu.edmgr.com!

Your username is: jmilano

Your password is: milano 427535

With kind regards,

The Editorial Office

Pituitary 


\section{REFERÊNCIAS}




\section{REFERÊNCIAS}

1. Nemergut EC, Dumont AS, Barry UT, Laws ER. Perioperative management of patients undergoing transsphenoidal pituitary surgery. Anesth Analg. 2005;101:1170-81.

2. Ezzat S, Asa SL, Couldwell WT, Barr CE, Dodge WE, Vance ML, McCurcheon IE. The prevalence of pituitary adenomas: a systematic review. Cancer. 2004;101:613-19.

3. Antunes ACM, Tella OI, Jr. Tratamento cirúrgico dos tumores hipofisários. In: Aguiar PHP, Antunes, A.C.M., Machado, H.R., Ramina, R., Teixeira, M.J., Veiga, J.C.E.V., ed. Tratado de técnica operatória em neurocirurgia. São Paulo: Atheneu; 2009:177-89.

4. Vance ML. Treatment of patients with a pituitary adenoma: one clinician's experience. Neurosurg Focus. 2004;16(4):E1. 
5. Wilson CB. A decade of pituitary microsurgery. The Herbert Olivecrona lecture. J Neurosurg. 1984;61:814-33.

6. Black PM, Zervas NT, Candia G. Management of large pituitary adenomas by transsphenoidal surgery. Surg Neurol. 1988;29:443-7.

7. Grosvenor AE, Laws ER. The evolution of extracranial approaches to the pituitary and anterior skull base. Pituitary. 2008;11:337-45.

8. Isolan GR, de Aguiar PH, Laws ER, Strapasson AC, Piltcher O. The implications of microsurgical anatomy for surgical approaches to the sellar region. Pituitary. 2009.- on line

9. Vance ML, Laws ER, Jr. Role of medical therapy in the management of acromegaly. Neurosurgery. 2005;56:877-885; discussion 877-85.

10. Pouratian N, Prevedello DM, Jagannathan J, Lopes MB, Vance ML, Laws ER, Jr. Outcomes and management of patients with Cushing's disease without pathological confirmation of tumor resection after transsphenoidal surgery. J Clin Endocrinol Metab. 2007;92:3383-8.

11. Sonino N, Zielezny M, Fava GA, Fallo F, Boscaro M. Risk factors and longterm outcome in pituitary-dependent Cushing's disease. J Clin Endocrinol Metab. 1996;81:2647-52.

12. Hammer GD, Tyrrell JB, Lamborn KR, Applebury CB, Hennergan ET, Bell S, Rahl R, Lu A, Wilson CB. Transsphenoidal microsurgery for Cushing's 
disease: initial outcome and long-term results. J Clin Endocrinol Metab. 2004;89:6348-57.

13. Greenfield JP, Howard BM, Huang C, Boockvar JA. Endoscopic endonasal transsphenoidal surgery using a skull reference array and laser surface scanning. Minim Invasive Neurosurg. 2008;51:244-6.

14. Elias WJ, Chadduck JB, Alden TD, Laws ER, Jr. Frameless stereotaxy for transsphenoidal surgery. Neurosurgery. 1999;45:271-5.

15. Jane JA, Jr., Thapar K, Kaptain GJ, Maartens N, Laws ER, Jr. Pituitary surgery: transsphenoidal approach. Neurosurgery. 2002;51:435-42.

16. Nimsky C, Ganslandt O, Kober H, Buchfelder M, Fahlbusch R. Intraoperative magnetic resonance imaging combined with neuronavigation: a new concept. Neurosurgery. 2001;48:1082-9.

17. Martin $\mathrm{CH}$, Schwartz R, Jolesz F, Black PM. Transsphenoidal resection of pituitary adenomas in an intraoperative MRI unit. Pituitary. 1999;2:155-62.

18. Bohinski RJ, Warnick RE, Gaskill-Shipley MF, Zuccarello M, van Loveren HR, Kormos DW, Tew JM, Jr.. Intraoperative magnetic resonance imaging to determine the extent of resection of pituitary macroadenomas during transsphenoidal microsurgery. Neurosurgery. 2001;49:1133-43. 
19. Nimsky C, Ganslandt O, Von Keller B, Romstock J, Fahlbusch R. Intraoperative high-field-strength MR imaging: implementation and experience in 200 patients. Radiology. 2004;233:67-78.

20. Ramina R, Coelho Neto M, Giacomelli A, Barros E, Jr, Vosgerau R, Nascimento A, Coelho G. Optimizing costs of intraoperative magnetic resonance imaging. A series of 29 glioma cases. Acta Neurochir (Wien). 2010 Jan; 152(1):27-33.

21. Oser $A B$, Moran $C J$, Kaufman BA, Park TS. Intracranial tumor in children: MR imaging findings within 24 hours of craniotomy. Radiology. $1997 ; 205: 807-12$.

22. Teng $\mathrm{MM}$, Huang $\mathrm{Cl}$, Chang $\mathrm{T}$. The pituitary mass after transsphenoidal hypophysectomy. AJNR Am J Neuroradiol. 1988;9:23-6.

23. Laohaprasit V, Silbergeld DL, Ojemann GA, Eskridge JM, Winn HR. Postoperative CT contrast enhancement following lobectomy for epilepsy. $J$ Neurosurg. 1990;73:392-5.

24. Henegar MM, Moran CJ, Silbergeld DL. Early postoperative magnetic resonance imaging following nonneoplastic cortical resection. J Neurosurg. 1996;84:174-9.

25. Dina TS, Feaster SH, Laws ER, Jr., Davis DO. MR of the pituitary gland postsurgery: serial MR studies following transsphenoidal resection. AJNR Am J Neuroradiol. 1993;14:763-9. 
26. Rajaraman V, Schulder M. Postoperative MRI appearance after transsphenoidal pituitary tumor resection. Surg Neurol. 1999;52:592-8

27. Kiliç T, Ekinci G, Seker A, Elmaci I, Erzen C, Pamir MN. Determining optimal MRI follow-up after transsphenoidal surgery for pituitary adenoma: scan at 24 hours postsurgery provides reliable information. Acta Neurochir (Wien). 2001;143:1103-26.

28. Kremer P, Forsting M, Ranaei G, Wüster C, Hamer J, Sartor K, Kunze S. Magnetic resonance imaging after transsphenoidal surgery of clinically nonfunctional pituitary macroadenomas and its impact on detecting residual adenoma. Acta Neurochir (Wien). 2002;144:433-43.

29. Yoon PH, Kim DI, Jeon P, Lee SI, Lee SK, Kim SH. Pituitary adenomas: early postoperative MR imaging after transsphenoidal resection. AJNR Am J Neuroradiol. 2001;22:1097-104.

30. Lanzieri CF, Larkins M, Mancall A, et al. Cranial postoperative site: MR imaging appearance. AJNR Am J Neuroradiol. 1988;9:27-34.

31. Albert FK, Forsting M, Sartor K, Adams HP, Kunze S. Early postoperative magnetic resonance imaging after resection of malignant glioma: objective evaluation of residual tumor and its influence on regrowth and prognosis. Neurosurgery. 1994;34:45-60. 
32. Cairncross JG, Pexman JH, Rathbone MP, DelMaestro RF. Postoperative contrast enhancement in patients with brain tumor. Ann Neurol. 1985;17:5702.

33. Guyton AC. Os hormônios hipofisários e seu controle pelo hipotálamo. In: Guyton AC, ed. Tratado de fisiologia médica. 8 ed. Rio de Janeiro: Guanabara Koogan; 1992:720-30.

34. Pedrozo AA. Hipotálamo. In: Meneses MS, ed. Neuroanatomia aplicada. 2 ed. Rio de Janeiro: Guanabara Koogan; 2006:218-24.

35. Rhoton AL, Jr. The sellar region. Neurosurgery. 2002;51(4 Suppl):S335-74.

36. Ferreri AJ, Garrido SA, Markarian MG, Yanez A. Relationship between the development of diaphragma sellae and the morphology of the sella turcica and its content. Surg Radiol Anat. 1992;14:233-9.

37. Lang J. Hypophyseal region--anatomy of the operative approaches. Neurosurg Rev. 1985;8:93-124.

38. Meneses MS, Jackowski AP. Vascularização do sistema nervoso central. In: Meneses MS, ed. Neuroanatomia aplicada. 2 ed. Rio de Janeiro: Guanabara Koogan; 2006:320-45.

39. Rhoton AL, Jr. The cavernous sinus, the cavernous venous plexus, and the carotid collar. Neurosurgery. 2002;51(4 Suppl):S375-410. 
40. Yasuda A, Campero A, Martins C, Rhoton AL, Jr., de Oliveira E, Ribas GC. Microsurgical anatomy and approaches to the cavernous sinus. Neurosurgery. 2005;56(1 Suppl):4-27.

41. Harris FS, Rhoton AL. Anatomy of the cavernous sinus. A microsurgical study. J Neurosurg. 1976;45:169-80.

42. Renn $\mathrm{WH}$, Rhoton AL, Jr. Microsurgical anatomy of the sellar region. $J$ Neurosurg. 1975;43:288-98.

43. Yilmazlar S, Kocaeli H, Aydiner F, Korfali E. Medial portion of the cavernous sinus: quantitative analysis of the medial wall. Clin Anat. 2005;18:416-22.

44. Kursat E, Yilmazlar S, Aker S, Aksoy K, Oygucu H. Comparison of lateral and superior walls of the pituitary fossa with clinical emphasis on pituitary adenoma extension: cadaveric-anatomic study. Neurosurg Rev. 2008;31:918.

45. Yasuda A, Campero A, Martins C, Rhoton AL, Jr., Ribas GC. The medial wall of the cavernous sinus: microsurgical anatomy. Neurosurgery. 2004;55:17989.

46. Peker S, Kurtkaya-Yapicier O, Kilic T, Pamir MN. Microsurgical anatomy of the lateral walls of the pituitary fossa. Acta Neurochir (Wien). 2005;147:6418. 
47. Dietemann JL, Kehrli P, Maillot C, Diniz R, Reis M Jr, Neugroschi C, Vinclair L. Is there a dural wall between the cavernous sinus and the pituitary fossa? Anatomical and MRI findings. Neuroradiology. 1998;40:627-30.

48. Marrone $\mathrm{ACH}$, Aquini MG, Meneses MS. Vias da sensibilidade especial. In: Meneses MS, ed. Neuroanatomia aplicada. 2 ed. Rio de Janeiro: Guanabara Koogan; 2006:303-19.

49. O’Rahille R. Encéfalo, nervos crânicos e meninges. In: Gardner E, Gray DJ, O’Rahille R, eds. Benevento R, trans. Anatomia - estudo regional do corpo humano. 4 ed. Rio de Janeiro: Guanabara Koogan; 1988:572-604.

50. Sociedade Brasileira de Anatomia. Terminologia Anatômica. São Paulo: Ed. Manole Ltda.; 2001.

51. Elster AD. Modern imaging of the pituitary. Radiology. 1993;187:1-14.

52. Hardy J, Vezina JL. Transsphenoidal neurosurgery of intracranial neoplasm. In: Thompson RA, Green JR, eds. Advances in Neurology. Vol 15. New York: Raven Press; 1976:261-75.

53. Rhoton AL, Jr. The supratentorial arteries. Neurosurgery. 2002;51(4 Suppl):S53-120.

54. Shimon I, Melmed S. Management of pituitary tumors. Ann Intern Med. $1998 ; 129: 472-83$. 
55. Thapar K, Kovacs K, Laws ER. The classification and molecular biology of pituitary adenomas. Adv Tech Stand Neurosurg. 1995;22:3-53.

56. Gondim JA, Tella OI, Jr., Schops M. Intrasellar pressure and tumor volume in pituitary tumor: relation study. Arq Neuropsiquiatr. 2006;64:971-5.

57. Levy MJ, Jager HR, Powell M, Matharu MS, Meeran K, Goadsby PJ. Pituitary volume and headache: size is not everything. Arch Neurol. $2004 ; 61: 721-5$.

58. Gondim JA, de Almeida JP, de Albuquerque LA, Schops M, Gomes E, Ferraz T. Headache associated with pituitary tumors. J Headache Pain. 2009;10:15-20.

59. Hardy DG. Transsphenoidal microsurgery of the normal and pathological pituitary. Clin Neurosurg. 1969;16:185-217.

60. Knosp E, Steiner E, Kitz K, Matula C. Pituitary adenomas with invasion of the cavernous sinus space: a magnetic resonance imaging classification compared with surgical findings. Neurosurgery. 1993;33:610-7.

61. Thapar K, Kovacs K, Muller PJ. Clinical-pathological correlations of pituitary tumours. Baillieres Clin Endocrinol Metab. 1995;9:243-70.

62. Laws ER, Jr., Thapar K. Surgical management of pituitary adenomas. Baillieres Clin Endocrinol Metab. 1995;9:391-405. 
63. Anderson JR, Antoun N, Burnet N, Chatterjee K, Edwards O, Pickard JD, Sarkies N. Neurology of the pituitary gland. J Neurol Neurosurg Psychiatry. 1999;66:703-21.

64. Losa M, Mortini P, Franzin A, Barzaghi R, Mandelli C, Giovanelli M. Surgical management of thyrotropin-secreting pituitary adenomas. Pituitary. 1999;2:127-31.

65. Mindermann T, Wilson CB. Thyrotropin-producing pituitary adenomas. $J$ Neurosurg. 1993;79:521-7.

66. Lauterbur, P.C. Image formation by induced local interactions: examples employing nuclear magnetic resonance. Nature. 1973;242:190-1.

67. Nichols DA, Laws ER, Houser OW, Newton TH, Wilson CB. Gd-DTPAenhanced MR imaging of pituitary adenomas. AJNR Am J Neuroradiol. 1988;10:949-54.

68. Cottier JP, Destrieux C, Brunereau L, Bertrand P, Moreau L, Jan M. Cavernous sinus invasion by pituitary adenoma: MR imaging. Radiology. 2000;215:463-9.

69. Thapar K, Laws ER. Pituitary tumors: functioning and nonfunctioning. In Winn, RH,ed. Youmans Neurological Surgery, $5^{\text {th }}$ ed., Philadelphia: Elsevier; 2004: Vol 1, 1169-1206. 
70. Sage MR, Wilson AJ, Scroop R. Contrast media and the brain: the basis of CT and MR imaging enhancement. Neuroimaging Clin N Am 1998;8: 695707.

71. Provenzale JM, Mukundan S, Dewhirst M. The role of blood-brain barrier permeability in brain tumor imaging and therapeutics. AJR Am J Roentgenol 2005;185:763-7.

72. Miki Y, Matsuo M, Nishizawa S, Kuroda Y, Keyaki A, Makita Y, Kawamura J. Pituitary adenomas and normal pituitary tissue: enhancement patterns on gadopentetate-enhanced MR imaging. Radiology. 1990;177:35-8.

73. Davis PC, Gokhale KA, Joseph GJ, Peterman SB, Adams DA, Tindall GT, Hudgins PA, Hoffman JC Jr. Pituitary adenoma: correlation of half-dose gadolinium-enhanced MR imaging with surgical findings in 26 patients. Radiology. 1991;180:779-84.

74. Hemminghytt S, Kalkhoff RK, Daniels DL, Williams AL, Grogan JP, Haughton VM. Computed tomographic study of hormone-secreting microadenomas. Radiology. 1983;146:65-9.

75. Sakamoto $\mathrm{Y}$, Takahashi M, Korogi $\mathrm{Y}$, Bussaka H, Ushio $\mathrm{Y}$. Normal and abnormal pituitary glands: gadopentetate dimeglumine-enhanced MR imaging. Radiology. 1991;178:441-5. 
76. Finelli DA, Kaufman B. Varied microcirculation of pituitary adenomas at rapid, dynamic, contrast-enhanced MR imaging. Radiology. 1993;189:20510.

77. Bonneville JF, Cattin F, Moussa-Bacha K, Portha C. Dynamic computed tomography of the pituitary gland: the "tuft sign". Radiology. 1983;149:145-8.

78. Bonneville JF, Bonneville F, Cattin F. Magnetic resonance imaging of pituitary adenomas. Eur Radiol. 2005;15:543-8.

79. Bartynski WS, Lin L. Dynamic and conventional spin-echo MR of pituitary microlesions. AJNR Am J Neuroradiol. 1997;18:965-72.

80. Kucharczyk W, Bishop JE, Plewes DB, Keller MA, George S. Detection of pituitary microadenomas: comparison of dynamic keyhole fast spin-echo, unenhanced, and conventional contrast-enhanced MR imaging. AJR Am J Roentgenol. 1994;163:671-9.

81. Korogi $\mathrm{Y}$, Takahashi $\mathrm{M}$, Sakamoto $\mathrm{Y}$, Shinzato J. Cavernous sinus: correlation between anatomic and dynamic gadolinium-enhanced MR imaging findings. Radiology. 1991;180:235-7.

82. Molitch ME. Disorders of prolactin secretion. Endocrinol Metab Clin North Am. 2001;30:585-610. 
83. Jolesz FA. 1996 RSNA Eugene P. Pendergrass New Horizons Lecture. Image-guided procedures and the operating room of the future. Radiology. 1997;204:601-12.

84. Jolesz FA, Shtern F. The operating room of the future. Report of the National Cancer Institute Workshop, "Imaging-Guided Stereotactic Tumor Diagnosis and Treatment". Invest Radiol. 1992;27:326-8.

85. Black PM, Moriarty T, Alexander E, 3rd, Stieg P. Woodard EJ, Gleason PL, Martin $\mathrm{CH}$, Kikinis R, Schwartz RB, Jolensz FA. Development and implementation of intraoperative magnetic resonance imaging and its neurosurgical applications. Neurosurgery. 1997;41:831-42.

86. Schwartz RB, Hsu L, Wong TZ, Kacher DF, Zamani AA, Black PM, Alexander E $3^{\text {rd }}$, Stieg PE, Moriarty TM, Martin CA, Kikinis R, Jolensz FA. Intraoperative MR imaging guidance for intracranial neurosurgery: experience with the first 200 cases. Radiology. 1999;211:477-88.

87. Knauth M, Wirtz CR, Tronnier VM, Aras N, Kunze S, Sartor K. Intraoperative MR imaging increases the extent of tumor resection in patients with highgrade gliomas. AJNR Am J Neuroradiol. 1999;20:1642-46.

88. Bohinski RJ, Kokkino AK, Warnick RE, Gaskill-Shipley MF, Kormos DW, Lukin RR, Tew JM Jr. Glioma resection in a shared-resource magnetic resonance operating room after optimal image-guided frameless stereotactic resection. Neurosurgery. 2001;48:731-42. 
89. Bradley WG. Achieving gross total resection of brain tumors: intraoperative MR imaging can make a big difference. AJNR Am J Neuroradiol. 2002;23:348-9.

90. Metzger AK, Lewin JS. Optimizing brain tumor resection. Low-field interventional MR imaging. Neuroimaging Clin N Am. 2001;11:651-7.

91. Schneider JP, Trantakis C, Rubach M, Schultz T, Dietrich J, Winkler D, Renner C, Schober R, Geiger K, Brosteanu O, Zimmer C, Kahn T. Intraoperative $\mathrm{MRI}$ to guide the resection of primary supratentorial glioblastoma multiforme - a quantitative radiological analysis. Neuroradiology. 2005;47:489-500.

92. Nimsky C, Ganslandt O, Fahlbusch R. Comparing 0.2 tesla with 1.5 tesla intraoperative magnetic resonance imaging analysis of setup, workflow, and efficiency. Acad Radiol. 2005;12:1065-79.

93. Albayrak B, Samdani AF, Black PM. Intra-operative magnetic resonance imaging in neurosurgery. Acta Neurochir (Wien). 2004;146:543-56.

94. Kucharczyk W, Bernstein M. Do the benefits of image guidance in neurosurgery justify the costs? From stereotaxy to intraoperative MR. AJNR Am J Neuroradiol. 1997;18:1855-9..

95. Oh DS, Black PM. A low-field intraoperative MRI system for glioma surgery: is it worthwhile? Neurosurg Clin N Am. 2005;16:135-41. 
96. Fahlbusch R, Ganslandt O, Buchfelder M, Schott W, Nimsky C. Intraoperative magnetic resonance imaging during transsphenoidal surgery. J Neurosurg. 2001;95:381-90.

97. Lewin JS, Hlavin ML, Duerk JL, Clampitt ME, Selman WR. Intra-operative MR for guidance of transsphenoidal procedures: imaging characteristics and issues. Paper presented at: Sixth Meeting of the International Society for Magnetic Resonance in Medicine1998; Berkeley, CA. apud Ahn JY, Jung JY, Kim J, Lee KS, Kim SH. How to overcome the limitations to determine the resection margin of pituitary tumours with low-field intra-operative MRI during trans-sphenoidal surgery: usefulness of Gadolinium-soaked cotton pledgets. Acta Neurochir (Wien). 2008;150:763-71.

98. Nimsky C, Ganslandt O, Tomandl B, Buchfelder M, Fahlbusch R. Low-field magnetic resonance imaging for intraoperative use in neurosurgery: a 5-year experience. Eur Radiol. 2002;12:2690-03.

99. Ahn JY, Jung JY, Kim J, Lee KS, Kim SH. How to overcome the limitations to determine the resection margin of pituitary tumours with low-field intraoperative MRI during trans-sphenoidal surgery: usefulness of Gadoliniumsoaked cotton pledgets. Acta Neurochir (Wien). 2008;150:763-71.

100. Pergolizzi RS, Jr., Nabavi A, Schwartz RB, Hsu L, Wong TZ, Martin C, Black PM, Jolesz FA. Intra-operative MR guidance during trans-sphenoidal pituitary resection: preliminary results. J Magn Reson Imaging. 2001;13:136-41. 
101 Kaplan HC, Baker HL, Jr., Houser OW, Laws ER, Jr., Abboud CF, Scheithauer BW. CT of the sella turcica after transsphenoidal resection of pituitary adenomas. AJR Am J Roentgenol. 1985;145:1131-40.

102. Jeffries BF, Kishore PR, Singh KS, Ghatak NR, Krempa J. Contrast enhancement in the postoperative brain. Radiology. 1981;139:409-13.

103. Rodriguez O, Mateos B, de la Pedraja R, Villoria R, Hernando JI, Pastor A, Pomposo I, Aurrecoechea $\mathrm{J}$ et al. Postoperative follow-up of pituitary adenomas after trans-sphenoidal resection: MRI and clinical correlation. Neuroradiology. 1996;38:747-54.

104. Steiner E, Knosp E, Herold CJ, Kramer J, Stiglbauer R, Staniszewski K, Imhof $\mathrm{H}$ et al. Pituitary adenomas: findings of postoperative MR imaging. Radiology 1992;185:521-27.

105. Bonneville JF, Bonneville F, Schillo F, Cattin F, Jacquet G. [Follow-up MRI after trans-sphenoidal surgery]. J Neuroradiol. 2003;30:268-79.

106. Jane JA, Jr., Dumont AS, Sheehan JP, Laws ER, Jr. Surgical techniques in transsphenoidal surgery: what is the standard of care in pituitary adenoma surgery? Current Opinion in Endocrinology \& Diabetes. 2004;14:264-70.

107. Ausiello JC, Bruce JN, Freda PU. Postoperative assessment of the patient after transsphenoidal pituitary surgery. Pituitary 2008; 11:391-401. 
108. Schwartz TH, Stieg PE, Anand VK. Endoscopic transsphenoidal pituitary surgery with intraoperative magnetic resonance imaging. Neurosurgery 2006; 58 (ONS Suppl1): ONS 44-ONS 51. 